\title{
THE SELF-DETERMINED AND PARTNER-PREDICTED TOPIC PREFERENCES OF ADULTS WITH APHASIA
}

\author{
Ange Beringer
}

Submitted in partial fulfilment of the requirements for the degree

Masters in AAC

In the Centre for Augmentative and Alternative Communication Faculty of Humanities

University of Pretoria.

October 2010 


\section{AKNOWLEDGEMENTS}

- Professor Juan Bornman, for her belief in me and invaluable guidance, enthusiasm and encouragement throughout this journey. Thank-you!

- Kerstin Tonsing, for her thoughtful, thorough, and fundamental input. Your passionate approach to research and clinical practice is a wonderful example to me.

- Rina Owen, for her willing and expert assistance with all the stats-related aspects of the study.

- The adults with aphasia and their familiar communication partners for being willing to take part in the study. I thoroughly enjoyed our memorable 'chats'.

- The clinicians who assisted me to recruit participants for the study.

- Nancy Raubenheimer, for translating the Abstract into Afrikaans for me, and for her refreshing friendship.

- Roxanne Sims, my business partner and friend. Your support has been amazing and means so much to me. Thank-you for carrying the load on so many occasions.

- My family and friends, for their love, support and encouragement over the past three years.

- Tracey Du Toit, Christos Tsouris and many others from Central Parks City Church, for their prayers and encouragement.

- My husband, for his unwavering support, encouragement, protection and love. Your selflessness and willingness to assist me in every area astounded me. You are my best friend and I love you madly.

- My King, for continually reminding me that He calls things that are not as though they were (Romans 4:17b). Without Your cheers from the sidelines, I would never have reached this point.

- The financial assistance of the National Research Foundation (NRF) towards this research project is hereby acknowledged. Opinions expressed in this report and conclusions arrived at, are those of the author and not necessarily attributable to the NRF. 


\begin{abstract}
The impact of aphasia on the lives of the individuals with the disorder as well as their family and friends is significant. Augmentative and alternative communication (AAC) systems that use topics to organise the message content within the systems have been found to be an effective way of facilitating the communicative attempts of individuals with aphasia. These topics need to be pre-selected for storage in the AAC systems prior to their use in naturally occurring communication instances. Most frequently, the familiar communication partners of adults with aphasia are asked to act as informants and predict which topics their partner with aphasia would like to have included in their AAC system. Informant-input however, is not always accurate and the need for adults with aphasia themselves to be actively involved in this process has been stressed by many researchers.
\end{abstract}

The main aim of the study therefore was to determine the topic preferences (on a threepoint semantic differential scale) of adults with expressive aphasia as indicated by both the adults themselves and their familiar communication partners.

Participants with aphasia $(n=10)$ were requested to choose someone that knew them well and with whom they communicated regularly to take part in the study with them. This person was termed a 'familiar communication partner' and was requested to participate in the study by predicting the topic preferences of their partner with aphasia with the use of the Talking Mats ${ }^{\mathrm{TM}}$ framework. These familiar communication partners $(\mathrm{n}=10)$ were also requested to think of any additional topics that their partners with aphasia would like to talk about that were not included in the 37 Pictographic Communication Resources (PCR) topics presented to them. These additional topics were then added to the 37 PCR topics and presented to the adults with aphasia for evaluation by means of the Talking Mats $^{\mathrm{TM}}$ framework.

Results of the study revealed that the participants with aphasia wanted to talk about the majority of the PCR topics presented to them (70.81\%), with their familiar communication partners also predicting that the adults with aphasia would like to talk 
about the majority of the PCR topics $(64.05 \%)$. Topics that the adults with aphasia wanted to talk about included those related to aphasia and physical impairment, as well as those related to work and other appropriate social roles. The average agreement of topic preferences, provided by both participant groups, over all topics and dyads was $65 \%$. This indicates that in general, the familiar communication partners predicted their partner with aphasia's topic preferences relatively accurately. Variations occurred across topics (30-100\%) and dyads (48.65-89.19\%). Knowledge of the topic preferences of adults with aphasia and the topic preference discrepancies within dyads can aid clinicians and AAC specialists in appropriately facilitating the pre-selection and storage of topics within AAC systems for use by adults with aphasia.

\section{KEY WORDS}

Adult with aphasia, Augmentative and Alternative Communication (AAC), AAC systems, dyad, familiar communication partner, informants, pre-selection, Talking Mats ${ }^{\mathrm{TM}}$, topics, topic preferences. 


\section{OPSOMMING}

Die impak wat afasie op individue met hierdie toestand asook hul vriende en families het, is beduidend. AAK-sisteme (aanvullende en alternatiewe kommunikasie) wat verskillende onderwerpe gebruik om die inhoud van boodskappe te organiseer, word as 'n effektiewe metode beskou om pasiënte met afasie se pogings tot kommunikasie te fasiliteer. Hierdie onderwerpe word vooraf geselekteer en in die AAK-sisteme gestoor voordat dit in natuurlike kommunikasie situasies gebruik kan word. Oor die algemeen word die mees bekende kommunikasievennote van die volwassene met afasie gevra om as informante op te tree om die onderwerpe wat hul maat moontlik by sy/haar AAK sisteem sou wou insluit, te voorspel. Hierdie informant insette is egter nie altyd akkuraat nie, en die behoefte van volwassenes met afasie om self aktief by die proses betrokke te wees, is reeds deur menigte navorsers beklemtoon.

Die hoofdoel van hierdie studie was om die onderwerpe van voorkeur (op 'n drie-punt semantiese differensiaalskaal) van volwassenes met ekspressiewe afasie, soos deur beide hulself en hul bekende kommunikasievennote, vas te stel.

Deelnemers met afasie $(\mathrm{n}=10)$ is gevra om iemand wat hul goed ken en met wie hulle gereeld kommunikeer, te kies om saam met hulle aan die studie deel te neem. Hierdie persoon is die "bekende kommunikasievennoot" genoem en is gevra om aan die studie deel te neem deur, die onderwerp-voorkeure van hul maat met afasie, met behulp van die "Talking Mats ${ }^{\mathrm{TM} "}$ raamwerk, te voorspel. Hierdie "bekende kommunikasievennote" $(n=10)$ is ook gevra om, afgesien van die onderwerpe wat reeds by die 37 Pictographic Communication Resources (PCR) onderwerpe ingesluit is, aan enige bykomende onderwerpe waaroor hul maats sou wou gesels, te dink. Hierdie addisionele onderwerpe is by die 37PCR onderwerpe gevoeg, en is aan die volwassenes met afasie gegee om met behulp van die Talking Mats ${ }^{\mathrm{TM}}$ raamwerk te evalueer.

Resultate van die studie het getoon dat deelnemers met afasie oor die meerderheid van die PCR onderwerpe $(70.81 \%)$ wou gesels, terwyl hul bekende kommunikasievennote 
ook voorspel het dat die volwassenes met afasie oor die meerderheid van die PCR onderwerpe (64.05\%) sou wou gesels. Onderwerpe wat meestal deur die volwassenes met afasie gekies is, het meestal met afasie en fisiese gestremdheid verband gehou.. Ander voorkeur onderwerpe het met werk en ander sosiale rolle verband gehou. Die gemiddelde ooreenstemming van onderwerpvoorkeure, soos deur beide deelnemende groepe bepaal, met betrekking tot alle onderwerpe en pare, was 65\%. Dit toon dat die bekende kommunikasievennote meestal hul maats met afasie se onderwerpvoorkeure korrek kon voorspel. Variasies in resultate met betrekking tot die onderwerpe (30 $100 \%)$ en pare $(48.65-89.19 \%)$ het voorgekom. Hierdie kennis oor watter onderwerpe volwassenes met afasie meestal verkies, asook die verskille binne die kommunikasiepare, kan klinici en AAK spesialiste help om meer toepaslike gespreksonderwerpe vir volwassenes met afasie te kan pre-selekteer en op AAK hulpmiddels te stoor.

\section{SLEUTELWOORDE}

Volwassene met afasie, Aanvullende en Alternatiewe Kommunikasie (AAK), AAKsisteme, pare, bekende kommunikasievennoot, informante, pre-seleksie, Talking Mats ${ }^{\mathrm{TM}}$, onderwerpe, onderwerpvoorkeure. 


\section{TABLE OF CONTENTS}

\section{CHAPTER 1: INTRODUCTION AND PROBLEM STATEMENT 13}

1.1 PROBLEM STATEMENT .............................................................................. 13

1.2 TERMINOLOGY ......................................................................................... 16

1.2.1 Augmentative and Alternative Communication.................................... 16

1.2.2 Augmentative and Alternative Communication system ....................... 16

1.2.3 Dyad............................................................................................................. 16

1.2.4 Expressive Aphasia ............................................................................ 16

1.2.5 Familiar communication partner ........................................................... 16

1.2.6 Informant .......................................................................................... 17

1.2.7 Pre-selection ....................................................................................... 17

1.2.8 Talking Mats ${ }^{\mathrm{TM}}$................................................................................... 17

1.2 .9 Topics.................................................................................................. 17

1.2.10 Topic preferences...................................................................................... 17

1.3 ABBREVIATIONS.................................................................................... 18

1.4 OUTLINE OF CHAPTERS ......................................................................... 18

1.5 SUMMARY ......................................................................................................... 18

CHAPTER 2: LITERATURE REVIEW ......................................... 19

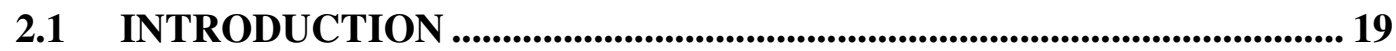

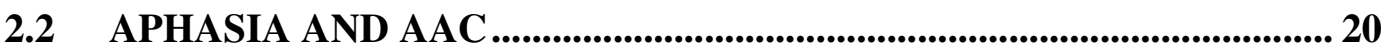

2.3 TOPICS IN APHASIA THERAPY ......................................................... 27

2.4 PRE-SELECTION OF TOPICS …………................................................... 30

2.5 ACTIVE INVOLVEMENT OF ADULTS WITH APHASIA ................... 33

2.6 SUMMARY ...................................................................................................... 35

CHAPTER 3: METHODOLOGY ........................................................... 37

3.1 INTRODUCTION ........................................................................................ 37

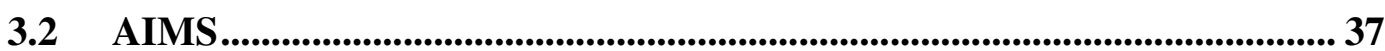

3.2.1 Main Aim ........................................................................................................ 37

3.2.2 Sub-aims............................................................................................................ 37 
3.3 RESEARCH DESIGN_............................................................................. 38

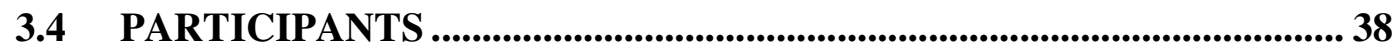

3.4.1 Sampling and recruitment.............................................................. 38

3.4.2 Selection criteria ........................................................................................ 38

3.4.3 Descriptive criteria ................................................................................. 41

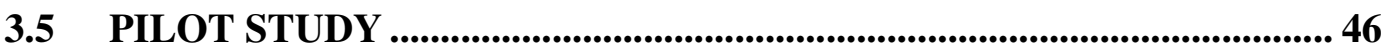

3.6 MATERIALS AND EQUIPMENT......................................................50

3.6.1 Conversational topics and topic cards...........................................................5 50

3.6.2 Biographical questionnaires ................................................................... 51

3.6.3 Equipment used during the Talking Mats ${ }^{\mathrm{TM}}$ framework ................... 51

3.7 PROCEDURES AND DATA COLLECTION...........................................5 52

3.7.1 Data collection ............................................................................................52

3.7.2 Ethical issues............................................................................................5 54

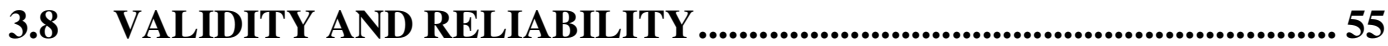

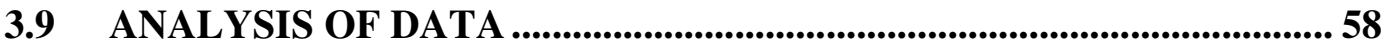

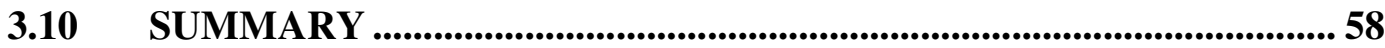

CHAPTER 4: RESULTS AND DISCUSSION ............................... 59

4.1 INTRODUCTION .................................................................................................... 59

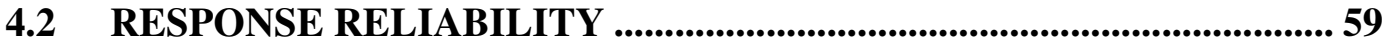

4.3 TOPIC PREFERENCES BY THE FAMILIAR COMMUNICATION PARTNERS: GROUP A .................................................................................60

4.3.1 Frequency of total number of 'Yes', 'Maybe' and 'No' preferences provided by Group A...............................................................................................60

4.3.2 Frequency of 'Yes', 'Maybe' and 'No' preferences per topic by Group A.

4.4 TOPIC PREFERENCES BY ADULTS WITH APHASIA: GROUP B.. 66

4.4.1 Frequency of total number of 'Yes', 'Maybe' and 'No' preferences provided by Group B ...................................................................................66

4.4.2 Frequency of 'Yes', 'Maybe' and 'No' preferences per topic by

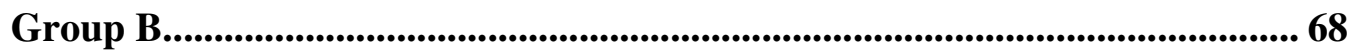

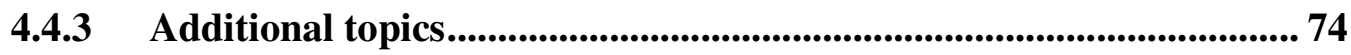


4.5 COMPARISON OF PREFERENCES OBTAINED FOR EACH TOPIC

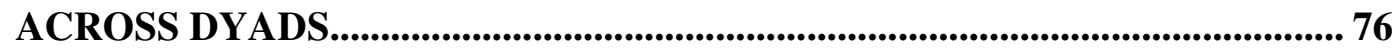

4.5.1 Topics that obtained high agreement ................................................. 77

4.5.2 Topics that obtained moderate agreement............................................. 80

4.5.3 Topics that obtained low agreement....................................................... 88

4.6 COMPARISON OF TOPIC PREFERENCES WITHIN DYADS ........... 93

4.6.1 Dyads with high percentage agreement .............................................. 94

4.6.2 Dyads with low percentage agreement .................................................. 97



CHAPTER 5: SUMMARY AND CONCLUSION..............................101

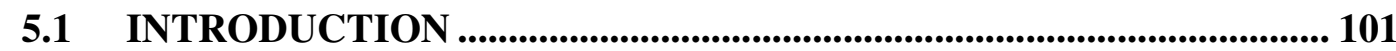

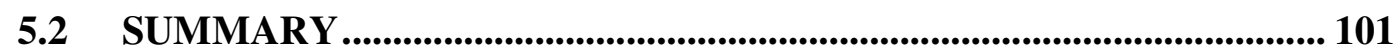

5.3 CRITICAL EVALUATION OF THE STUDY ........................................ 106

5.4 CLINICAL IMPLICATIONS ................................................................ 108

5.5 RECOMMENDATIONS FOR FUTURE RESEARCH ......................... 111



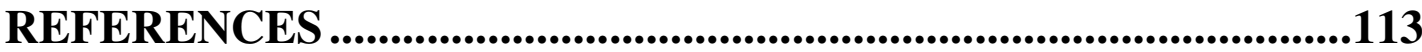




\section{LIST OF TABLES}

Table 3.1: Subject selection criteria for Participant Group A: Familiar Communication Partners. ...39

Table 3.2: Subject selection criteria for Participant Group B: Adults with Aphasia.. .40

Table 3.3: Descriptive information for Participant Group A: Familiar Communication Partners $(\mathbf{n}=\mathbf{1 0})$

Table 3.4: Descriptive information for Participant Group B: Adults with Aphasia $(n=10)$.................44

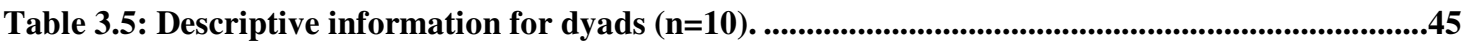

Table 3.6: Description of aims, procedures, results and recommendations of the pilot study..............47

Table 4.1: Frequency of 'Yes', 'Maybe' and 'No' preferences per topic $(n=37)$, by Group A. ............63

Table 4.2: Frequency of 'Yes', 'Maybe' and 'No' preferences per topic $(n=37)$ by Group B................69

Table 4.3: Additional topics and their preference placements .........................................................74

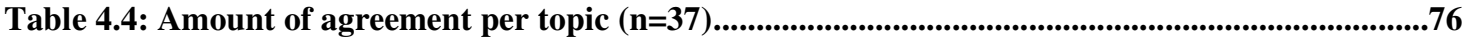

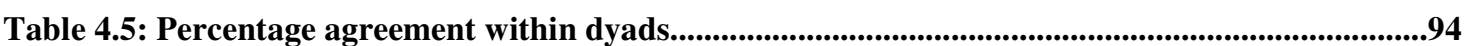




\section{LIST OF FIGURES}

Figure 3.1: Data Collection Procedure.

Figure 4.1: Frequency of total number of 'Yes', 'Maybe' and 'No' topic preferences provided by

Group A (n=10)

Figure 4.2: Frequency of total number of 'Yes', 'Maybe' and 'No' topic preferences provided by

Group B (n=10) .67

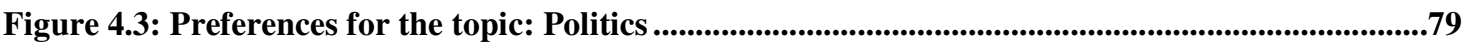

Figure 4.4: Preferences for the topic: Voting ......................................................................................................80



Figure 4.6: Preferences for the topic: Sex .............................................................................................................83

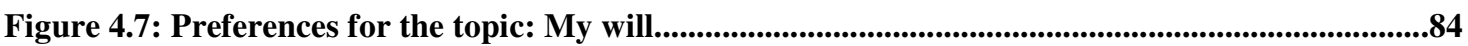

Figure 4.8: Preferences for the topic: Food/diet .............................................................................................85

Figure 4.9: Preferences for the topic: Alcohol and drug issues ...........................................................86

Figure 4.10: Preferences for the topic: Underwear ............................................................................................87

Figure 4.11: Preferences for the topic: My marriage/spouse...................................................................88

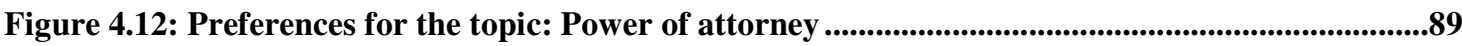

Figure 4.13: Preferences for the topic: Counselling ................................................................................................90

Figure 4.14: Preferences for the topic: Risk of another stroke...............................................................91

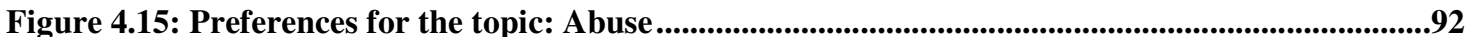




\section{LIST OF APPENDICES}

APPENDIX A: RECRUITMENT ASSISTANCE LETTER .125

APPENDIX B: SELECTION OF FAMILIAR COMMUNCIATION PARTNER 127 APPENDIX C: BACKGROUND INFORMATION: FAMILIAR COMMUNICATION PARTNER

APPENDIX D: BACKGROUND INFORMATION: PERSON WITH APHASIA ...............................130

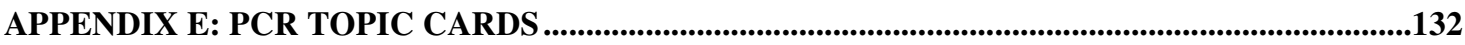

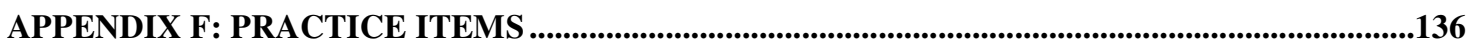

APPENDIX G: UNIVERSITY ETHICS APPROVAL .....................................................................137

APPENDIX H: FAMILY INFORMATION SHEET .........................................................................138

APPENDIX I: PARTICIPANT INFORMATION SHEET ...........................................................................140

APPENDIX J: ADULT WITH APHASIA CONSENT FORM................................................................142

APPENDIX K: OBSERVER SUPPORT CONSENT FORM .................................................................144

APPENDIX L: FAMILIAR COMMUNICATION PARTNER CONSENT FORM..............................145

APPENDIX M: VIDEO CONSENT FORM FOR PARTICIPANT WITH APHASIA ........................146 APPENDIX N: VIDEO CONSENT FORM FOR FAMILIAR COMMUNICATION PARTNER ...147 APPENDIX O: INTERVIEW AND TALKING MATS ${ }^{T M}$ PROCEDURAL GUIDELINES.................148 


\section{CHAPTER 1: INTRODUCTION AND PROBLEM STATEMENT}

\subsection{PROBLEM STATEMENT}

The profound impact of aphasia on the lives of individuals with the disorder as well as their significant others and family members, has been addressed through traditional and non-traditional (functional) treatment approaches by speech-language pathologists over the years (Garrett \& Lasker, 2005; Hux, Manasse, Weiss, \& Beukelman, 1994; van de Sandt-Koenderman, 2004). Individuals presenting with severe expressive aphasia are likely to communicate very little using natural speech and typically do not recover sufficiently to become functional, competent communicators unless nontraditional approaches to intervention are employed (Garrett \& Lasker, 2005). Nontraditional or functional approaches attend to the communication needs and lifestyles of adults with aphasia by addressing the social context, functional needs, interactional dynamics and hidden competencies of these individuals through both natural communication modalities and specific augmentative and alternative communication (AAC) techniques (Fox \& Fried-Oken, 1996; Garrett \& Kimelman, 2000). Hence, functional approaches such as AAC have been viewed as appropriate for intervention with adults with moderate to severe aphasia.

Although there has been limited evidence of the generalization of AAC systems and techniques into everyday contexts with this population (van de Sandt-Koenderman, 2004), AAC has been found to unmask the underlying communication competencies of adults with aphasia by providing an alternative means of communication, a means of facilitating the re-acquisition of spoken language skills and by enhancing specific language and communication functions (Kraat, 1990). Many studies have examined such underlying competencies through the use of AAC systems that use conversational topics to support the communication abilities of adults with expressive aphasia (Garrett, Beukelman, \& Low-Morrow, 1989; Ho, Weiss, Garrett, \& Lloyd, 2005; Lasker, Hux, 
Garrett, Moncrief, \& Eischeid, 1997; Garrett \& Huth, 2002; Fox, Sohlberg, \& FriedOken, 2001). Conversational topics have been depicted using visual aids such as photographs, picture symbols, newspaper clippings and written words displayed in AAC systems such as communication books or electronic devices (Hux et al., 2001; Garrett \& Huth, 2002). These visual aids are then used to assist adults with aphasia to initiate topics of conversation independently, as well as to provide a framework from which to coconstruct conversations, derive vocabulary items and even draw interactively (Garrett \& Huth, 2002; Lyon, 1995; van de Sandt-Koenderman, 2004). In these instances, the use of conversational topics has been found to facilitate the conversational abilities of adults with expressive aphasia.

Conversational topics need to be pre-selected in order to make visual referents to the topics available to an adult with aphasia. Adults with severe expressive aphasia, however, experience difficulty in participating in this pre-selection process, as they have trouble indicating which topics of conversation they would like to talk about (Garrett \& Huth, 2002). Predetermined, commercially available topic lists (Kagan, Winckel, \& Shumway, 1996), together with visual referents for these topics are available to facilitate the preselection of topics. The conversational topics within these lists are not always applicable to the individual circumstances and needs of the AAC user (Bryen, 2008). Therefore clinician-selected topics, and most frequently, topics selected by the familiar communication partners of the person with aphasia have been used in an attempt to obtain more individualised topics for use within AAC systems and techniques.

Although the active participation of communication partners is essential in many intervention efforts with adults with aphasia, the reliability of partner input has been documented as inconsistent (Shewan \& Cameron, 1984). This indicates that the conversational topics pre-selected by familiar communication partners cannot be assumed to be wholly accurate. It can be assumed that at times, therefore, the topics of conversation used within AAC systems are not the self-determined topics of the adult with aphasia. 
In order to address this, it has been suggested that adults with aphasia should be actively involved in the process of pre-selecting their preferred topics of conversation (Fox, et al., 2001). Due to the complex nature of aphasia, this is not an easy task and requires creativity and ingenuity on the part of researchers and clinicians. The provision of communicative support in the form of concrete materials has been found to assist adults with aphasia to participate in interviews and ratings in order to share their perspectives and opinions (Kagan, 1998a; Simmons-Mackie \& Damico, 1995). Talking Mats ${ }^{\text {TM }}$ is a dynamic framework that was developed to enable people with communication difficulties to express their thoughts and views (Murphy, 1998). The interactive and visual format of this framework has been found to be a comfortable and successful method of generating information for adults with aphasia and allows these individuals to inform their families, friends and caregivers of their views in a tangible way (Murphy, 2000; Gillespie, Murphy, \& Place, 2010).

The current study thus aimed to determine the topic preferences of adults with aphasia by providing them with the opportunity to pre-select their preferred topics of conversation. This opportunity was provided through the use of the Talking Mats ${ }^{\mathrm{TM}}$ framework and a predetermined list of conversational topics taken from the PCR binder (Kagan et al., 1996). The study also aimed to compare the self-determined topic preferences of adults with aphasia with those predicted for them by their familiar communication partners by describing similarities and differences. These comparisons were used to determine which topics obtained high and low levels of agreement as well as to gauge the level of agreement of topic preferences within each dyad. Specific qualities of the dyads as well as the nature of certain topics themselves were described as possible attributing factors to the degree of agreement demonstrated. Such information provides relevant guidelines for further research and also for clinical practice including design specifications of AAC systems as well as guidelines for commercial products used by adults with aphasia. Descriptions of the level of agreement across the topic preferences within each dyad provide useful insights and directions related to areas such as communication partner involvement and training when conducting research and clinical interventions with adults with aphasia. 


\subsection{TERMINOLOGY}

The following terms need some clarification as they are frequently referred to in the study:

\subsubsection{Augmentative and Alternative Communication}

Augmentative and alternative communication refers to the strategies used to enhance the communication participation of individuals with aphasia when complete restoration of natural speech is not possible (Hux et al., 2001). This is accomplished by replacing, supplementing, or scaffolding residual natural speech and providing a means of repairing disrupted communication.

\subsubsection{Augmentative and Alternative Communication system}

An integrated network of aided and unaided means to represent, select, and transmit a message; and the strategies, techniques, skills, and devices that an individual uses to communicate (Lloyd, Fuller, \& Arvidson, 1997).

\subsubsection{Dyad}

In this study, a dyad referred to the pair of an adult with aphasia and his/her familiar communication partner.

\subsubsection{Expressive Aphasia}

Expressive aphasia refers to an impairment in the formulation of language symbols resulting in difficulty to communicate using natural speech (Hux et al., 2001). This is caused from damage to specific language areas of the brain (Lloyd, et al., 1997). In this study, the selection criteria for the participants with aphasia were moderate to severe expressive aphasia.

\subsubsection{Familiar communication partner}

In this study, participants with aphasia were requested to select someone who knew them well and communicated with them on a regular basis to participate in the study with them. This person was termed a 'familiar communication partner'. 


\subsubsection{Informant}

Informants refer to anyone who is involved in making decisions about which words and messages to include in an AAC system (Brewster, 2004).

\subsubsection{Pre-selection}

Pre-selection refers to the process of selecting words and messages that are to be stored within an AAC system. In this study, pre-selection referred to the process of selecting topics to be stored within an AAC system for an adult with aphasia.

\subsubsection{Talking Mats ${ }^{\mathrm{TM}}$}

Talking Mats ${ }^{\mathrm{TM}}$ is a dynamic low-technology communication framework that has been specifically developed to help people with communication difficulties express their views and opinions in a simple, non-threatening and enjoyable way (Murphy, 1998). In this study, Talking Mats ${ }^{\mathrm{TM}}$ provided the participants with aphasia and their familiar communication partners with a means of presenting their topic preferences.

\subsubsection{Topics}

Topics have been defined as the subject matter of conversation. They introduce information and act as interactional units to provide conversational participants with a sense of meaning and cohesiveness (Stuart, Vanderhoof-Bileu, \& Beukelman, 1994).

\subsubsection{Topic preferences}

The term 'preferences' has unique definitions in different disciplines. In this study, the definition used in the field of psychology is employed. Preferences are "relatively stable evaluative judgments in the sense of liking or disliking a stimulus, or preferring it or not over other objects or stimuli" (Scherer, 2005, p. 703).

In this study therefore, 'topic preferences' refer to the participants (both adults with aphasia and their familiar communication partners) opinions on whether they would like to talk about the topics presented to them for evaluation. The preference options used in this study were: 'Yes', 'Maybe' or 'No'. 


\subsection{ABBREVIATIONS}

$\begin{array}{lll}\text { AAC - } & \text { Augmentative and Alternative Communication } \\ \text { PCR - } & \text { Pictographic Communication Resources } \\ \text { VSD - } & \text { Visual Scene Display } \\ \text { WAB - } & \text { Western Aphasia Battery }\end{array}$

\subsection{OUTLINE OF CHAPTERS}

Chapter 1 gives the introduction to the study as well as a list of terminology, the abbreviations used and an outline of the chapters.

Chapter 2 gives an overview of the theoretical issues relevant to this study. The use of topics in AAC systems for adults with aphasia is described. Methods of pre-selecting conversational topics for inclusion in these systems are discussed. The importance of the active involvement of adults with aphasia in the pre-selection process is emphasized.

In Chapter 3, the methodology of the study is provided. Information is given regarding the aims, the research design, the selection of conversational topics, the Talking Mats ${ }^{\mathrm{TM}}$ framework used, the participants as well as the equipment and material used. The data collection procedures as well as the analysis procedures are described.

Chapter 4 presents and discusses the results of the study.

Chapter 5 provides a summary of the study and discusses its limitations as well as implications for clinical practice and further research.

\subsection{SUMMARY}

The importance of the active involvement of adults with aphasia in the pre-selection of topics for inclusion in their AAC systems is emphasized in this chapter. In order for these individuals to be actively involved, appropriate consultative support is needed in the form of concrete materials and partner involvement. Providing adults with aphasia with such an opportunity would provide useful clinical information and commercial guidelines for materials developed for use with the target population. Terminology used in this study is defined, and an outline of the chapters is given. 


\section{CHAPTER 2: LITERATURE REVIEW}

\subsection{INTRODUCTION}

According to Blackstone, Williams and Wilkins (2007), the most important voices in research and clinical practice are often the hardest to hear due to the nature of the impairment they present with. As communication limitations preclude their lack of active involvement in these areas, individuals with complex communication needs have had limited influence on AAC research, technology development, and clinical practice. These individuals, however, hold an intensely personal stake in these areas. This also applies to adults with aphasia. Due to the challenges presented by the complex nature of aphasia, the familiar communication partners of these individuals act as informants as they are typically required to provide input on areas such as the preferred topics of conversation of the adult with aphasia for inclusion in an AAC system (Hux et al., 2001). However, informant-input is not always accurate (Balandin \& Iacono, 1998a, Graves, 2000), and hence the active involvement of adults with aphasia in the pre-selection of topics for use in an AAC system has been advocated (Fox et al., 2001). In order to provide adults with aphasia the opportunity to participate actively in research and clinical practice, appropriate support is needed (Fox \& Fried-Oken, 1996). Such support can be provided in the form of concrete materials and partner facilitation (Kagan, 1998a).

In this chapter the involvement of adults with moderate to severe expressive aphasia in the pre-selection of topics of conversation will be discussed with explanations of the necessity of communication partner involvement and concrete materials and tools to facilitate their active involvement. Low- and high-technology AAC systems that make use of topics to organize the content within the system will be described, in addition to the benefits of using topics to co-construct conversations with adults with aphasia. Each area will be described with reference to specific theories and research within the fields of aphasiology and AAC. 


\subsection{APHASIA AND AAC}

Aphasia is a communication disorder affecting an individual's ability to interpret and formulate language, and is typically acquired in a sudden manner as a result of damage to the language areas of the brain (Garrett \& Kimelman, 2000). The communication disorder experienced can range from a mild to a severe aphasia, affecting expressive and receptive language abilities to varying degrees (Hux et al., 2001). Some individuals may completely recover their language skills, whereas others are unable to recover their natural language abilities sufficiently despite receiving intensive speech-language intervention (Koul \& Corwin, 2003). Adults presenting with moderate to severe expressive aphasia fall within this category as their ability to use natural speech is severely and permanently impaired (Hux et al., 2001; Koul \& Corwin, 2003). In these cases, a shift in treatment approaches and therapy goals is necessary (Garrett \& Lasker, 2005, Beukelman, Fager, Ball, \& Dietz, 2007). Rather than focusing on the remediation of specific language deficits, therapy approaches that aim to improve the social use of language in context have been found more successful with this population (Kraat, 1990). These 'functional' approaches encourage a person with aphasia to convey messages by using natural communication modalities, such as residual speech, gestures, and writing, as well as specific AAC techniques (Fox \& Fried-Oken, 1996; Garrett \& Lasker, 2005).

AAC techniques are 'tools' that can be used to enhance, supplement or facilitate spoken and written communication skills (Kraat, 1990). These techniques can be applied in a global, restrictive or supplemental manner in order to improve the communication abilities of adults with aphasia (Hux et al., 2001). Although it would appear that such techniques 'fit' naturally with the treatment of adults with moderate to severe expressive aphasia, there has been limited use of such alternate forms of communication outside of structured treatment contexts (Koul \& Corwin, 2003; Garrett \& Kimelman, 2000; Lasker \& Bedrosian, 2001; Weinrich, Steele, Carlson, Kleczewska, Wertz, \& Baker, 1989; Jacobs, Drew, Ogletree, \& Pierce, 2004). Reasons for the limited generalization of AAC techniques into everyday, functional contexts is thought to be due to many factors, including inadequate emphasis given to communication partner training, contextual training, lack of acceptance of AAC by the users and those around them, false 
assumptions of the communicative needs of individuals with aphasia as well as due to the complicated nature of aphasia itself (Garrett \& Beukelman, 1992; Garrett \& Kimelman, 2000; van de Sandt-Koenderman, 2004; Fox \& Fried-Oken, 1996; Jacobs et al., 2004).

The use of AAC in aphasia rehabilitation has thus been critically examined by various authors and led to recommendations of ways in which to improve the generalisation of AAC techniques into natural environments. Kraat (1990) retrospectively described the results of multiple studies published during the late 1960s through the 1980s in which researchers attempted to teach non-speech modes of communication to individuals with severe aphasia. The analysis led her to suggest that AAC intervention should move away from the application of AAC techniques as a global replacement for speech and to rather start implementing 'augmentative' techniques in a more supplemental manner. This implies the use of various strategies to supplement or scaffold residual natural speech in order to accomplish a communicative activity that could otherwise not be performed.

More recent reviews support this recommendation. Koul and Corwin (2003) provided an evaluation of existing literature on the efficacy of technology and no-technology AAC interventions in adults with chronic severe or global aphasia. The data described in the paper implied that the use of individualised augmentative techniques was found to enhance the communicative effectiveness and efficiency of adults with aphasia.

Van de Sandt-Koenderman (2004) reviewed the state of the art high-technology and lowtechnology AAC applications for aphasia. It was recommended that AAC be an integral part of aphasia rehabilitation for all people with aphasia, and not be introduced as a last resort in treatment. Additionally, it was recommended that communication aids be personally tailored, both in what they can assist the person with aphasia to do and also in the vocabulary included. It was further mentioned that the perspective of clinicians as well as the adults with aphasia and their significant others be altered to accept that no AAC strategy or device will ever be as efficient as natural speech. These strategies and devices are second-best solutions that will not be used functionally, unless the user gains more than he or she has to invest. 
The implementation of AAC techniques and systems that follow the above recommendations has been found to improve the communicative efficiency of adults with aphasia, and has been documented by various authors (Garrett \& Beukelman, 1992; Garrett \& Huth, 2002; Garrett \& Lasker, 2005; Ho et al., 2005; Lyon, 1995; Kagan, 1998a; Waller, Debbis, Brodie, \& Cairns, 1998; Johnson, Hough, King, Vos, \& Jeffs, 2008; Hough \& Johnson, 2009). Low- and high-technology systems and techniques that have demonstrated improved communicative abilities when implemented by adults with aphasia are described below. Each of these systems and techniques have made use of topics as organisational units or as the communicative content conveyed. Partner involvement is also used in all of the described AAC systems and techniques.

The Written Choice Communication Strategy (Garrett \& Beukelman, 1992) is an AAC tool that facilitates communication with adults with severe aphasia by capitalizing on their residual communicative capabilities. Communication partners provide written word choices related to relevant topics to persons with aphasia and then allow them to choose appropriate responses from a written array (Lasker et al., 1997). The communication partner is required to encourage the person with aphasia to point to an answer and ask follow-up questions until the topic is exhausted or until either member of the dyad chooses to discontinue the conversation. In this way, the unit of treatment is expanded beyond the impaired individual to the dyad due to the use of partners as integral components of the treatment technique (Garrett \& Beukelman, 1995). Although this technique limits the adult with aphasia to a restricted set of choices and depends on the mentioned structured rules for interpersonal communication, it has been found to improve the quality of communicative interactions between adults with aphasia and their communication partners.

Another effective augmentative aid for adults with aphasia is interactive drawing (Lyon \& Helm-Estabrooks, 1987; Lyon, 1995). This technique has been found to be applicable and effective under the following conditions; when the adult with aphasia demonstrates residual language and communication skills and when the communication partner of the adult with aphasia demonstrates adequate interpretative skills. Communication partners 
are encouraged to support the use of drawing for communication by initiating the process with a drawing of their own that initiates a conversational topic, or suggests a joint topic of conversation. From this point, both parties within the dyad are required to actively participate in the communicative act of drawing (Lyon, 1995). For many people, however, drawing is a communication mode that does not come naturally, and has to be trained in aphasia therapy (van de Sandt-Koenderman, 2004).

Signing has been used to enhance the communicative efficacy of adults with aphasia through the use of formally taught signs as well as ideographic signs, mimicking and pantomime (Kraat, 1990; Beukelman \& Garrett, 1988). Ideographic or natural signs are often ambiguous and usually refer to a restricted set of concrete concepts, and therefore result in difficulty communicating about issues outside of the situational context (van de Sandt-Koenderman, 2004). A formal unaided system such as AmerInd has been used to provide adults with aphasia with an alternative means of communication, as a facilitator of verbalization, and as a deblocker of other language modalities (Rao, 2001). Due to the fact that the communication partners of the adult with aphasia need to comprehend the unaided system, AmerInd and other formal sign systems can only be used with a restricted number of communication partners.

Supported conversation for adults with aphasia is an intervention that was designed to reduce the psychosocial consequences of aphasia through the use of conversational partnerships (Kagan, 1998a). In order for successful exchange of information within these partnerships, training of the conversation partners and development of conversational resources are necessary. Communication partners act as a resource for the adult with aphasia and actively share the communication load. In this way, less emphasis is placed on the independent use of communication strategies by the adult with aphasia, and more emphasis on what the dyad achieves interdependently (Kagan, 1998a). Supported conversation for adults with aphasia provides conversation partners with materials to achieve this goal. These materials are found within the PCR binder, an extensive collection of pictographs organized thematically within a conversational structure (Kagan, et al., 1996). The topics addressed include context-specific, relevant, 
and often complex issues facing people with aphasia. The final section, titled 'I want to talk about' is designed to allow the adult with aphasia to initiate topics of interest to him or her with the assistance of their communication partner, and consists of 39 conversational topics depicted visually with the use of pictographs and written labels (Kagan et al., 1996). This intervention has been found to reduce the communication barriers and to increase life participation opportunities for adults with aphasia (Kagan, Black, Duchan, Simmons-Mackie, \& Square, 2001). Some challenges are related to this approach. Supporting the communication attempts of a person with aphasia and creating access to conversation, demands skill and training on the part of communication partners. Adults with aphasia are therefore dependent on access to such communication partners in order to benefit from this approach. In addition, this technique might run counter to familiar intervention strategies and may therefore be difficult for clinicians to accept and adjust to (Parr \& Byng, 1998; Simmons-Mackie, 1998).

Topic setters provide graphic representations of conversational topics and have been found to increase the ability of adults with severe aphasia to initiate and discuss topics of interest. Garrett and Huth (2002) found that the adults with aphasia participating in their study appeared better able to co-construct conversations with their communication partners when graphic topic setters were available to augment their natural communication modalities. In addition, the average duration of interactions as well as the number of communication exchanges per topic was found to increase within dyads when graphic topic setters were used. These positive effects however, differed across partners and topic types. The amount of initiations and the length of conversational exchanges demonstrated by the participant with aphasia varied, depending on the skills of the communication partners to interpret the communication signals and to co-construct conversational meaning with the participants with aphasia. Personal event topics were discussed for longer periods of time, and the participant with aphasia was found to initiate more frequently when personal event topics were discussed. Fox et al., (2001) documented the effects of conversational topic choice on the outcomes of augmentative communication intervention for adults with aphasia. Results of their study suggested that topic choice may be a variable that increases enjoyment and perceived control in 
interactions with adults with aphasia. Additionally, the communication aids were found to be used more frequently by the participants with aphasia when their conversational partners shared an interest in the topic depicted within the device. These results support AAC and aphasia research that recognizes the importance of context and communication partners for achieving generalization of therapy outcomes, and the importance of appropriate topics for successful and natural environment communication aid use (Fox et al., 2001).

Communication books are another augmentative communication aid that have been found to improve the communicative abilities of adults with aphasia (Garrett et al., 1989; Ho et al., 2005; Rogers, King, \& Alarcon, 2000). Communication books are frequently used to consolidate the various communication strategies used by an adult with aphasia and therefore represent multimodal communication systems. Garrett et al. (1989) used a communication book to combine a word dictionary, alphabet card, pocket for new information as well as a list of clues for communication partners to use should a breakdown in communication occur. Ho et al. (2005) investigated the use of remnants and pictographic symbols within communication books to improve the initiation and maintenance of social interactions between adults with global aphasia and their familiar conversational partners. The communication books used within the study included symbols, either remnant or pictographic, that depicted six topics. Results of the study supported the use of communication books for adults with global aphasia, revealing that topics of conversation were initiated by the adults with aphasia only when communication books were made available and that participants with aphasia were more responsive and engaged in increased pointing behaviour as a means of establishing and maintaining joint attention with remnant books than with pictographic books. A communication partner participating in the study also mentioned that the remnant book was more enjoyable and comfortable to use than the pictographic book. The creation of communication books involve planning, work, and team effort that involves the clinician, adult with aphasia and his or her frequent communication partners. Unfortunately, adults with aphasia are frequently provided with prefabricated communication books stocked with generic vocabulary and icons. In these cases, the limited communication book 
training and the limited opportunities provided to the individual with aphasia and his or her communication partners to provide input on the book's content and organisation frequently result in minimal functional use of communication books (Rogers et al., 2000). Three 'rules' are suggested by Rogers et al. (2000) for the successful incorporation of communication books into the communication activities of adults with aphasia; users must participate in the development of the book in order to make it personalised, users must be trained to communicate using the book and must be taught to update the contents of the book, making it a dynamic communication system.

The above techniques and systems use low-technology means of assisting the communication efforts of adults with aphasia. A few high-technology communication devices have been designed specifically for adults with aphasia (van de SandtKoenderman, 2004). Some of these devices have aimed to assist adults with aphasia with specific linguistic difficulties, such as word finding problems and problems generating messages and sentences and are therefore more disorder-orientated (Steele, Weinrich, Wertz, Kleczewska, \& Carlson, 1989; Koul \& Harding, 1998; Shelton, Weinrich, McCall, \& Cox, 1996). As a result, they have had limited value for functional use within communicative situations. More recently, however, devices have been developed to support conversation by providing ready-made utterances that can be used in conversations, and therefore have a more functional approach (van de SandtKoenderman, 2004). Most of these systems make use of a hierarchical topic structure, although variations exist in the manner in which words and utterances are accessed as well as the mode of representation used, that is, either symbol- or text-based content (Waller et al., 1998). Communication partners of the adults with aphasia are required to provide relevant communicative content to be placed within the AAC device used. An example of this is demonstrated with Talksbac (Waller et al., 1998), a word-based system that consists of two programs. Personal sentences and stories are entered into the device's database by the use of the 'carer program', where the 'user program' assists the adult with aphasia to retrieve these pre-stored conversational items by offering probable items based on the previous use of the system. 
Visual Scene Displays (VSD) provide an alternative method of storing and accessing communicative content (Light, Drager, McCarthy, Mellott, Millar, Parish, Parsons, Rhoads, Ward, \& Welliver, 2004). VSD's are low- and high- technology AAC device prototypes designed to support common interactions dealing with a wide range of topics, narratives, and experiences (Beukelman et al., 2007). Contextually rich photographs relating to experienced events and familiar people and places are used to facilitate navigation of an AAC device (Light \& Drager, 2007). This is an emerging intervention strategy that does not rely on the linguistic processes of stringing symbols together to generate messages (McKelvey, Dietz, Hux, Weissling, \& Beukelman, 2007). Instead, the VSD provides a visual depiction of an event occurring in its natural environment, thus establishing the context for a conversational interaction and providing the person with aphasia and his or her communication partner with information to support multiple communicative exchanges.

The low- and high-technology AAC systems and techniques mentioned above make use of conversational topics from which to organise the communicative content of the system, facilitate the initiation, maintenance and adaptation of conversations, and increase the sense of conversational control perceived by the adult with aphasia (Balandin \& Iacono, 1999; Garrett \& Huth, 2002). Communication partner involvement is also common across all the described techniques and systems. Therefore, in the AAC systems described above, communication partners help adults with aphasia to co-construct conversations with others, and the topics of conversation, when depicted visually, are used to provide a physical referent around which to build a conversation.

\subsection{TOPICS IN APHASIA THERAPY}

Topics have been defined as the subject matter of the conversation, or what is spoken about and can be reported to have been spoken about (Stuart, Vanderhoof, \& Beukelman, 1993). Topics introduce information and act as interactional units to provide conversational participants with a sense of meaning and cohesiveness (Stuart, et al., 1994). Communicatively intact individuals use various conversational topics to maintain 
their identities and to affiliate with other human beings (Davidson, Worrall, \& Hickson, 2003). Aphasia affects the person's ability to comment, to suggest, to question, to bargain, to joke, and to share his/her life story, and therefore affects the ability to communicate about topics of interest (Davidson et al., 2003). Due to the social significance of communication, such disrupted communication greatly impacts the psychosocial functioning of adults with aphasia (Simmons-Mackie, 2001). Those affected by aphasia report social isolation, loneliness, loss of autonomy, restricted activities, role changes, and stigmatization (Simmons-Mackie, 2001; LeDorze \& Brassard, 1995; Brumfitt, 1993; Herrmann \& Wallesch, 1989; Kagan \& Gailey, 1993). Findings from a study conducted by Davidson et al. (2003) reveal this impact, where the everyday communication activities of communicatively intact older people and older people with aphasia, living in the same community were described and compared. Both groups of adults participated in similar communication activities and spoke about common topics, however, those with aphasia were found to focus on topics reflecting the "here and now" and relating to people in their inner social networks. The group of communicatively intact older people was found to talk about more abstract topics of conversation and those which referred to people in more remote circles.

The importance of improving adults with aphasia's ability to participate in communicative instances in which they are able to share information, establish and maintain relationships, communicate their ideas, personalities, culture and life values is obvious. The inclusion of a wide variety of conversational topics within AAC systems may address these needs by providing adults with aphasia with the opportunity to communicate about such topics. Topics as recognizable units facilitate the coconstruction of conversations; provide a framework from which to derive appropriate vocabulary and also reveal the communicative competence of adults with aphasia.

The language limitations presented by adults with aphasia result in their difficulty to generate language at a micro-level, that is, to communicate meaning using spelling, word, phrase and sentence combinations (Garrett \& Lasker, 2005). Topics represent units of language at a macro-level and refer to broad categories of information. Visual 
representation of topics allows for mutual understanding between the person with aphasia and his/her communication partner. As a result, visual representations of topics may decrease the need for extensive generative language use (Beukelman et al., 2007). In addition, topics represented in the form of pictographic symbols, remnants or personally relevant photographs are easily comprehended and quick to locate.

Topics also facilitate the co-construction of conversations. Due to the difficulty experienced by adults with aphasia in independently formulating messages, they frequently adopt a variety of different strategies and co-construct their messages with their communication partners. Tangible referents of conversation topics (such as photographs, picture symbols and remnants displayed in AAC systems and techniques) provide an external, shared context in which such topics can be established and specific meanings conveyed (Stuart, Lasker, \& Beukelman, 2000). These referents remain physically available so that conversational partners can continuously refer to them to clarify a point or add information using any multiple modes of communication that are familiar and used by them. In this way, referents of topics allow the use of natural communication skills as well as alternative forms of communication and thereby facilitate the co-construction of conversations between the adult with aphasia and his/her communication partners (Garrett \& Huth, 2002).

Topics provide a framework for vocabulary. The individualization of AAC techniques and systems is viewed as crucial for the acceptance and generalization of the system into the daily communicative situations in which the user finds him/herself (Beukelman, McGinnis, \& Morrow, 1991). Using topic areas as frameworks for vocabulary selection has been recommended by many authors (Balandin \& Iacono, 1999; van de SandtKoenderman, 2004; Garrett et al., 1989). Selecting vocabulary for use with topics relevant to the AAC user may address the unique needs of the AAC user and as a result, have a positive effect on the user's willingness to use the system (Graves, 2000).

Communicative competence is defined as "the quality or state of being functionally adequate in daily communication, or of having sufficient knowledge, judgement, and skill 
to communicate" (Light, 1989, p. 138). Kagan (1998a) stresses that aphasia is a disorder of masked competencies where, as a result of their difficulty to engage in conversations and reveal what they know, think or feel; adults with aphasia are often regarded and treated as incompetent and without the ability to make decisions. Thus, the use of interventions that are successful in building and revealing communicative competencies in this population is essential (Kagan, 1998b). The use of topics can reveal the communicative competence of adults with aphasia by providing a means for them to communicate about relevant issues that reflect their age, culture, interests and social roles. Adults with aphasia have a broad understanding of how the world operates, and as a result, many competencies survive severe communication impairment (Garrett \& Beukelman, 1992). The provision of a wide range of visually depicted topics would allow adults with aphasia to communicate across the range of communication functions, including the transfer of information, communication of needs and wants, the development and maintenance of social closeness, and expression of social etiquette (Light, 1988), and thereby provide a means by which the communicative competencies of adults with aphasia can be revealed.

The inclusion of functional, motivational and individualised topics within AAC systems and techniques for adults with aphasia therefore seems to hold great potential to improve the functional communication of these individuals. The topics to be included in these $\mathrm{AAC}$ techniques and systems need to be pre-selected prior to their inclusion in the system. Methods of topic pre-selection will be discussed in the next section.

\subsection{PRE-SELECTION OF TOPICS}

Communicatively intact individuals retrieve and produce words needed to create and convey messages with little or no effort (Arvidson \& Lloyd, 1997). AAC users, however, have limited ability to generate their own novel messages, and are typically dependent on others to pre-select and store message content within their AAC systems (Stuart et al., 2000). The process of pre-selecting message content is thus unique to the field of AAC (Beukelman \& Mirenda, 2005). As already mentioned, differences in age, culture, 
gender, and social role affect the types of messages that AAC users will be most likely to communicate (Stuart et al., 2000). Individuals also vary with regard to their preferences in communicating a range of communication functions, such as to maintain social closeness, to transfer new information, to indicate basic needs and wants and to express social etiquette (Light, 1988). It is therefore a challenging task to ensure that the messages included in AAC systems reflect the individual needs and preferences of the user (Beukelman \& Mirenda, 2005).

As was discussed previously, conversational topics rather than individual words or phrases have been found to be appropriate organisational units in AAC systems for adults with aphasia. Topics pre-stored within the AAC systems, irrespective of whether they are low- or high-technology systems, need to be individualised, functional and reflect what is interesting and important to the user (Yorkston et al., 1989, Beukelman et al., 1991; King, Spoeneman, Stuart, \& Beukelman, 1995). The question thus arises as to how to determine these relevant conversational topics for each individual with aphasia. As mentioned, adults with aphasia are commonly provided with prefabricated communication books or boards, which contain predetermined lists of topics and vocabulary that facilitate communication about basic needs such as pain, food preferences, and health concerns (Garrett \& Kimelman, 2000; Beukelman et al., 2007; Rogers et al., 2000). Although these systems provide some relevant communication topics, they lack contextualization and personalization (Beukelman et al., 2007; Ho et al., 2005). As a result, most of these topics and vocabulary are not used in functional settings, and the adult with aphasia is reluctant to use the system (van de Sandt-Koenderman, 2004).

In order to provide an adult with aphasia with personally relevant and functional conversational topics, alternative methods of topic pre-selection need to be employed. These methods require the involvement of informants. Informants refer to anyone who is involved in making decisions about what messages to include in an AAC system (Brewster, 2004). Family members, friends, caregivers, colleagues, and clinicians represent informants (Arvidson \& Lloyd, 1997). Adults with aphasia frequently depend on their communication partners to interpret their communicative attempts and assist in 
repairing communication breakdowns (Light \& Gulens, 2000). As a result, their communication partners occupy a central role in their communication participation and success (Garrett \& Beukelman, 1992; Kagan, 1998a). These communication partners are therefore typically involved in providing and selecting topics that will be relevant to their partner with aphasia (Worrall, 1999). Methods of topic pre-selection that make use of informants include environmental and ecological inventories and blank page topic selection (Garrett et al., 1989; Garrett \& Lasker, 2005; Arvidson \& Lloyd, 1997).

Environmental inventories are conducted by observing and recording the daily events of the AAC user. Conversational topics required within the user's communication environments are identified (Beukelman et al., 1991). Informants then generate a list of words relevant to the conversational topics identified (Arvidson \& Lloyd, 1997). Ecological inventories are similar, in that they identify the current and future environments in which the AAC user is expected to function. These inventories thus provide information on the communication demands in different environments, and generate topics and vocabulary that will enable the identified communicative demands to be met (Arvidson \& Lloyd, 1997). Blank page topic selection simply requires informants to write down all the topics they think might be useful to the AAC user (Morrow, Mirenda, Beukelman, \& Yorkston 1993). These three methods have been used successfully to determine relevant topics for adults with aphasia. Beukelman and Garrett (1988) stress that in order to pre-select appropriate messages for adults with aphasia a message inventory in multiple environments is necessary. Garrett and Lasker (2005) and Garrett and Beukelman (1992) recommend obtaining an inventory of the favourite conversational topics of the adult with aphasia from their family members. An Inventory of Topics worksheet (Garrett \& Beukelman, 1992) can be used to obtain such information, or informants can be asked to provide appropriate topics using the blank page method mentioned.

The use of informants in pre-selecting messages for communicatively impaired individuals is, however, not unproblematic. Limited research has been conducted on the accuracy of informant's selection and prediction of conversational topics for inclusion in 
AAC systems. Balandin and Iacono (1998a) investigated the abilities of professionals (speech pathologists and rehabilitation counsellors) to predict the topics and vocabulary used by employees during meal break conversations at work. They compared the predicted topics and vocabulary with the actual words used by employees without disabilities in meal break conversations. They noted that participants were able to predict some topics and vocabulary, but, overall, lacked accuracy.

Findings from another study revealed that staff members working with adults with learning difficulties presented with an unquestioned assumption that what was actually talked about was what the adults with learning difficulties wanted and needed to talk about (Graves, 2000). This phenomenon is defined as circularity, where vocabulary may only be selected for communication about topics the user can already communicate about, or which others wish them to communicate about (Brewster, 2004). In this case, topics that the communication partners feel are important may be selected at the expense of what the AAC users may want to communicate about (Arvidson \& Lloyd, 1997). The age, interests, attitudes and beliefs of the informants therefore have the potential to result in biased pre-selected topics. In order to reduce the impact of such biases, the use of multiple informants is recommended (Beukelman et al., 1991). The best option of reducing such impacts, however, would be for the adults with aphasia themselves to be actively involved in the process of selecting topics for use within their AAC systems. Due to their significant communication impairments, they are unable to act as sole informants (Beukelman et al., 1991) and require support from others for their involvement in the pre-selection process (Garrett \& Beukelman, 1992). The use of tools and strategies that allow adults with aphasia to control decisions regarding the message content of their AAC systems is also necessary.

\subsection{ACTIVE INVOLVEMENT OF ADULTS WITH APHASIA}

Blackstone et al. (2007) offered key principles of AAC research and practice for consideration and discussion within the AAC community. Amongst these is the principle stating that people who rely on AAC should participate actively in AAC research and 
practice. They stress that "Individuals with complex communication needs hold an intensely personal stake in AAC research and practice and their characteristics, experiences, preferences, priorities, opinions, suggestions, and expertise must be sought, respected, attended to, understood, and employed in the design, development, delivery, and evaluation of AAC systems and services" (p. 193). The authors emphasise that in order to provide AAC users with the opportunity to actively participate in AAC research and practice, different types and degrees of support are needed. Beukelman et al. (1991) emphasize that the people who use AAC should be extensively involved in the selection of vocabulary for their own AAC system and should be given the necessary consultative support that will make this task positive and efficient. Due to the complex nature of aphasia and the difficulty experienced by individuals with aphasia to make sense of isolated words, creative means of assisting their active involvement are necessary (Fox \& Fried-Oken, 1996).

Fox and Fried-Oken (1996) further recommend the creation of pictorial systems so that adults with aphasia can select topics from an array or with the assistance of a clinician. In addition, adults with aphasia can be presented with suggested topics and then asked to make the final decision as to whether individual words, phrases or sentences should be included or not (Yorkston et al., 1989). This method was used by Garrett et al. (1989), who described a multimodal AAC system developed for a man with Broca's aphasia. One component of the system was a word dictionary arranged topically around his favourite conversational themes. The word dictionary was compiled by conducting an exhaustive inventory of specific words pertaining to each conversational theme. The second step involved the participant editing the themes and words collected during the inventory phase. As a result, the final product was a word dictionary containing messages that the participant, rather than the informants, felt were important.

The current research project aimed to describe the topic preferences of adults with aphasia by providing them with the support needed to be actively involved in the selection of topics for inclusion in their AAC systems. It was decided to use the 39 topics from the PCR binder (Kagan et al., 1996), as well as the Talking Mats ${ }^{\mathrm{TM}}$ framework to 
provide adults with aphasia a means of active involvement. Talking Mats ${ }^{\mathrm{TM}}$ (Murphy, 1998) can be described as a strategy that allows people who require communication intervention to express their thoughts or emotions about specific topics through an easyto-use visual framework. It involves physically moving graphic symbols around a mat to facilitate discussion of a topic. Murphy (2000) conducted a study in order to examine whether or not Talking Mats ${ }^{\mathrm{TM}}$ could be used successfully with people with aphasia in allowing them to be included in discussions and decisions about their lives. Results of the study indicated that the Talking Mats ${ }^{\mathrm{TM}}$ framework has the potential to help people with aphasia express their views. The use of this interactive and visual format appeared to be a more comfortable and successful method of generating information for people with aphasia as opposed to a structured interview or questionnaire. By implementing this framework, the current research project primarily aimed to describe the self-determined and partner-predicted topic preferences of adults with aphasia.

\subsection{SUMMARY}

Due to the linguistic challenges presented by the complex nature of aphasia, as well as the heterogeneity of individual needs and communication styles, individuals with aphasia frequently adopt a variety of different strategies in order to communicate a message. Topics have been found to be effective organizational units around which to use such strategies to co-construct messages with various communication partners (Stuart et al., 2000). These topics need to be personally relevant and contextualized in order for adults with aphasia to participate in age-appropriate and motivating communicative instances. Since adults with aphasia experience difficulty in generating a list of their preferred topics, they are dependent on informants to pre-select topics for use within their AAC systems. Informant- input is not unproblematic and the active involvement of adults with aphasia themselves in this process is advocated (Fox et al., 2001). Unique and creative methods of assisting their active participation are needed and such techniques typically make use of partner involvement and concrete resources. 
The current study thus aimed to describe the self-determined and partner-predicted topic preferences of adults with aphasia. Support for the active involvement of adults with aphasia in this process was provided in the form of an existing topic list and the Talking Mats $^{\mathrm{TM}}$ framework. The information obtained could provide valuable insights into the topic preferences of adults with aphasia, the predicted topic preferences provided by the familiar communication partners as well as similarities and differences between the two. The amount of agreement of topic preferences within dyads along with descriptions of the dyad relationships could also provide interesting insights. 


\section{CHAPTER 3: METHODOLOGY}

\subsection{INTRODUCTION}

This chapter describes the research methodology used. The main aim, sub-aims, research design, and participants are described. Results of the pilot study are provided. The materials and equipment for data collection, as well as the data collection procedure is explained, followed by discussion of the reliability and validity issues within the study. Lastly, a description is given of the procedure used for data analysis.

\subsection{AIMS}

\subsubsection{Main Aim}

The main aim of the study is to determine the topic preferences (related to topics from the PCR) (Kagan et al., 1996) of adults with expressive aphasia as indicated by both the adults themselves and their familiar communication partners.

\subsubsection{Sub-aims}

The main aim is realized by means of four sub-aims:

1) To determine the topic preferences (related to topics from the PCR) of adults with expressive aphasia as indicated by their familiar communication partners.

2) To determine the topic preferences (related to topics from the PCR) of adults with expressive aphasia as indicated by the adults themselves.

3) To compare the topic preferences provided by both participant groups by describing the amount of agreement/disagreement of preferences obtained for each topic across all 10 dyads.

4) To compare the topic preferences provided by both participant groups by describing the amount of agreement/disagreement of topic preferences within each of the 10 dyads. 


\subsection{RESEARCH DESIGN}

This study employed a non-experimental comparative design (McMillan \& Schumacher, 2006). This type of design reports things the way they are, either currently or in the past without providing intervention. In addition to the description of certain phenomena or conditions, comparative research compares a specific variable in two groups. The goal of this study was to describe the topic preferences of adults with expressive aphasia as indicated by both the adults themselves and their familiar communication partners using topics taken from the PCR file, as well as to draw comparisons from the descriptive data obtained, thus indicating the use of the described research design (McMillan \& Schumacher, 2006). A significant limitation of this research design is a lack of control over threats to the internal validity of the study, which may include loss of participants, instrument validity, maturation and factors related to the research environment (McMillan \& Schumacher, 2006). Therefore, close attention to the nature of the participants selected, in this case adults with expressive aphasia, as well as the data collection techniques and procedures used is of particular importance in order to provide accurate and reliable descriptions and comparisons (McMillan \& Schumacher, 2006).

\subsection{PARTICIPANTS}

\subsubsection{Sampling and recruitment}

Purposive sampling was used to identify participants with expressive aphasia. Clinicians working within the field of acquired neurological conditions in the large metropolitan area of Johannesburg were contacted telephonically and then via email by the researcher (See Appendix A). The nature of the study was described as well as the selection criteria for the potential participants. All of the referred participants who met the selection criteria were contacted by the researcher.

\subsubsection{Selection criteria}

Two Groups of participants are included in this study. Participant Group A: Familiar Communication Partners and Participant Group B: Adults with Aphasia. Each group will be described individually. 
Participant Group A comprised the familiar communication partners of the adults with aphasia. Each adult with aphasia was required to select someone that knows them well and with whom they communicate on a regular basis to participate with them in the study. This was requested verbally with additional written and pictorial input (Appendix B). The participants with aphasia communicated who they would like to participate in the study with them by either saying the person's name, writing the person's name, pointing at the person or by physically directing and accompanying the researcher to the person. The individuals selected by the adults with aphasia were then screened to ensure that they complied with the selection criteria as summarized in Table 3.1. These individuals were referred to as familiar communication partners.

\section{Table 3.1: Subject selection criteria for Participant Group A: Familiar Communication Partners.}

\begin{tabular}{|c|c|c|}
\hline Criteria & Justification for Inclusion & Method \\
\hline 1. Adult & $\begin{array}{l}\text { Aphasia is primarily an impairment } \\
\text { that affects adults, therefore the } \\
\text { communication partners of the adults } \\
\text { with aphasia were required to fit } \\
\text { within the adult category. In addition, } \\
\text { the PCR topics were designed for use } \\
\text { with adults with aphasia. }\end{array}$ & $\begin{array}{l}\text { As determined by information } \\
\text { provided in the biographical } \\
\text { questionnaire. This questionnaire was } \\
\text { completed by the selected familiar } \\
\text { communication partner. }\end{array}$ \\
\hline 2. Proficient English speaker & $\begin{array}{l}\text { To ensure full comprehension of the } \\
\text { instructions and topics used within the } \\
\text { study. }\end{array}$ & $\begin{array}{l}\text { As determined by information } \\
\text { provided in the biographical } \\
\text { questionnaire, completed by the } \\
\text { selected familiar communication } \\
\text { partner. }\end{array}$ \\
\hline $\begin{array}{l}\text { 3. Reported to have normal or } \\
\text { corrected vision. }\end{array}$ & $\begin{array}{l}\text { Sufficient vision to see the PCR topic } \\
\text { cards and 3-point semantic } \\
\text { differential scale was required in } \\
\text { order to ensure accurate placement } \\
\text { responses from the participants. }\end{array}$ & $\begin{array}{l}\text { As determined by the ability of the } \\
\text { familiar communication partner to see } \\
\text { the topic card on the table top. }\end{array}$ \\
\hline $\begin{array}{l}\text { 4. Reported to have normal or } \\
\text { corrected hearing thresholds. }\end{array}$ & $\begin{array}{l}\text { Participants were required to hear the } \\
\text { verbal instructions and presentation of } \\
\text { topic cards adequately. }\end{array}$ & $\begin{array}{l}\text { As determined through informal } \\
\text { communication with the researcher, } \\
\text { who is a qualified speech-language } \\
\text { pathologist }\end{array}$ \\
\hline $\begin{array}{l}\text { 5. Absence of communication } \\
\text { impairment. }\end{array}$ & $\begin{array}{l}\text { The selected familiar communication } \\
\text { partner was required to have intact } \\
\text { language abilities in order to provide } \\
\text { accurate information regarding their } \\
\text { relationship with the person with } \\
\text { aphasia, as well as provide accurate }\end{array}$ & $\begin{array}{l}\text { As determined through informal } \\
\text { communication with the researcher, } \\
\text { who is a qualified speech-language } \\
\text { pathologist. }\end{array}$ \\
\hline
\end{tabular}




\begin{tabular}{|c|c|c|}
\hline Criteria & Justification for Inclusion & Method \\
\hline & $\begin{array}{l}\text { predictions of the topic preferences of } \\
\text { the person with aphasia. }\end{array}$ & \\
\hline $\begin{array}{l}\text { 6. Must know the person with aphasia } \\
\text { well and communicate with him/her } \\
\text { on a regular basis. }\end{array}$ & $\begin{array}{l}\text { Familiar communication partners } \\
\text { were selected for the purpose of the } \\
\text { study. Familiar communication } \\
\text { partners are defined as knowing the } \\
\text { person well and communicating with } \\
\text { them on a regular basis. }\end{array}$ & $\begin{array}{l}\text { The person with aphasia was required } \\
\text { to select a familiar communication } \\
\text { partner to participate in the study with } \\
\text { them based on the description } \\
\text { provided. }\end{array}$ \\
\hline
\end{tabular}

In Participant Group B, participants were selected from potential candidates referred by therapists working within the field of acquired neurological conditions in a large metropolitan area. Participant selection criteria for the present study were derived and adapted from those used in a study conducted by Fox, et al. (2001). Table 3.2 summarises the participant selection criteria for Group B, as well as the justification thereof and the method used.

Table 3.2: Subject selection criteria for Participant Group B: Adults with Aphasia.

\begin{tabular}{|c|c|c|}
\hline Criteria & Justification for Inclusion & Method \\
\hline 1. Adult & $\begin{array}{l}\text { Aphasia is typically an adult } \\
\text { impairment. The topic cards used } \\
\text { within the study, obtained from the } \\
\text { PCR manual, were intended for use } \\
\text { with adults with aphasia. }\end{array}$ & $\begin{array}{l}\text { As determined by information provided } \\
\text { in the biographical questionnaire. This } \\
\text { questionnaire was completed by the } \\
\text { participant with aphasia with the } \\
\text { assistance of a family member. }\end{array}$ \\
\hline $\begin{array}{l}\text { 2. Diagnosed with moderate to } \\
\text { severe expressive aphasia by a } \\
\text { speech-language pathologist. }\end{array}$ & $\begin{array}{l}\text { Adults with moderate to severe } \\
\text { expressive aphasia are the target } \\
\text { population for the proposed study due } \\
\text { to the overall paucity of research } \\
\text { involving the active participation of } \\
\text { adults with moderate to severe } \\
\text { expressive aphasia (Rautakoski, } \\
\text { Korpijaakko-Huuhka \& Klippi, 2008). } \\
\text { Adults with this classification of } \\
\text { aphasia are also appropriate candidates } \\
\text { for AAC (Hux et al., 2001). }\end{array}$ & $\begin{array}{l}\text { As determined by the participants' } \\
\text { performance on the spontaneous } \\
\text { speech, repetition, naming and } \\
\text { comprehension subtests of the Western } \\
\text { Aphasia Battery (Kertesz, 1982), } \\
\text { administered by the researcher. }\end{array}$ \\
\hline $\begin{array}{l}\text { 3. Minimum of } 6 \text { months post onset } \\
\text { of a neurological injury within the } \\
\text { left-hemisphere. }\end{array}$ & $\begin{array}{l}\text { Participants needed to be outside of the } \\
\text { period of spontaneous recovery in order } \\
\text { to provide a true reflection of their } \\
\text { communication abilities (Cherney \& } \\
\text { Robey, 2005). }\end{array}$ & $\begin{array}{l}\text { As determined by information provided } \\
\text { in the biographical questionnaire. This } \\
\text { questionnaire was completed by the } \\
\text { participant with aphasia with the } \\
\text { assistance of a family member. }\end{array}$ \\
\hline $\begin{array}{l}\text { 4. Proficient English speaker prior } \\
\text { to neurological injury. }\end{array}$ & $\begin{array}{l}\text { Participants were required to have been } \\
\text { proficient English speakers prior to the }\end{array}$ & $\begin{array}{l}\text { As determined by information provided } \\
\text { in the biographical questionnaire. This }\end{array}$ \\
\hline
\end{tabular}




\begin{tabular}{|c|c|c|}
\hline Criteria & Justification for Inclusion & Method \\
\hline & $\begin{array}{l}\text { onset of aphasia in order to ensure } \\
\text { maximum comprehension of the } \\
\text { instructions and topic cards used within } \\
\text { the study, which was conducted in } \\
\text { English. }\end{array}$ & $\begin{array}{l}\text { questionnaire was completed by the } \\
\text { participant with aphasia with the } \\
\text { assistance of a family member. }\end{array}$ \\
\hline $\begin{array}{l}\text { 5. No reports of dramatic } \\
\text { fluctuations in alertness. }\end{array}$ & $\begin{array}{l}\text { Participants were required to be alert } \\
\text { for the duration of both interview } \\
\text { sessions. Each session was } \\
\text { approximately one hour in duration. }\end{array}$ & $\begin{array}{l}\text { As determined by the participants' } \\
\text { speech-language therapy report and } \\
\text { information provided by the } \\
\text { participants family. }\end{array}$ \\
\hline $\begin{array}{l}\text { 6. Without reports of diffuse } \\
\text { neurological damage. }\end{array}$ & $\begin{array}{l}\text { The absence of any further cognitive- } \\
\text { communication deficits is necessary for } \\
\text { a precise aphasia classification. }\end{array}$ & $\begin{array}{l}\text { As determined by the participants' } \\
\text { speech-language therapy report and } \\
\text { background information provided by } \\
\text { the participants family }\end{array}$ \\
\hline $\begin{array}{l}\text { 7. Without reports of learning or } \\
\text { psychiatric disorders }\end{array}$ & $\begin{array}{l}\text { The presence of learning/psychiatric } \\
\text { disorders may have a negative impact } \\
\text { on the participant's ability to actively } \\
\text { participant in the interview sessions. }\end{array}$ & $\begin{array}{l}\text { As determined by the participants' } \\
\text { speech-language therapy report and } \\
\text { background information provided by } \\
\text { the participants family. }\end{array}$ \\
\hline $\begin{array}{l}\text { 8. Reported to have normal or } \\
\text { corrected vision without evidence of } \\
\text { a visual field cut. }\end{array}$ & $\begin{array}{l}\text { Sufficient vision to see the PCR topic } \\
\text { cards and 3-point semantic differential } \\
\text { scale was required in order to ensure } \\
\text { accurate preference responses from the } \\
\text { participants. }\end{array}$ & $\begin{array}{l}\text { As determined by the participant's } \\
\text { therapy reports and by the participant's } \\
\text { ability to place the practice topic cards } \\
\text { on the Talking Mat. }\end{array}$ \\
\hline $\begin{array}{l}\text { 9. Reported to have normal hearing } \\
\text { thresholds, or corrected hearing. }\end{array}$ & $\begin{array}{l}\text { Participants were required to hear the } \\
\text { verbal instructions and presentation of } \\
\text { topic cards adequately. }\end{array}$ & $\begin{array}{l}\text { As determined from information } \\
\text { provided by the participants' speech- } \\
\text { language pathologist. Speech-language } \\
\text { pathologists in South Africa are trained } \\
\text { as both speech-language pathologists } \\
\text { and audiologists and are therefore } \\
\text { aware of the hearing thresholds of their } \\
\text { clients. }\end{array}$ \\
\hline $\begin{array}{l}\text { 10. Functional use of one arm and } \\
\text { hand. }\end{array}$ & $\begin{array}{l}\text { Participants were required to physically } \\
\text { manipulate PCR topic cards during the } \\
\text { evaluation process using the Talking } \\
\text { Mats }{ }^{\mathrm{TM}} \text { framework. }\end{array}$ & $\begin{array}{l}\text { As determined by the participants' } \\
\text { therapy reports and information } \\
\text { provided by the participants family. }\end{array}$ \\
\hline
\end{tabular}

\subsubsection{Descriptive criteria}

Both participant groups were asked to complete biographical questionnaires providing relevant descriptive details, as well as some detail about their relationship with each other (See Appendix C and D). The familiar communication partners selected were not always family members of the adults with aphasia; therefore a family member was requested to assist in the completion of the form addressed to the adult with aphasia due to their knowledge of the person with aphasia's specific biographical information 


\section{Participant Group A: Familiar Communication Partners}

The sample of familiar communication partners comprised 10 participants: 5 females and 5 males. A detailed description of participants is included in Table 3.3. The familiar communication partners' ages ranged from 35 to 70 years. All were proficient in English and none reported communication, vision or hearing difficulties that impacted on their activities of daily living.

\section{Participant Group B: Adults with Aphasia}

The sample of persons with aphasia comprised 10 participants: six females and four males. The participants' ages ranged from 36 to 81 years. The time post onset of aphasia within this group ranged from 1.8 years to 26 years. Additional descriptive information is detailed in Table 3.4

\section{Dyads: Adult with aphasia and his/her familiar communication partner}

The sample of dyads therefore comprised 10 pairs of adults with aphasia and their familiar communication partners. A detailed description of the dyads is included in Table 3.5. The length of time that individuals within each dyad had known each other ranged from 1.4 years to 56 years. Six dyads knew each other prior to the onset of aphasia, while four dyads did not. Seven dyads saw each other daily, two dyads saw each other many times per week and one dyad saw each other once a month. The dyad that saw each other once a month represented a sibling relationship: brother (adult with aphasia) and sister (familiar communication partner). When requested to select a familiar communication partner, it was indicated by the adult with aphasia that the only person who visits him is his sister. She was therefore selected as his familiar communication partner despite the infrequency of visits within this particular dyad, compared to the other nine dyads. 
Table 3.3: Descriptive information for Participant Group A: Familiar Communication Partners (n=10)

\begin{tabular}{|c|c|c|c|c|c|c|c|c|c|c|}
\hline & $\mathbf{1}$ & 2 & 3 & 4 & 5 & 6 & 7 & 8 & 9 & 10 \\
\hline Gender & M & $\mathrm{F}$ & M & $\mathrm{F}$ & M & $\mathrm{F}$ & $\mathrm{F}$ & $\mathrm{M}$ & $\mathrm{F}$ & M \\
\hline Age & 59 & 61 & 62 & 35 & 57 & 58 & 70 & 56 & 59 & 55 \\
\hline Education & Degree $\mathrm{x} 2$ & Diploma & Matric & Diploma & Grade 10 & Matric & Grade 10 & $\begin{array}{c}\text { Post- } \\
\text { graduate } \\
\text { qualification }\end{array}$ & Diploma & Diploma \\
\hline Occupation & Engineer & $\begin{array}{c}\text { Personal } \\
\text { assistant }\end{array}$ & $\begin{array}{c}\text { Chief } \\
\text { Executive } \\
\text { Officer }\end{array}$ & $\begin{array}{c}\text { Laboratory } \\
\text { manager }\end{array}$ & Plumber & $\begin{array}{l}\text { Business } \\
\text { manager }\end{array}$ & Housewife & Attorney & Au pair & $\begin{array}{c}\text { Insurance } \\
\text { risk } \\
\text { surveyor }\end{array}$ \\
\hline First language & English & English & English & Afrikaans & English & English & Sesotho & Afrikaans & English & English \\
\hline
\end{tabular}


Table 3.4: Descriptive information for Participant Group B: Adults with Aphasia $(n=10)$

\begin{tabular}{|c|c|c|c|c|c|c|c|c|c|c|}
\hline & 1 & 2 & 3 & 4 & 5 & 6 & 7 & 8 & 9 & 10 \\
\hline Gender & $\mathrm{F}$ & $\mathrm{F}$ & $\mathrm{F}$ & M & M & M & $\mathrm{F}$ & $\mathrm{F}$ & M & $\mathrm{F}$ \\
\hline Age & 57 & 43 & 60 & 36 & 63 & 50 & 65 & 81 & 56 & 59 \\
\hline Education & Matric & Diploma & Diploma & Diploma & Diploma & Grade 10 & Diploma & $\begin{array}{c}\text { Post- } \\
\text { graduate } \\
\text { qualification }\end{array}$ & $\begin{array}{c}\text { Post- } \\
\text { graduate } \\
\text { qualification }\end{array}$ & Matric \\
\hline Occupation & $\begin{array}{l}\text { Executive } \\
\text { secretary }\end{array}$ & $\begin{array}{l}\text { Personal } \\
\text { assistant }\end{array}$ & Teacher & Manager & $\begin{array}{l}\text { Representati } \\
\text { ve }\end{array}$ & $\begin{array}{l}\text { Building } \\
\text { manager }\end{array}$ & $\begin{array}{l}\text { Personal } \\
\text { assistant }\end{array}$ & Retired & $\begin{array}{c}\text { Self- } \\
\text { employed }\end{array}$ & Housewife \\
\hline Handedness & $\mathrm{R}$ & $\begin{array}{l}\text { Ambit- } \\
\text { dextrous }\end{array}$ & $\mathrm{L}$ & $\mathrm{R}$ & $\mathrm{R}$ & $\mathrm{R}$ & $\mathrm{R}$ & $\mathrm{R}$ & $\mathrm{L}$ & $\mathrm{R}$ \\
\hline First language & English & Afrikaans & English & Afrikaans & Afrikaans & English & English & Afrikaans & English & English \\
\hline Marital status & Married & Married & Married & Married & Divorced & Divorced & Divorced & Widowed & Married & Married \\
\hline Etiology & CVA & TBI & CVA & CVA & CVA & CVA & CVA & CVA & CVA & CVA \\
\hline Aphasia type & $\begin{array}{l}\text { Severe } \\
\text { Broca's }\end{array}$ & $\begin{array}{l}\text { Severe } \\
\text { Broca's }\end{array}$ & $\begin{array}{c}\text { Moderate } \\
\text { Broca's }\end{array}$ & $\begin{array}{c}\text { Moderate } \\
\text { Broca's }\end{array}$ & $\begin{array}{l}\text { Moderate } \\
\text { Broca's }\end{array}$ & $\begin{array}{l}\text { Severe } \\
\text { Broca's }\end{array}$ & $\begin{array}{l}\text { Severe } \\
\text { Broca's }\end{array}$ & $\begin{array}{l}\text { Moderate } \\
\text { Broca's }\end{array}$ & $\begin{array}{l}\text { Moderate } \\
\text { Anomic }\end{array}$ & $\begin{array}{c}\text { Moderate } \\
\text { Anomic }\end{array}$ \\
\hline $\begin{array}{l}\text { WAB score } \\
\text { (AQ) }\end{array}$ & 29.7 & 29.3 & 39.8 & 39.6 & 47.9 & 14.5 & 31.1 & 32.9 & 64.4 & 62.5 \\
\hline $\begin{array}{c}\text { Time post } \\
\text { onset }\end{array}$ & $\begin{array}{c}5 \text { years } 9 \\
\text { months }\end{array}$ & $\begin{array}{c}1 \text { year } \\
8 \text { months }\end{array}$ & 8 years & $\begin{array}{c}2 \text { years } 6 \\
\text { months }\end{array}$ & $\begin{array}{c}4 \text { years } 8 \\
\text { months }\end{array}$ & $\begin{array}{c}5 \text { years } 3 \\
\text { months }\end{array}$ & 26 years & $\begin{array}{l}4 \text { years } \\
6 \text { months }\end{array}$ & $\begin{array}{c}1 \text { year } \\
8 \text { months }\end{array}$ & $\begin{array}{c}6 \text { years } \\
4 \text { months }\end{array}$ \\
\hline $\begin{array}{l}\text { Who assisted } \\
\text { the participant } \\
\text { with aphasia to } \\
\text { complete the } \\
\text { form? }\end{array}$ & Husband & Husband & Husband & Wife & $\begin{array}{l}\text { Sister-in- } \\
\text { law }\end{array}$ & Sister & $\begin{array}{l}\text { Sister-in- } \\
\text { law }\end{array}$ & Son & Self & Husband \\
\hline
\end{tabular}


Table 3.5: Descriptive information for dyads $(n=10)$.

\begin{tabular}{|c|c|c|c|c|c|c|c|c|c|c|}
\hline Dyad number: & $\mathbf{1}$ & 2 & 3 & 4 & 5 & 6 & 7 & 8 & 9 & 10 \\
\hline $\begin{array}{c}\text { Nature of } \\
\text { relationship to adult } \\
\text { with aphasia }\end{array}$ & Husband & $\begin{array}{c}\text { Paid } \\
\text { companion }\end{array}$ & Husband & Wife & Friend & Sister & Friend & Son & $\begin{array}{c}\text { Paid } \\
\text { companion }\end{array}$ & Husband \\
\hline $\begin{array}{c}\text { Time known each } \\
\text { other }\end{array}$ & 29 years & $\begin{array}{l}1 \text { year } \\
4 \text { months }\end{array}$ & 40 years & 11 years & $\begin{array}{l}2 \text { years } \\
6 \text { months }\end{array}$ & 50 years & 5 years & 56 years & $\begin{array}{l}1 \text { year } \\
6 \text { months }\end{array}$ & 11 years \\
\hline $\begin{array}{l}\text { Did dyad know each } \\
\text { other before onset of } \\
\text { aphasia? }\end{array}$ & Yes & No & Yes & Yes & No & Yes & No & Yes & No & Yes \\
\hline $\begin{array}{l}\text { How often does dyad } \\
\text { see each other? }\end{array}$ & Daily & Daily & Daily & Daily & Daily & $\begin{array}{l}\text { Once per } \\
\text { month }\end{array}$ & Daily & $\begin{array}{l}\text { Many times a } \\
\text { week }\end{array}$ & $\begin{array}{c}\text { Many times } \\
\text { per week }\end{array}$ & Daily \\
\hline $\begin{array}{l}\text { Who typically } \\
\text { decides on what is } \\
\text { done during visits? }\end{array}$ & Both & Circumstance & Partner & Both & Both & Partner & Both & Circumstance & Person & Both \\
\hline $\begin{array}{l}\text { Who completed the } \\
\text { questionnaire } \\
\text { regarding the dyad } \\
\text { relationship? }\end{array}$ & $\begin{array}{l}\text { Partner- } \\
\text { Husband }\end{array}$ & $\begin{array}{c}\text { Partner- } \\
\text { Companion }\end{array}$ & $\begin{array}{l}\text { Partner- } \\
\text { Husband }\end{array}$ & $\begin{array}{l}\text { Partner- } \\
\text { Wife }\end{array}$ & $\begin{array}{l}\text { Partner- } \\
\text { Friend }\end{array}$ & $\begin{array}{l}\text { Partner- } \\
\text { Sister }\end{array}$ & $\begin{array}{c}\text { Partner- } \\
\text { Friend }\end{array}$ & Partner-Son & $\begin{array}{c}\text { Partner- } \\
\text { Companion }\end{array}$ & $\begin{array}{l}\text { Partner- } \\
\text { Husband }\end{array}$ \\
\hline
\end{tabular}




\subsection{PILOT STUDY}

A pilot study was conducted in order to test the proposed methodology and measuring instruments of the study. Two dyads were interviewed for the pilot study, using the procedure proposed for the main study. Table 3.6 gives a detailed description of the aims, procedures, results and recommendations of the pilot study. 
Table 3.6: Description of aims, procedures, results and recommendations of the pilot study.

\begin{tabular}{|c|c|c|c|}
\hline Aims & Procedure & Results & Recommendation \\
\hline $\begin{array}{l}\text { 1. To establish whether the selected } \\
\text { method of obtaining informed consent } \\
\text { from the participants presenting with } \\
\text { aphasia was effective. }\end{array}$ & $\begin{array}{l}\text { A family member or the selected } \\
\text { familiar communication partner of } \\
\text { each participant with aphasia was } \\
\text { requested to complete an Observer } \\
\text { Consent Support Form after observing } \\
\text { the participant with aphasia } \\
\text { completing the consent form. This } \\
\text { form required the 'observer' to state } \\
\text { whether they felt that the person with } \\
\text { aphasia understood the nature of the } \\
\text { study and was willing to participate as } \\
\text { well as to provide any comments on } \\
\text { the consent process. }\end{array}$ & $\begin{array}{l}\text { Both 'observers' within each dyad } \\
\text { reported that they felt that the person } \\
\text { with aphasia understood the nature of } \\
\text { the study and was willing to } \\
\text { participate. Neither of the 'observers' } \\
\text { added any comments regarding the } \\
\text { consent process. } \\
\text { Additionally, it was noted that both } \\
\text { participants with aphasia expressed } \\
\text { comprehension of what the study } \\
\text { involved as well as their willingness } \\
\text { to participate in the study. }\end{array}$ & $\begin{array}{l}\text { It was recommended that the same } \\
\text { methods of obtaining consent be used } \\
\text { during data collection in the main } \\
\text { study. }\end{array}$ \\
\hline $\begin{array}{l}\text { 2. To establish whether the biographic } \\
\text { questionnaires provided adequate } \\
\text { information about each individual } \\
\text { participant, and regarding the } \\
\text { dynamics of the dyad. }\end{array}$ & $\begin{array}{l}\text { Participants within each dyad were } \\
\text { requested to complete biographic } \\
\text { questionnaires about themselves as } \\
\text { well as regarding the dyad } \\
\text { relationship. Where participants with } \\
\text { aphasia were unable to complete the } \\
\text { form themselves, the familiar } \\
\text { communication partner was requested } \\
\text { to assist in this process. } \\
\text { After completion of the pilot study, } \\
\text { members of one of the dyads were } \\
\text { able to complete a feedback form } \\
\text { related to the biographic } \\
\text { questionnaires used during the } \\
\text { interview process. The feedback form } \\
\text { asked various questions about how } \\
\text { the biographic questionnaires could } \\
\text { be improved. }\end{array}$ & $\begin{array}{l}\text { Results from the feedback form } \\
\text { suggested that family members of the } \\
\text { person with aphasia assisted the adult } \\
\text { with aphasia to complete the } \\
\text { biographic questionnaires, and not the } \\
\text { selected familiar communication } \\
\text { partner. This was done due to the } \\
\text { nature of certain questions requesting } \\
\text { personal details about the person with } \\
\text { aphasia that the selected familiar } \\
\text { communication partner may not } \\
\text { know. } \\
\text { It was found that the biographic } \\
\text { questionnaires did not yield all of the } \\
\text { required descriptive information } \\
\text { pertaining to the individual } \\
\text { participants as well as the dynamics } \\
\text { of the dyad. }\end{array}$ & $\begin{array}{l}\text { It was recommended that a family } \\
\text { member of the participant with } \\
\text { aphasia assisted the adult with aphasia } \\
\text { to complete the biographical } \\
\text { questionnaire, and not the selected } \\
\text { familiar communication partner. } \\
\text { The selected familiar communication } \\
\text { partner would be requested to } \\
\text { complete the form regarding the dyad } \\
\text { relationship. It was recommended that } \\
\text { the researcher be present during the } \\
\text { completion of this form in order to } \\
\text { ensure that each question was } \\
\text { answered in as much detail as } \\
\text { possible. } \\
\text { It was also recommended that some } \\
\text { additional questions be added to the }\end{array}$ \\
\hline
\end{tabular}




\begin{tabular}{|c|c|c|c|}
\hline Aims & Procedure & Results & Recommendation \\
\hline & & & $\begin{array}{l}\text { biographical questionnaires and that } \\
\text { changes be made to some of the } \\
\text { existing questions in order to obtain } \\
\text { more specific information regarding } \\
\text { each participant and dyad } \\
\text { relationship. These additions are } \\
\text { presented in Appendices C and D. }\end{array}$ \\
\hline $\begin{array}{l}\text { 3. To establish whether the selected } \\
\text { sequence of tasks during each session } \\
\text { ran effectively and appropriately. }\end{array}$ & $\begin{array}{l}\text { The sequence of tasks within each } \\
\text { interview session was decided upon } \\
\text { before the interviews were conducted. } \\
\text { The sequence to be followed was } \\
\text { typed out for the use of the researcher } \\
\text { during each session. Two dyads } \\
\text { underwent the proposed procedure. }\end{array}$ & $\begin{array}{l}\text { It was found that the selected } \\
\text { sequence of tasks within the interview } \\
\text { sessions ran effectively and } \\
\text { appropriately. }\end{array}$ & $\begin{array}{l}\text { It was recommended that the same } \\
\text { sequence of tasks be followed during } \\
\text { the main study. }\end{array}$ \\
\hline $\begin{array}{l}\text { 4. To determine whether the time and } \\
\text { sessions needed for each interview } \\
\text { was appropriate and comfortable for } \\
\text { the members within the dyad. }\end{array}$ & $\begin{array}{l}\text { Two interview scenarios were } \\
\text { attempted: The first pilot dyad was } \\
\text { interviewed across two sessions. The } \\
\text { duration of the first session was } 2 \\
\text { hours, the duration of the second } \\
\text { session was } 1 \text { hour. The second pilot } \\
\text { dyad was interviewed across one } \\
\text { longer session. }\end{array}$ & $\begin{array}{l}\text { It was noted that the first dyad were } \\
\text { more relaxed and at ease and could } \\
\text { focus on the task at hand, whereas the } \\
\text { second dyad had to attend to various } \\
\text { distractions during the longer } \\
\text { interview period. The first interview } \\
\text { session performed with the first dyad } \\
\text { lasted two hours due to extra time } \\
\text { needed for the researcher to arrange } \\
\text { the necessary equipment. }\end{array}$ & $\begin{array}{l}\text { It was recommended that each dyad } \\
\text { be interviewed across two sessions of } \\
\text { approximately } 1 \text { hour each in } \\
\text { duration. The researcher would make } \\
\text { adjustments to the organization of the } \\
\text { necessary equipment in order to } \\
\text { ensure that each interview session } \\
\text { was approximately one hour in } \\
\text { duration. }\end{array}$ \\
\hline $\begin{array}{l}\text { 5. To establish whether the } \\
\text { instructions given to the members } \\
\text { within each dyad were clear and } \\
\text { easily understood. }\end{array}$ & $\begin{array}{l}\text { The members within one dyad were } \\
\text { able to complete a feedback form } \\
\text { which requested comments regarding } \\
\text { the instructions given during the } \\
\text { interview sessions. }\end{array}$ & $\begin{array}{l}\text { The dyad reported that the } \\
\text { instructions were clear and } \\
\text { understandable. No suggestions were } \\
\text { given for improvement. }\end{array}$ & $\begin{array}{l}\text { It was recommended that the same } \\
\text { instructions be given during the main } \\
\text { study. }\end{array}$ \\
\hline $\begin{array}{l}\text { 6. To establish whether the size of the } \\
\text { textured mat was large enough to } \\
\text { contain all the PCR topic cards in } \\
\text { addition to the "something else" topic } \\
\text { cards created by the familiar }\end{array}$ & $\begin{array}{l}\text { The mat selected for the pilot study } \\
\text { was } 50 \times 35 \mathrm{~cm} \text {. The researcher } \\
\text { observed whether the selected mat } \\
\text { was large enough to contain all of the } \\
\text { PCR topic cards in addition to the }\end{array}$ & $\begin{array}{l}\text { It was found that the selected mat size } \\
\text { was not large enough to contain all of } \\
\text { the PCR topic cards and additional } \\
\text { "something else" topic cards. }\end{array}$ & $\begin{array}{l}\text { It was recommended that a larger mat } \\
\text { of } 60 \times 40 \mathrm{~cm} \text { be used during the } \\
\text { main study. }\end{array}$ \\
\hline
\end{tabular}




\begin{tabular}{|c|c|c|c|}
\hline Aims & Procedure & Results & Recommendation \\
\hline communication partner. & $\begin{array}{l}\text { "something else" topic cards created } \\
\text { by the familiar communication } \\
\text { partner. }\end{array}$ & & \\
\hline $\begin{array}{l}\text { 7. To establish whether the PCR topic } \\
\text { cards were legible and easy to } \\
\text { physically manipulate and place by } \\
\text { both members of the dyad. }\end{array}$ & $\begin{array}{l}\text { Feedback information from the } \\
\text { mentioned feedback form was used to } \\
\text { determine this. }\end{array}$ & $\begin{array}{l}\text { Feedback from members within the } \\
\text { dyad stated that the PCR topic cards } \\
\text { were legible and easy to manipulate } \\
\text { and place. }\end{array}$ & $\begin{array}{l}\text { It was recommended that the same } \\
\text { PCR topic cards used within the pilot } \\
\text { study be used during the main study. }\end{array}$ \\
\hline $\begin{array}{l}\text { 8. To determine whether the } \\
\text { information obtained from the } \\
\text { biographical questionnaires was } \\
\text { efficiently and effectively coded. }\end{array}$ & $\begin{array}{l}\text { A code was assigned to each answer } \\
\text { provided within the biographical } \\
\text { questionnaires in order to categorise } \\
\text { the data for analysis purposes. }\end{array}$ & $\begin{array}{l}\text { The information obtained from the } \\
\text { biographical questionnaires was } \\
\text { coded effectively and efficiently. }\end{array}$ & $\begin{array}{l}\text { It was recommended that the same } \\
\text { method of coding biographical } \\
\text { information be used during the main } \\
\text { study. }\end{array}$ \\
\hline
\end{tabular}




\subsection{MATERIALS AND EQUIPMENT}

\subsubsection{Conversational topics and topic cards}

The conversational topics selected for use within the study were taken from the PCR Manual (Kagan et al., 1996), a published resource used in clinical practice with adults with aphasia. It was designed with the purpose of improving communicative access for individuals with aphasia by providing non-aphasic communication partners with the necessary supplementary materials to facilitate discussions with people with aphasia. It was designed for use with individuals with severe aphasia, but can also be used with various types and severity levels of aphasia (Kagan et al., 1996). One of the sections within the manual has been designed to allow the adult with aphasia to initiate topics of interest to him or her. This section is entitled "I want to talk about" and consists of 39 conversational topics (Kagan et al., 1996). These topics include context-specific, relevant, and often complex issues facing people with aphasia, and go far beyond the basic needs and wants of these individuals (Kagan, 1998a).

The 39 conversational topics include the following: current events, politics, sports, my hobbies, my family, my job, my feelings, a problem, communication problem, where I live, 'place name and picture of setting', my transportation, my health, food/diet, my stroke, physiotherapy, occupational therapy, speech and language therapy, clothing, underwear, my children, my friend, my marriage/spouse, money, power of attorney, my medication, counselling, the future, risk of another stroke, sex, abuse, privacy, physical progress, communication progress, my medical decision, alcohol and drugs, voting, my will, as well as a something else category (Kagan et al., 1996). Each topic card comprised a line drawing of the relevant topic with a printed foil. The topic referring to 'place name and picture of setting' was removed from the topic list for use within the study due to the need for customisation of the topic card to represent the place in which the interview was held. All the interviews were held at the participants' homes. The topic where I live referred to the home of the participants, and therefore to avoid repetition, 'place name and picture of setting' was removed. 
Additionally, blank topic cards were used for each dyad to represent the topic referred to as something else. After the familiar communication partner had judged the PCR topic cards, they were requested to think of any other topics that their partner with aphasia may want to talk about. These topics were then written on the blank topic cards with a black marker pen and were included amongst the PCR topics to be judged by the participant with aphasia. Therefore, each participant with aphasia and their familiar communication partners were presented with 37 PCR topics for evaluation. A maximum of 5 additional topics were written on the blank topic cards by the familiar communication partners. These additional topics were then also presented to the adult with aphasia for evaluation.

\subsubsection{Biographical questionnaires}

Biographical information of all participants and information related to the dyad relationship was obtained by means of two questionnaires. One was completed by the familiar communication partner and the other was completed by the adult with aphasia with the assistance of a family member, as explained in section 3.4.3. These questionnaires are provided in Appendices C and D.

\subsubsection{Equipment used during the Talking Mats ${ }^{\mathrm{TM}}$ framework}

The topic preferences were determined with the use of the Talking Mats ${ }^{\mathrm{TM}}$ framework, which made use of the following items:

- Topic cards representing the 37 topics from the PCR Manual (Kagan et al., 1996) (Appendix E). Each topic item was represented with a line drawing and written foil and placed on a card which was laminated and fitted with Velcro on the back. Five blank topic cards were used for the additional topics created by the familiar communication partner.

- A black marker pen for writing additional topics on blank cards.

- A textured mat, measuring $60 \mathrm{~cm}$ x $40 \mathrm{~cm}$.

- A video camera.

- A digital camera.

- Equipment and materials needed to conduct the Western Aphasia Battery (WAB) (Kertsz, 1982). 
- Equipment and materials needed for the practice items (Appendix F).

\subsection{PROCEDURES AND DATA COLLECTION}

\subsubsection{Data collection}

Once participants were recruited for the study, two interview sessions were arranged at a location that was comfortable and convenient to the participants. The first interview session was used to explain the nature of the study, obtain consent from the adult with aphasia, request the adult with aphasia to select a familiar communication partner, as well as to administrate a language assessment battery. The second interview session required the members within each dyad to complete biographical questionnaires in order to provide information regarding individual members of the dyad and the nature of the dyad relationship. Topic preferences were also obtained during this interview session, first from the familiar communication partner and then from the adult with aphasia.

The familiar communication partners $(n=10)$ were requested to evaluate the 37 topics taken from the PCR file (Kagan et al., 1996) using the Talking Mats ${ }^{\mathrm{TM}}$ method, based on what they believed their partner with aphasia would like to talk about. In response to the question: 'Do you think ... (adult with aphasia) would like to talk about...?' each topic was placed under the 'Yes', 'Maybe', or 'No' preference options on the mat according to the participants individual predictions. As mentioned previously, after all 37 topics were evaluated, the familiar communication partners were requested to think of any additional topics that their partner with aphasia would like to talk about that were not included in the 37 topics taken from the PCR file. These additional topics were then hand drawn and written on blank topic cards and added to the 37 topics presented for evaluation to the respective adults with aphasia.

The adults with aphasia $(n=10)$ were provided with practice items prior to evaluating the PCR topics in order to ensure their understanding of the Talking Mats ${ }^{\mathrm{TM}}$ method. This involved asking the adults with aphasia the question: "Is ... (name of picture symbol) necessary for survival?" Four picture symbols on cards with printed foils were presented 
to the adults with aphasia within the above question. These were food, water, television and car (Appendix F). The adults with aphasia were required to place these cards under 'Yes', 'Maybe' or 'No' depending on their personal opinion. In order to ensure that the participants with aphasia understood the question asked and method employed, they were required to place water and food under the 'Yes' preference option.

Once the practice mat was complete, the participants with aphasia were requested to evaluate the 37 PCR topics together with the additional topics selected by their familiar communication partners using the same procedure employed with Participant Group A. In response to the question: 'Would you like to talk about ...' each participant placed each topic under either the 'Yes', 'Maybe', or 'No' option on the Talking Mat according to their particular preferences. Once each participant had evaluated the topic cards, he/she was requested to re-look the mat and decide if he/she wanted to change anything (Murphy, Gray, \& Cox, 2007). Both interview sessions were videotaped and digital photographs were taken of the completed mats. A summary of the data collection procedure is outlined in Figure 3.1.

A more detailed description of Talking Mats ${ }^{\mathrm{TM}}$ is provided below.

\section{Talking Mats ${ }^{\mathrm{TM}}$}

Talking Mats ${ }^{\mathrm{TM}}$ is a dynamic low-technology communication framework that has been specifically developed to help people with a range of communication difficulties, including adults with moderate to severe expressive aphasia express their views and opinions in a simple, non-threatening and enjoyable way (Murphy, 2000). Talking Mats $^{\mathrm{TM}}$ consists of a textured mat on which picture symbols are placed as a conversation progresses (Murphy et al., 2007). It has been used successfully with people with dementia, intellectual disabilities and aphasia (Murphy et al., 2007; Murphy \& Cameron, 2008; Brewster, 2004; Murphy, 2000; Gillespie, et al., 2010). Talking Mats ${ }^{\mathrm{TM}}$ was therefore selected as the method in which to assist the participants with aphasia to evaluate the conversational topics in this study. 


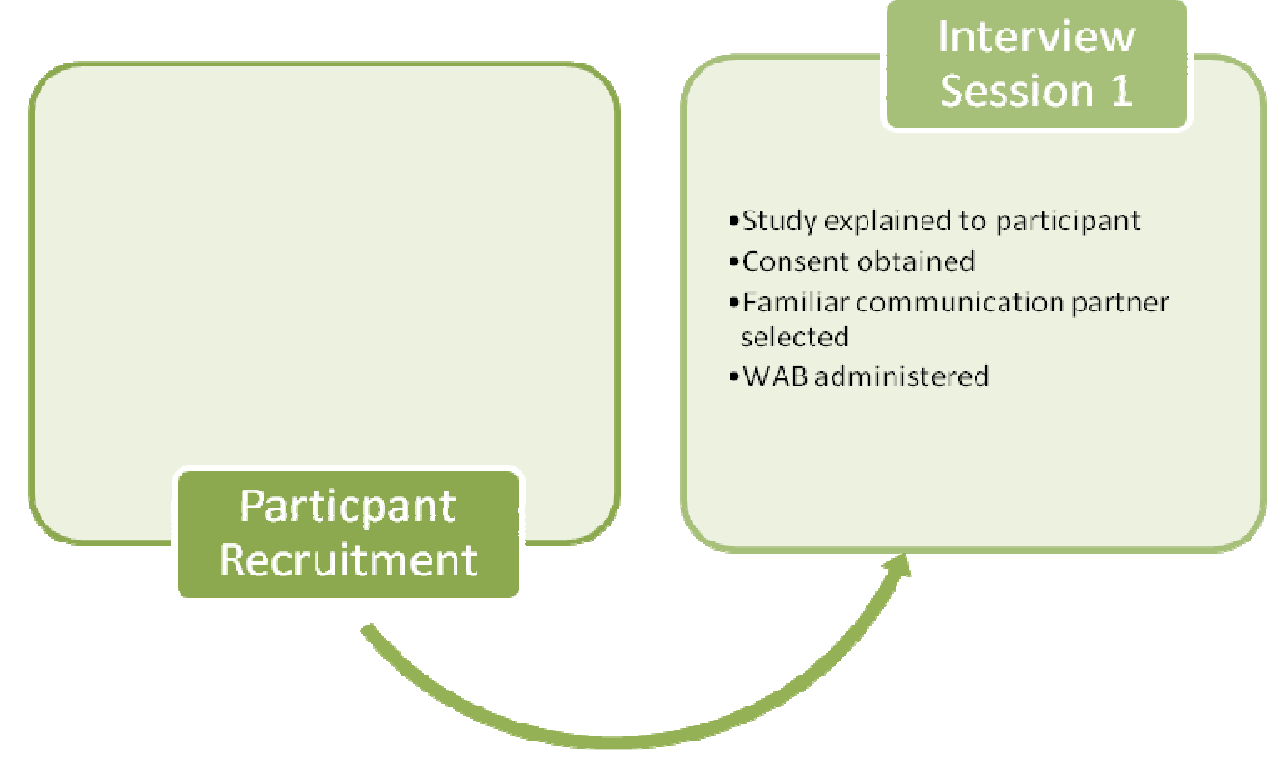

- Biographical questionnaires completed

-Topic oreference predictions obtained from familiar communication partner - Additional topics provided by familiar communication partner - Practice mat completed by adult with aphasia

-Topic preferences obtained from adult with aphasia

Figure 3.1: Data Collection Procedure.

\subsubsection{Ethical issues}

Approval of the research project was sought and obtained from the ethical committee of the University of Pretoria (Appendix G).

The participation of adults with aphasia in the study called for close examination of the process of informed consent. Penn, Frankel, Watermeyer and Muller (2008) state that "every attempt should be made to maximize and acknowledge competence and autonomy and the right to choose to participate" (p. 24) when obtaining informed consent from adults with aphasia. Additionally, it is recommended that a range of checks and balances are put in place to ensure a process of ongoing consent (Penn et al., 2008).

Therefore, for the purposes of this study, a three-step consent process used by Murphy et al. (2007) was adopted in order to ensure full understanding and consent on the part of the participants. First, the potential participants and their families were sent information forms about the study, explaining the nature of the study and requesting for their 
participation. Second, if the potential participants demonstrated an interest to take part in the study, the researcher arranged to meet with them. The study was explained verbally to the participants and they were asked if they wanted to participate. A family member was requested to observe the adult with aphasia respond to whether they were willing to take part in the study or not. These family members were then requested to complete an Observer Consent Support form in order to verify that the adult with aphasia communicated willingness to take part in the study. Finally, a policy of ongoing consent was followed whereby the researcher ensured at each subsequent visit that the participants were fully aware of what was expected of them and were willing to proceed. The information sheets explaining the nature of the study as well as the consent forms used for the adults with aphasia made use of pictures to enhance the meaning of what was said within the materials (Murphy et al., 2007) (See Appendices H, I, J, K, L, M, \& N).

A further ethical issue was that of the importance of feedback of the results of the study to those that participated in it, thereby providing direct benefits to the study participants (Murphy, 2000). A booklet containing the PCR topic cards that the participants with aphasia preferred was provided to them after completion of the study for their daily communicative use.

\subsection{VALIDITY AND RELIABILITY}

The primary methods of data collection used within this study were biographical questionnaires and the Talking Mats ${ }^{\mathrm{TM}}$ framework. The biographical questionnaires were completed within the interview sessions, thereby allowing a semi-structured approach to completing the questionnaires as the researcher was able to probe or re-phrase questions where necessary. The Talking Mats ${ }^{\mathrm{TM}}$ framework was conducted in a semi-structured interview format. Strengths and weaknesses of both these methods of data collection are discussed as well as the methods used to ensure optimal validity and reliability measures within the study. 
Biographical questionnaires are economical, they provide an efficient means of capturing answers to closed-ended questions and they provide time for participants to respond. Weaknesses of this method of data collection involve the difficulty of capturing information provided to open-ended questions, the possibility of participant's answers being influenced by the restricted responses provided to them, as well as the potential for fake and socially desirable answers to be provided (McMillan \& Schumacher, 2006). The biographical questionnaires used within this study were completed in the presence of the researcher. This allowed the researcher to request more detail for specific questions, allowing the participants to provide additional information for the questions with restricted response options. The researcher was also able to explain questions that were perhaps not understood by the participants. Changes and additions to the biographical questionnaires were made following recommendations from the pilot study. This resulted in certain questions being re-phrased and additional options provided for questions with restricted response options. The biographical questionnaires requested objective and factual information related to factors such as age, occupation, relevant time periods, and activities performed. Questions requesting this objective information reduce the potential of inaccurate information being provided due to faking or social desirability, thereby reducing this threat (McMillan \& Schumacher, 2006).

The Talking Mats ${ }^{\mathrm{TM}}$ framework employed in this study provided participants with a simple and non-threatening means of evaluating topic cards. This method allowed participants to proceed at their own pace and experience ownership of their responses (Cameron \& Murphy, 2002). However, the interview style employed during the Talking Mats ${ }^{\mathrm{TM}}$ framework was time consuming and susceptible to interviewer bias. It was also important for the researcher to be aware that the views expressed by the participants on the specific day of the interviews, reflected their opinions on that particular day and may therefore change. Additionally, when the participant placed a topic card under the 'Yes' or 'No' preference options, the reasons for such placement were not always evident. Therefore the researcher was required to take care to avoid making assumptions for the chosen placement (Murphy, Tester, Hubbard, Downs \& McDonald, 2005). 
In order to minimize the possible effects of the above-mentioned factors within this study, implementation guidelines were used by the researcher. These guidelines aimed to maximise the comprehension and participation of the adults with aphasia and ensured that the participants were provided with time to respond to each topic card and provide explanations for their preferences if they wished (Murphy, 2000; Bornman \& Murphy, 2006). Additionally, the researcher was a trained speech-language pathologist and was therefore able to conduct the Talking Mats ${ }^{\mathrm{TM}}$ framework in a clinically appropriate manner, reducing the likelihood of researcher effects and interviewer bias. After each participant had evaluated all of the topic cards, they were asked to re-look their mat and make any changes they felt necessary. This ensured that each participant confirmed their topic preferences. Thereafter a digital photograph of the completed mat was taken in order for the researcher to capture the topic preferences accurately.

All interview sessions were videotaped. Once all of the interviews had been performed, $20 \%$ of the videotaped material (that is, $20 \%$ of the interview sessions and $20 \%$ of the Talking Mats ${ }^{\mathrm{TM}}$ sessions) was viewed by an independent second observer to determine adherence to the predetermined procedures. The videos were scored according to a set of interview guidelines and Talking Mats ${ }^{\mathrm{TM}}$ implementation guidelines. These guidelines are outlined in Appendix O. The independent second observer also examined 20\% of the photographs of completed mats and checked that the topic preferences on the photographs correlated to the transcribed topic preferences used for data analysis.

The results of the scoring performed by the independent second observer revealed pointby-point agreement of $100 \%$ on procedural reliability of interview guidelines, $100 \%$ on procedural reliability of the Talking Mats ${ }^{\mathrm{TM}}$ procedure, and $100 \%$ correlation of the photographs of completed mats and transcribed topic preferences used for the data analysis. 


\subsection{ANALYSIS OF DATA}

The topic preferences provided by both participant groups were transcribed from the digital photographs of the completed mats onto computerised tables. Descriptive statistics were used to summarise the results, including frequencies of topic preferences across participants and topics, as well as percentage agreements per topic and per dyad. The videotaped interviews were examined in order to capture verbatim feedback from the adult with aphasia and his/her familiar communication partner within each dyad. This feedback was used to exemplify the topic preferences provided by each participant and dyad. Information obtained from the biographical questionnaires was documented using frequencies and percentages. This information was used to describe individual participants, as well as the dyad relationships.

\subsection{SUMMARY}

The research methodology of the study was described in this chapter. The aims, sub-aims and the research design, as well as the participants, pilot study and data collection procedures were described. The material used for data collection and the methods of data analysis employed were also detailed. 


\section{CHAPTER 4: RESULTS AND DISCUSSION}

\subsection{INTRODUCTION}

The results of the study are presented and discussed in this chapter. The chapter commences with a discussion of the reliability of the responses obtained from both participant groups. This is followed by the presentation of the results according to the four sub-aims of the study as described in Chapter 3. The predicted topic preferences provided by Participant Group A, the familiar communication partners of the adults with aphasia, are described first. Secondly, the topic preferences provided by Participant Group B, the adults with aphasia, are described. Thirdly, the topic preferences provided by both participant groups are compared by describing the amount of agreement/disagreement of preferences obtained for each topic across all 10 dyads. Fourthly, the topic preferences provided by both participant groups are compared by describing the amount of agreement/disagreement of topic preferences within each of the 10 dyads. Verbatim comments are provided in italics to exemplify the findings within each sub-aim.

Throughout the chapter, individual familiar communication partners are referred to as A01, or A02, belonging to Participant Group A. Adults with aphasia are referred to as B01, and so on. Dyad 1 therefore refers to participants A01 and B01.

\subsection{RESPONSE RELIABILITY}

The topic preferences provided by both participant groups were distributed across the three possible options; 'Yes', 'Maybe', and 'No'. It was clear that none of the participants randomly assigned topic cards to only one area of the mat, as they provided verbal and nonverbal explanations for the reasons behind their decisions, and hence the placement of the topic card. Nonverbal explanations were provided with the use of gestures, vocalisations, eye contact, body language and facial expressions. Some of the participants explained their understanding of the mid-point option, 'Maybe'. They 
commented that the mid-point was used to place topics that they were not sure about, or felt that they did not have sufficient knowledge to make definite decisions regarding the topic being discussed. "I'm putting all the things under 'Maybe' that we have never spoken about. These are personal things, that I encourage her to talk about with others who are more involved in these areas" (A02), and "This topic is sort of a done deal in a way, but I'll put it under 'Maybe' just in case" (A01). Many of the participants with aphasia demonstrated this type of reasoning by shrugging their shoulders or moving a topic card between the 'Yes' and 'No' preference options before placing the card under the 'Maybe' option. These findings indicate that the participants carefully considered the topic cards before placing them under the three possible options.

\subsection{TOPIC PREFERENCES BY THE FAMILIAR COMMUNICATION PARTNERS: GROUP A}

The topic preferences provided by the familiar communication partners are presented first in terms of the total amount of 'Yes', 'Maybe' and 'No' preferences made from all 10 participants, and second in terms of the amount of 'Yes', 'Maybe' and 'No' preferences provided per topic.

\subsubsection{Frequency of total number of 'Yes', 'Maybe' and 'No' preferences provided by Group A}

The total topic preferences provided by Participant Group A are presented in Figure 4.1 by displaying the topic preferences per participant. The frequency of 'Yes' preferences provided by all 10 participants was 237 out of a possible 370 . The frequency of 'No' preferences was 68 out of a possible 370. The frequency of 'Maybe' preferences was 65 out of a possible 370. In other words, the familiar communication partners of the participants with aphasia predicted that their partners with aphasia would like to talk about $64.05 \%$ of proposed topics. They predicted that the adults with aphasia would not like to talk about $18.37 \%$ of the topics, and may like to talk about $17.56 \%$ of the topics. 


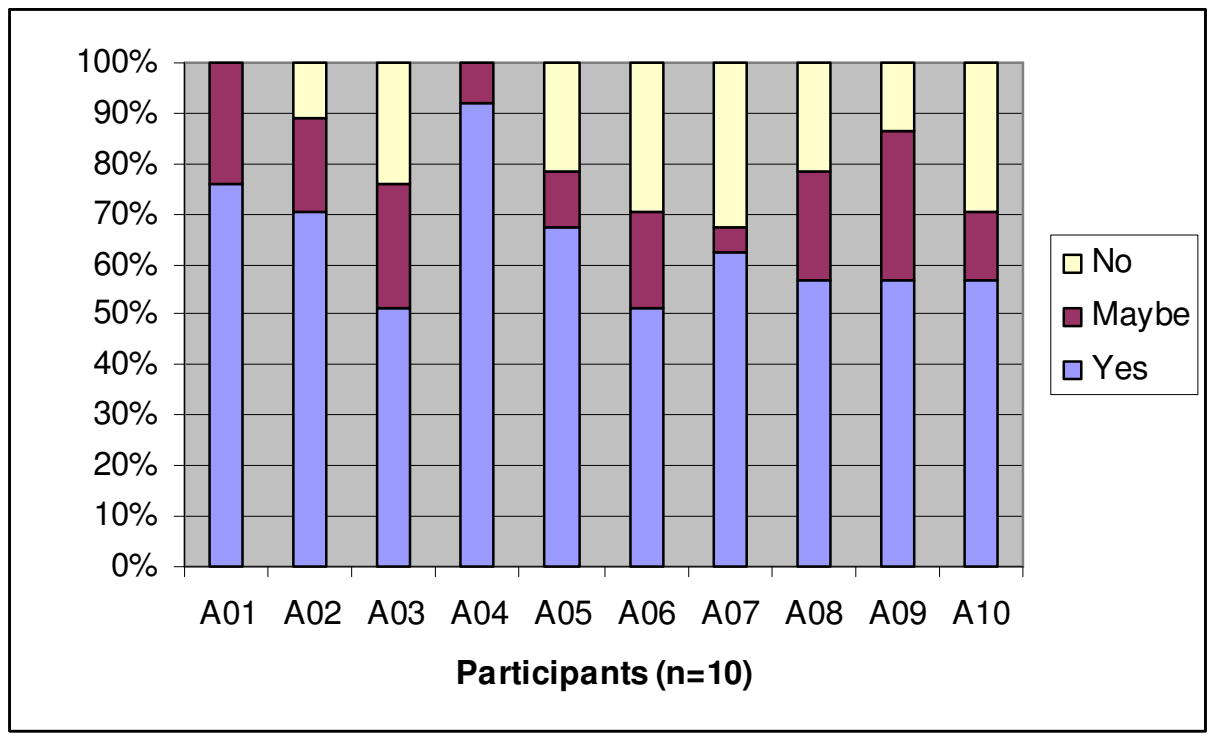

Figure 4.1: Frequency of total number of 'Yes', 'Maybe' and 'No' topic preferences provided by Group A (n=10)

The familiar communication partners therefore predicted that their partners with aphasia would like to talk about the majority of the topics presented. This was emphasized by some of their comments. Communication partner A01 asked: "Is it normal that there are more 'Yes' than 'No'? Well, you know, we talk about everything”. Communication partner A04 placed 34 out of 37 topics under the 'Yes' preference option and when she was looking over her placement of the topics, stated: "We talk a lot!".

These findings reflect an understanding on the part of the familiar communication partners that adults talk about a wide range of topics, and that their partners with aphasia would also like to talk about such topics. A comment made by familiar communication partner A03 was: "Ja, you know, you wish you could talk about all of these things. It gives you a wake-up call”. Familiar communication partner A01 commented after he had evaluated the 37 topics and reviewed his Talking Mat: "Obviously we don't talk about these things, but certainly in terms of what she is interested in, all of these are relevant in terms of what we do and talk about". 


\subsubsection{Frequency of 'Yes', 'Maybe' and 'No' preferences per topic by Group A.}

The 'Yes', 'Maybe' and 'No' topic preferences provided for each of the 37 topics are presented in Table 4.1. The topics are arranged in descending order from highest to lowest number of 'Yes' preferences.

All ten familiar communication partners predicted that their partners with aphasia would want to talk about the topics my children and my family. At least seven familiar communication partners predicted that their partner with aphasia would like to talk about the following topics: my feelings, a problem, communication problem, my stroke, speech and language therapy, money, my medication, the future, my physical progress, my hobbies, my health, clothing, my friend, communication progress, sports, my transportation, and my marriage/spouse.

Topics that obtained less 'Yes' preferences were my job, underwear, risk of another stroke and sex, placed under the 'Yes' option by only four communication partners. Alcohol and drug issues were placed under 'Yes' by three partners; politics and power of attorney by two communication partners and counselling and abuse by one communication partner.

Topics that obtained the highest number of 'No' preferences were alcohol and drug issues being rejected by six communication partners; politics and abuse by five partners; my job, underwear, sex and power of attorney by four partners; counselling by three and risk of another stroke by two communication partners.

Topics that received the greatest number of 'Maybe' preferences were counselling, placed under 'Maybe' by six communication partners and risk of another stroke, power of attorney and abuse placed under 'Maybe' by four partners. 
Table 4.1: Frequency of 'Yes', 'Maybe' and 'No' preferences per topic $(n=37)$, by Group A.

\begin{tabular}{|c|c|c|c|}
\hline Topic & Yes & Maybe & No \\
\hline my family & 10 & 0 & 0 \\
\hline my children & 10 & 0 & 0 \\
\hline my feelings & 9 & 1 & 0 \\
\hline a problem & 9 & 1 & 0 \\
\hline communication problem & 9 & 1 & 0 \\
\hline my stroke & 9 & 0 & 1 \\
\hline speech and language therapy & 9 & 0 & 1 \\
\hline money & 9 & 0 & 1 \\
\hline my medication & 9 & 0 & 1 \\
\hline the future & 9 & 0 & 1 \\
\hline progress (physical) & 9 & 1 & 0 \\
\hline my hobbies & 8 & 1 & 1 \\
\hline my health & 8 & 2 & 0 \\
\hline clothing & 8 & 1 & 1 \\
\hline my friend & 8 & 2 & 0 \\
\hline progress (communication) & 8 & 2 & 0 \\
\hline sports & 7 & 0 & 3 \\
\hline my transportation & 7 & 1 & 2 \\
\hline my marriage/spouse & 7 & 2 & 1 \\
\hline current events & 6 & 4 & 0 \\
\hline where I live & 6 & 2 & 2 \\
\hline food/diet & 6 & 3 & 1 \\
\hline occupational therapy & 6 & 2 & 2 \\
\hline my medical decision & 6 & 3 & 1 \\
\hline physiotherapy & 5 & 1 & 4 \\
\hline privacy & 5 & 4 & 1 \\
\hline voting & 5 & 2 & 3 \\
\hline my will & 5 & 1 & 4 \\
\hline my job & 4 & 2 & 4 \\
\hline underwear & 4 & 2 & 4 \\
\hline risk of another stroke & 4 & 4 & 2 \\
\hline
\end{tabular}




\begin{tabular}{|l|c|c|c|}
\hline \multicolumn{1}{|c|}{ Topic } & Yes & Maybe & No \\
\hline sex & 4 & 2 & 4 \\
\hline alcohol and drug issues & 3 & 1 & 6 \\
\hline politics & 2 & 3 & 5 \\
\hline power of attorney & 2 & 4 & 4 \\
\hline counselling & 1 & 6 & 3 \\
\hline abuse & 1 & 4 & 5 \\
\hline
\end{tabular}

The majority of the topics placed under the 'Yes' option could be classified as 'core' topics of conversation as they include topics that seem to be commonly referenced in both aphasic and communicatively intact adult conversations (Davidson et al., 2003; Stuart et al., 1994, Tonsing \& Alant, 2004; Balandin \& Iacono, 1998b). This will be discussed in more detail in the next section of this chapter. The predicted preferences provided by the familiar communication partners, however, yielded some interesting findings. These are discussed further.

At least seven of the familiar communication partners predicted that their partners with aphasia would want to talk about the topics related to their communication impairment and additional physical disability. These topics include: a problem, communication problem, physical progress, speech-language therapy, communication progress and my stroke. These findings indicate an acute awareness on the part of the familiar communication partners of the impact of aphasia on their communicatively impaired partners and their subsequent desire to talk about topics related to aphasia and disability. The impact of aphasia on the lives of the spouses, family members and friends of adults with aphasia is significant (Le Dorze \& Brassard, 1995), and presents a major life adjustment that both partners face together, and that will leave them both utterly changed (Brumfitt, 1993).

When presented with the topic, my stroke, familiar communication partner A06 commented "It's something we've avoided but perhaps it's a good thing to talk about". She then placed the topic card under the 'Yes' preference option. This comment 
highlights the sensitive nature of the topic, but also the need for adults with aphasia to be provided with the opportunity to discuss this topic, should they want to.

During the process of predicting the topic preferences of the adults with aphasia, it was noted that some of the familiar communication partners commented on their desire or lack of desire for the various topics to be discussed. At times, topic preference predictions were based on the ability of the partners with aphasia to discuss these topics. In the literature, these observations have been described as circularity (Brewster, 2004). Circularity is defined as the process whereby vocabulary may only be selected for communication about topics the user can already communicate about, or which others wish them to communicate about. Circularity indicates an unquestioned assumption that what is actually spoken about is what the communicatively impaired individual wants and needs to talk about (Brewster, 2004).

Below are some examples of circularity observed in the current study:

Familiar communication partner A06

Sex: "I hope not. Does he need to talk about sex?" (topic card placed under 'No').

The future: "I'm scared to put this one as 'Yes'. Well, maybe we need to talk about that" (topic card placed under 'Yes').

Where I live: "That's a big problem. He hates it here, so it's something I avoid because there is no other alternative. I'll carry on avoiding it. It will be interesting to see, because if he does want to talk about it, then we'll have to address that" (topic card placed under 'No').

Familiar communication partner A01:

Privacy: "Not an issue” (topic card placed under 'Maybe').

Abuse: "These are not an issue" (topic card placed under 'Maybe').

Power of attorney: "Is a done deal" (topic card placed under 'Maybe').

Counselling: "That's not happening” (topic card placed under 'Maybe').

Sex: "We don't discuss" (topic card placed under 'Maybe'). 


\subsection{TOPIC PREFERENCES BY ADULTS WITH APHASIA: GROUP B}

The topic preferences provided by the adults with aphasia are presented first in terms of the total amount of 'Yes', 'Maybe' and 'No' preferences made per participant and in total, and second in terms of the amount of 'Yes', 'Maybe' and 'No' preferences provided per topic. Following this, the preferences of the additional topics provided by the familiar communication partners are presented.

\subsubsection{Frequency of total number of 'Yes', 'Maybe' and 'No' preferences provided by Group B}

The topic preferences provided by Participant Group B are presented in Error! Reference source not found. The frequency of 'Yes' preferences provided by all 10 participants was 262 out of a possible 370. The frequency of 'No' preferences was 57 out of a possible 370. The frequency of 'Maybe' preferences was 51 out of a possible 370. In other words, the adults with aphasia indicated that they would like to talk about $70.81 \%$ of the proposed PCR topics. They would not like to talk about $15.40 \%$ of the topics and they may like to talk about $13.78 \%$ of the proposed topics. These findings are emphasized by comments and indications made by some of the participants with aphasia. Before the topic evaluation process began, Participant's B02, B03 and B04 communicated with the use of gestures, facial expressions and vocalizations that they would like to talk about all of the topics. Participant B09 commented, "I want to talk about everything". 


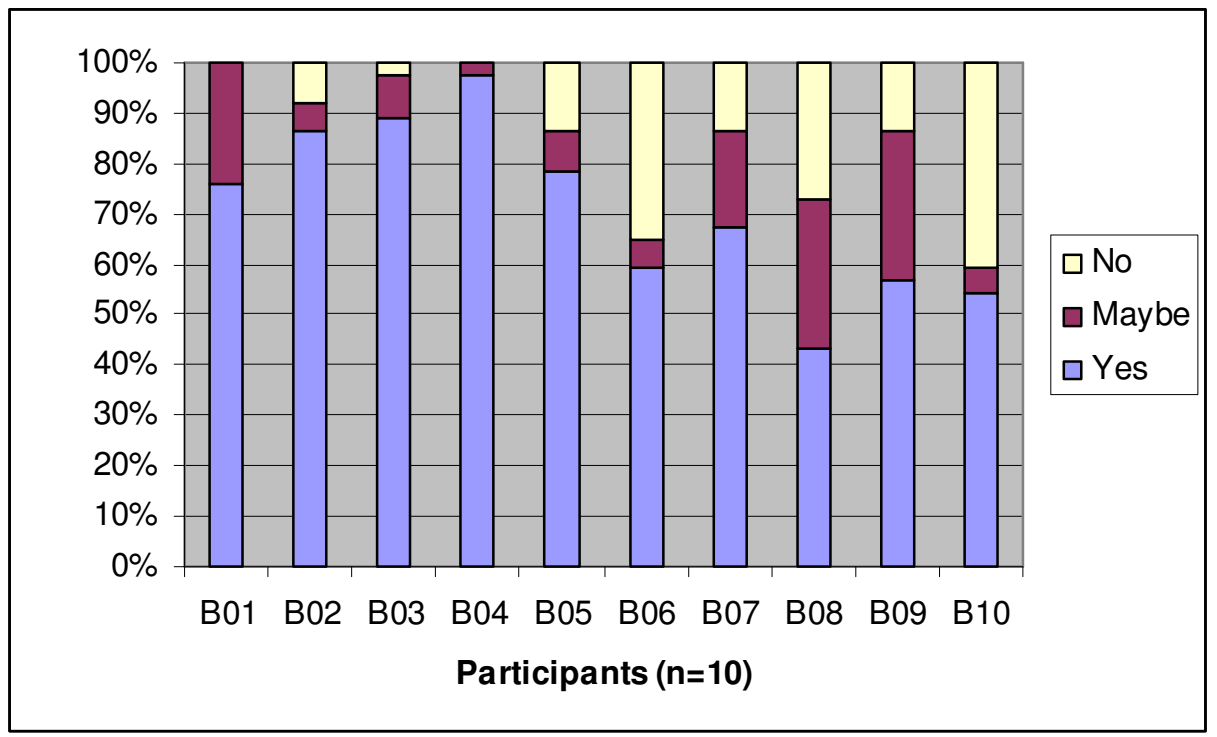

Figure 4.2: Frequency of total number of 'Yes', 'Maybe' and 'No' topic preferences provided by Group B $(\mathbf{n}=10)$

The 37 topics taken from the PCR file (Kagan et al., 1996) were developed from research regarding the expressed communication needs and wide-ranging concerns of hundreds of adults with aphasia and their families who had attended the Aphasia Centre in North York, Canada (Kagan, 1998a). The high frequency of topics placed under the 'Yes' preference option reflected in this study suggests that the topics within the PCR list are a relevant resource for use with the target population. Additionally, these findings suggest that the topics within the PCR topic list are not culture-bound due to the fact that the list was determined through large scale research in Canada (Kagan et al., 1996), yet obtained high 'Yes' preferences from South African adults with aphasia.

Communication and the ability to engage in conversations, allows people to express and create their ideas, personalities, culture and life values as well as providing a means to define themselves, achieve self-esteem and maintain relationships with others (SimmonsMackie, 2001; Kagan \& Gailey, 1993). Severe aphasia has a dramatic effect on an individual's ability to engage in conversations, and therefore engage in social life. It is therefore understandable that, as mentioned previously, some of the participants with 
aphasia in this study responded that they would like to talk about all the topics before they were even aware of what the topics were, and that once presented with the topics, they revealed that they would want to talk about the majority of the 37 topics, as shown in Figure 4.2.

In addition, these findings echo those from Davidson et al.'s (2003) study which revealed that older people (both with and without aphasia) engaged in conversations about a wide range of common topics. This may suggest that although adults with aphasia experience significant difficulty in 'talking' about various topics, they still manage to 'communicate' with others about a wide range of topics. Providing adults with aphasia with access to a wide range of relevant topics is therefore important.

\subsubsection{Frequency of 'Yes', 'Maybe' and 'No' preferences per topic by Group B.}

The 'Yes', 'Maybe' and 'No' preferences provided for each of the 37 topics are presented in Table 4.2. The topics are arranged in descending order from highest to lowest number of 'Yes' preferences.

All 10 participants with aphasia wanted to talk about the topics occupational therapy, speech and language therapy, my children, my friend, and communication progress. In addition, at least seven participants indicated that they would like to talk about the following topics: current events, my hobbies, my family, my job, communication problems, my transportation, food/diet, physiotherapy, clothing, money, my medical decision, my feelings, where I live, my health, my stroke, underwear, the future, sex, and physical progress.

Topics that obtained minimal 'Yes' preferences were politics, voting, risk of another stroke, and abuse, placed under the 'Yes' option by 4/10 (40\%) participants and alcohol and drug issues, by only $2 / 10(20 \%)$ participants. 
Subsequently, these topics that obtained minimal 'Yes' preferences, obtained the highest number of 'No' preferences, with politics and voting being rejected by four participants and risk of another stroke, abuse and alcohol and drug issues being rejected by five participants.

Minimal 'Maybe' preferences were assigned to the majority of the 37 topics; however, discussing a problem and issues relating to privacy obtained four; the largest amount of 'Maybe' preferences.

Table 4.2: Frequency of 'Yes', 'Maybe' and 'No' preferences per topic $(n=37)$ by Group B.

\begin{tabular}{|l|l|l|l|}
\hline \multicolumn{1}{|c|}{ Topics } & Yes & Maybe & No \\
\hline occupational therapy & 10 & 0 & 0 \\
\hline speech and language therapy & 10 & 0 & 0 \\
\hline my children & 10 & 0 & 0 \\
\hline my friend & 10 & 0 & 0 \\
\hline progress (communication) & 10 & 0 & 0 \\
\hline my hobbies & 9 & 1 & 0 \\
\hline my family & 9 & 1 & 0 \\
\hline clothing & 9 & 1 & 0 \\
\hline current events & 8 & 2 & 0 \\
\hline sports & 8 & 0 & 2 \\
\hline my job & 8 & 0 & 2 \\
\hline communication problem & 8 & 2 & 0 \\
\hline my transportation & 8 & 0 & 2 \\
\hline food/diet & 8 & 0 & 2 \\
\hline physiotherapy & 8 & 0 & 2 \\
\hline money & 8 & 2 & 0 \\
\hline my medical decision & 7 & 1 & 1 \\
\hline my feelings & 7 & 1 \\
\hline where I live & 7 & 3 & 0 \\
\hline my health & 7 & 0 & 0 \\
\hline my stroke & & 3 & \\
\hline
\end{tabular}




\begin{tabular}{|l|l|l|l|}
\hline \multicolumn{1}{|c|}{ Topics } & Yes & Maybe & No \\
\hline underwear & 7 & 1 & 2 \\
\hline the future & 7 & 2 & 1 \\
\hline sex & 7 & 1 & 2 \\
\hline progress (physical) & 7 & 2 & 1 \\
\hline a problem & 6 & 4 & 0 \\
\hline my medication & 6 & 1 & 3 \\
\hline counselling & 6 & 3 & 1 \\
\hline privacy & 6 & 4 & 0 \\
\hline my marriage/spouse & 5 & 2 & 3 \\
\hline power of attorney & 5 & 3 & 2 \\
\hline my will & 5 & 1 & 4 \\
\hline politics & 4 & 2 & 4 \\
\hline risk of another stroke & 4 & 1 & 5 \\
\hline abuse & 4 & 1 & 5 \\
\hline voting & 4 & 2 & 4 \\
\hline alcohol and drug issues & 2 & 3 & 5 \\
\hline
\end{tabular}

The high number of 'Yes' preferences provided to the majority of the presented topics, reinforce the functional value of these topics for use in real-life communicative instances. The majority of these highly preferred topics seem to be those that most adults would want to communicate about. These topics could be classified as 'core' topics of conversation as they include topics that have been found to be commonly referenced in both aphasic and communicatively intact adult conversations (Davidson et al., 2003; Balandin \& Iacono, 1998b; Tonsing \& Alant, 2004; Stuart et al., 1994). Davidson et al. (2003) employed naturalistic observation to record the everyday communication activities of two groups of older adults, one group with aphasia and one group without aphasia. Balandin and Iacono (1998b) and Tonsing and Alant (2004) recorded the conversations of groups of communicatively intact adults in the work place using mini cassette recorders, whereas Stuart et al. (1994) used voice-activated audio tape recorders to collect language samples from the everyday conversations of elderly, communicatively intact men and women. Although the ages and gender of the participants, physical locations of the recorded conversations, topic allocation methods and countries in which 
the studies were conducted (Australia, Australia, South Africa and United States of America respectively) differ across the studies, topics that were commonly referenced across all four studies include: family, friends, food, health, current events and sport. Topics referenced across three of the studies include: hobbies, work, money, transport, housing, emotional response, clothing, and future events. These commonly referenced topics overlap with a notable amount of the highly preferred topics of the participants with aphasia in the current study, thus reinforcing these topics as core topics of adult conversation. These overlapping topics include: my family, my friend, food/diet, my health, current events, sport, my hobbies, my job, money, my transportation, where I live, my feelings, clothing, and the future.

Certain preferred topics, however, relate specifically to issues experienced by adults with aphasia and co-existing physical disabilities, such as communication progress, speechlanguage therapy, occupational therapy, communication problem, physiotherapy, my stroke, and physical progress. These topics are discussed in more detail below.

Only five of the participants with aphasia in the study were receiving speech-language therapy and two of the participants were receiving occupational therapy when the interviews took place, however, all 10 participants indicated that they would like to talk about these topics. Eight participants with aphasia wanted to talk about physiotherapy even though only four participants were receiving physiotherapy at the time that the interviews took place. Although specific details of the rehabilitation services obtained by each participant were not documented, it can be assumed that in the acute stages of their recovery after the onset of aphasia, the majority of the participants received speechlanguage therapy, occupational therapy and physiotherapy. These findings suggest that these services, although not currently being received by all participants are of interest to adults with aphasia and that they would like to communicate about them.

The average time since the onset of aphasia for the 10 participants is 79.6 months, that is, 6.6 years. The shortest time since the onset of aphasia was 20 months for one of the participants and the longest time since the onset of aphasia was 312 months for another 
participant. Despite the length of time since the onset of aphasia, all 10 participants wanted to talk about their communication progress and at least seven participants wanted to talk about communication problem and my stroke. These topics relate to their adjustment to their acquired communication impairment. The onset of aphasia represents a fundamental change in an individuals life and the process of adjusting to the disability and a new sense of self is a long and hard one (Stuart et al., 2000). It is not surprising therefore, that the majority of the participants with aphasia in this study indicated that they would like to talk about topics related to their impairment. The wishes and expectations of adults with aphasia living with the communication impairment from 1 to 48 months have been found to be that they would recover and communicate as they did before the onset of the impairment (Zemva, 1999). It appears that regardless of the length of time post onset of aphasia, adults living with the communication difficulty still desire to communicate about these issues.

Eight of the adults with aphasia participating in the study wanted to communicate about the topic my job. The remaining two participants rejected this topic. One of these participants was 81 years old and therefore in the retirement phase of life and the other participant was a housewife prior to the onset of aphasia. The eight participants who had previously been employed, however, had been unemployed since the onset of aphasia. The participants with aphasia in Parr's (2007) study on social exclusion communicated their concerns about being unemployed, including loss of income, as well as the major change of lifestyle and identity the aphasia had brought. They indicated that their jobs had brought them status, pleasure, influence and power. This finding reinforces the importance of communicating about the pre-morbid functioning of the adult with aphasia, in particular his/her job in order to assist him/her to re-define him/herself post onset of aphasia (Stuart et al., 2000). Stuart et al. (2000) recommend that details of the adult with aphasia's former employment as well as their comments, hopes and desires about seeking new employment should be spoken about and included in the message content of their AAC systems. 
Six adults with aphasia wanted to communicate about counselling, three were unsure and one participant did not want to talk about it. Emotional impairments have been found to be the most frequently described psychological effects of aphasia, with both the adults with aphasia and their relatives being exposed to considerable psychosocial changes and stress (Herrmann \& Wallesch, 1989). Despite this, counselling has been found to be infrequently organised for adults with aphasia and their family members, who as a result are not provided with assistance and strategies for the adequate treatment and management of the emotional effects of aphasia (Herrmann \& Wallesch, 1989). It is interesting that only six participants with aphasia indicated a desire to talk about counselling, whereas all ten participants with aphasia wanted to discuss the services of speech-language therapy and occupational therapy. This perhaps indicates that some adults with aphasia are ambivalent towards this topic despite the significant psychosocial impact of aphasia.

The 37 topics within the "I want to talk about" section in the PCR file were organised so that the most sensitive topics are found on the last page of the section. This was done so that these topics could be removed if the communication partner felt they were inappropriate in certain situations (Kagan et al., 1996). The topics categorised as sensitive include: sex, abuse, privacy, physical progress, communication progress, my medical decision, alcohol and drug issues, voting and my will. Three of the least preferred topics were those that fall within this 'sensitive' category; abuse, voting and alcohol and drug issues.

Risk of another stroke was an issue that four participants wanted to discuss; one was unsure and five did not want to talk about it. The majority therefore did not want to discuss this topic. When this topic was presented to the participants, the common reactions were nervous laughter, worried and anxious facial expressions and verbalizations or a stern rejection of the topic. Although this topic may need to be addressed and discussed by adults with aphasia with their family members at some stage post onset of aphasia, it appears that it is a topic that is not favoured and therefore needs to be handled with sensitivity. 


\subsubsection{Additional topics}

As mentioned previously, after the familiar communication partners (Participant Group A) had evaluated all 37 PCR topics using the Talking Mats ${ }^{\mathrm{TM}}$ framework, they were requested to think of additional topics that their partner with aphasia would like to talk about that were not included in the 37 topics. These additional topics were then handdrawn and written on blank topic cards and included in the topics to be evaluated during the Talking Mats ${ }^{\mathrm{TM}}$ framework for the relevant adult with aphasia. Table 4.3 lists these additional topics per participant with aphasia as well as listing the preferences of those topics by the participant with aphasia. Participant B10's partner did not provide any additional topics for evaluation stating that the 37 PCR topics appeared to cover most relevant topics. All of the additional topics were placed under the 'Yes' preference option by the adults with aphasia, apart from B05's placement of the topic weather under 'Maybe'. Whilst placing the additional topics, B01 and B04 communicated uncertainty regarding their preferences of the topics $\mathbf{T V}$ and $\mathbf{T V}$ shows respectively. They, however, placed these topics under 'Yes' after their hesitation.

Table 4.3: Additional topics and their preference placements

\begin{tabular}{|c|l|c|}
\hline Dyad & \multicolumn{1}{|c|}{ Fringe Topics } & \multicolumn{1}{|c|}{$\begin{array}{c}\text { Person with aphasia's } \\
\text { preference placement }\end{array}$} \\
\hline 1 & $\begin{array}{l}\text { Pets, TV, Holidays, Cooking, Entertaining } \\
\text { Yes }\end{array}$ & \multicolumn{1}{|c|}{ Yes } \\
\hline 2 & $\begin{array}{l}\text { Décor, Physical appearance, Garden, Animals, } \\
\text { Cooking }\end{array}$ & Yes \\
\hline 3 & $\begin{array}{l}\text { Italy, Retirement, Holiday home, Game reserve } \\
\text { visits, Son's careers }\end{array}$ & Yes \\
\hline 4 & Religion, Movies, TV shows, Fears, Holidays & Maybe \\
\hline 5 & Weather & Yes \\
\hline 5 & Shopping, Jokes & Yes \\
\hline 6 & Motorbikes, My house & Yes \\
\hline 7 & Christianity, Other people's feelings & Yes \\
\hline 8 & Family farm, Other children, Grandchildren & Yes \\
\hline 9 & Nature, Travel, Environment & \\
\hline
\end{tabular}




\begin{tabular}{|c|c|c|}
\hline Dyad & Fringe Topics & $\begin{array}{c}\text { Person with aphasia's } \\
\text { preference placement }\end{array}$ \\
\hline 10 & No topics provided & N/A \\
\hline
\end{tabular}

These findings suggest that the familiar communication partners of adults with aphasia provide appropriate and personally relevant topics for their partners with aphasia when requested to. This highlights the possibility of customising topic lists for individual persons with aphasia. Such person-specific topics could be referred to as 'fringe' topics. Fringe vocabulary reflects individual's activities, interests, environment, personal style, and age group membership, which fringe topics also address (Stuart, Beukelman, and King, 1997). Because these fringe topics were provided by the familiar communication partners without the presence of their partners with aphasia, there was no negotiation of the topics with the adults with aphasia. In clinical environments, however, the fringe topics provided by familiar communication partners could be presented to the adults with aphasia for placement and discussion. In this way, topics such as TV and TV shows will be discussed by the adult with aphasia and his/her communication partner to clarify the true perceptions of the adult with aphasia.

There may have been an element of the Hawthorne effect (McMillan \& Schumacher, 2006), or social desirability due to the fact that the additional topics were hand written on blank topic cards and therefore did not look the same as the 37 PCR topics, indicating that they were additions. The adults with aphasia were not informed that the additional topics were provided by their familiar communication partners, however, may have guessed that the topics were selected by their communication partners due the visual discrepancy of the additional topics. Hence, in order to please their partners or the researcher may have selected them favourably without giving them consideration.

In this study, only one familiar communication partner was consulted to predict the topic preferences and provide additional topics of interest to their partner with aphasia. Adults with aphasia communicate differently with different types of communication partners. Thus, consultation with of range of communication partners (spouse, family member, friend, acquaintance, paid companion, and stranger) has been recommended in order to 
provide unique and relevant topics for storage in the AAC system used by the adult with aphasia (Blackstone et al., 2007; Beukelman et al., 1991).

\subsection{COMPARISON OF PREFERENCES OBTAINED FOR EACH TOPIC ACROSS DYADS}

The PCR topic preferences provided by both participant groups were compared by describing the amount of agreement/disagreement of preferences obtained for each topic across all 10 dyads.

The amount of agreed preferences (i.e. 'Yes'-'Yes', 'Maybe'-'Maybe', and 'No'-'No') obtained per topic across all 10 dyads was used to calculate the percentage agreement for each of the 37 topics. Where members within a dyad placed a topic under 'Yes' and 'Maybe' or 'Maybe' and 'No', partial agreement existed. In the case where more definite disagreement occurred ('Yes' and 'No'), however, total disagreement was assigned. The various types of agreement obtained by each topic across all 10 dyads are presented in Table 4.4. These findings are described in more detail below.

Table 4.4: Amount of agreement per topic $(n=37)$

\begin{tabular}{|l|c|c|c|c|c|c|}
\hline \multirow{2}{*}{ Topic } & \multicolumn{3}{|c|}{ Total agreement } & \multicolumn{1}{c|}{$\begin{array}{c}\text { Partial } \\
\text { agreement/ } \\
\text { unsure }\end{array}$} & $\begin{array}{c}\text { Total } \\
\text { disagreement }\end{array}$ & \% agreement \\
\hline Yes & Maybe & No & & $100 \%$ \\
\hline my children & 10 & 0 & 0 & & & $90 \%$ \\
\hline my family & 9 & 0 & 0 & 1 & $90 \%$ \\
\hline communication problem & 8 & 1 & 0 & 1 & & $90 \%$ \\
\hline speech and language therapy & 9 & 0 & 0 & & & $80 \%$ \\
\hline current events & 6 & 2 & 0 & 2 & & $80 \%$ \\
\hline politics & 2 & 2 & 4 & 1 & & $80 \%$ \\
\hline my hobbies & 8 & 0 & 0 & 2 & & $80 \%$ \\
\hline my friend & 8 & 0 & 0 & 2 & & $80 \%$ \\
\hline money & 8 & 0 & 0 & 2 & & $80 \%$ \\
\hline progress (communication) & 8 & 0 & 0 & 2 & & $80 \%$ \\
\hline my medical decision & 6 & 1 & 1 & 2 & & $70 \%$ \\
\hline sports & 6 & 0 & 1 & & 3 & $70 \%$ \\
\hline where I live & 5 & 0 & 2 & 2 & 1 & $70 \%$ \\
\hline my health & 6 & 1 & 0 & 3 & & $70 \%$ \\
\hline my stroke & 7 & 0 & 0 & 3 & & \\
\hline
\end{tabular}




\begin{tabular}{|c|c|c|c|c|c|c|}
\hline \multirow{2}{*}{ Topic } & \multicolumn{3}{|c|}{ Total agreement } & \multirow{2}{*}{$\begin{array}{c}\text { Partial } \\
\text { agreement/ } \\
\text { unsure }\end{array}$} & \multirow{2}{*}{$\begin{array}{c}\text { Total } \\
\text { disagreement }\end{array}$} & \multirow{2}{*}{$\%$ agreement } \\
\hline & Yes & Maybe & No & & & \\
\hline clothing & 7 & 0 & 0 & 2 & 1 & $70 \%$ \\
\hline my medication & 6 & 0 & 1 & 1 & 2 & $70 \%$ \\
\hline the future & 7 & 0 & 0 & 2 & 1 & $70 \%$ \\
\hline privacy & 4 & 3 & 0 & 2 & 1 & $70 \%$ \\
\hline voting & 3 & 2 & 2 & & 3 & $70 \%$ \\
\hline my job & 4 & 0 & 2 & 2 & 2 & $60 \%$ \\
\hline my feelings & 6 & 0 & 0 & 3 & 1 & $60 \%$ \\
\hline my transportation & 6 & 0 & 0 & 1 & 3 & $60 \%$ \\
\hline food/diet & 6 & 0 & 0 & 3 & 1 & $60 \%$ \\
\hline occupational therapy & 6 & 0 & 0 & 2 & 2 & $60 \%$ \\
\hline sex & 4 & 0 & 2 & 3 & 1 & $60 \%$ \\
\hline progress (physical) & 6 & 0 & 0 & 3 & 1 & $60 \%$ \\
\hline my will & 3 & 0 & 3 & 2 & 2 & $60 \%$ \\
\hline a problem & 5 & 0 & 0 & 5 & & $50 \%$ \\
\hline physiotherapy & 4 & 0 & 1 & 1 & 4 & $50 \%$ \\
\hline underwear & 3 & 0 & 2 & 3 & 2 & $50 \%$ \\
\hline my marriage/spouse & 4 & 0 & 1 & 4 & 1 & $50 \%$ \\
\hline alcohol and drug issues & 1 & 1 & 3 & 2 & 3 & $50 \%$ \\
\hline power of attorney & 1 & 1 & 1 & 5 & 2 & $30 \%$ \\
\hline counselling & 1 & 1 & 1 & 7 & & $30 \%$ \\
\hline risk of another stroke & 2 & 0 & 1 & 5 & 2 & $30 \%$ \\
\hline abuse & 0 & 1 & 2 & 3 & 4 & $30 \%$ \\
\hline
\end{tabular}

\subsubsection{Topics that obtained high agreement}

Topics that obtained percentage agreements of $70-100 \%$ were regarded as 'high agreement' and included my children, my family, communication problem, speech and language therapy, current events, politics, my hobbies, my friend, money, communication progress, my medical decision, sports, where I live, my health, my stroke, clothing, my medication, the future, privacy, and voting.

The high percentage agreement of these topics indicate that in general, the familiar communication partners had an accurate idea of what their partners with aphasia's preferences of these topics would be. When predicting the preferences of the 37 topics, the majority of the familiar communication partners supported their predictions with reference to conversations that they had had with their partner with aphasia in 
communicative instances in the past. This was stated when the familiar communication partners were looking over their predictions on their Talking Mats ${ }^{\mathrm{TM}}$ : "These are pretty much the things we have discussed" (A09), and "These are all the things that we have spoken about" (A02). Where relevant, some of these highly agreed topics are described and discussed further.

Communication problem, speech and language therapy, my stroke, and communication progress: these four topics all relate to the communication impairment experienced by the adult with aphasia. These topics of conversation have obtained high 'Yes' preferences from both participant groups and high percentage agreement within dyads. Aphasia affects an individual's ability to comment, to suggest, to question, to bargain, and to joke (Davidson et al., 2003) and in turn has a significant impact on an individual's sense of self and quality of life. The finding that the above mentioned topics are highly preferred by adults with aphasia and predicted as such by their partners highlights the impact of aphasia on the lives of those with the impairment and their communication partners.

The topic preferences provided to the topic politics are presented in Figure 4.3. This topic did not obtain a significant amount of 'Yes' preferences by both participant groups; however, it obtained agreed preferences within dyads resulting in a high amount of agreement. This suggests that the familiar communication partners in this study were aware of what their partners with aphasia's desire to talk about politics was. Two dyads selected the topic as 'Yes', two selected it as 'Maybe' and four dyads rejected the topic. These results could reflect specific demographics related to South Africans and the fact that politics is a complex topic about which everyone has their own opinion. One dyad (Dyad 3) presented with total disagreement of this topic. This is interesting as the dyad represent a husband and wife who had known each other for 40 years. 




Figure 4.3: Preferences for the topic: Politics

The topic voting is presented in Figure 4.4. Confident predictions of the topic were displayed by the majority of the familiar communication partners when presented with this topic. Three dyads selected the topic as 'Yes', two dyads were unsure and two dyads rejected the topic. Reference was either given to previous voting experiences, or to the adult with aphasia's opinion on the topic of voting. Participant A01 commented: "She wasn't keen on voting, but I said 'No, you must vote'”, and participant A03 stated "Voting, yes we all went together to vote".

Three dyads, however, presented with total disagreement of this topic. B05 placed the topic under 'Yes', whereas A05 predicted that the topic would be rejected. B08 rejected the topic, whereas A08 predicted that it would be placed under 'Yes'. B10 rejected the topic, whereas A10 placed the topic under 'Yes'. These findings are interesting due to the differing nature of these dyad relationships. Dyad 5 did not know each other prior to the onset of aphasia, Dyad 8 represent a mother and son who obviously knew each other prior to the onset of aphasia, but may not have discussed voting and performed this activity together and Dyad 10 represent a married couple who had known each other for 11 years. These results suggest that agreed preferences of the topic voting are not 
necessarily attributed to whether the dyad knew each other before the onset of aphasia or not. This may emphasize the controversial nature of the topic and realistic possibility of discrepancies between predicted preferences and those provided by adults with aphasia.

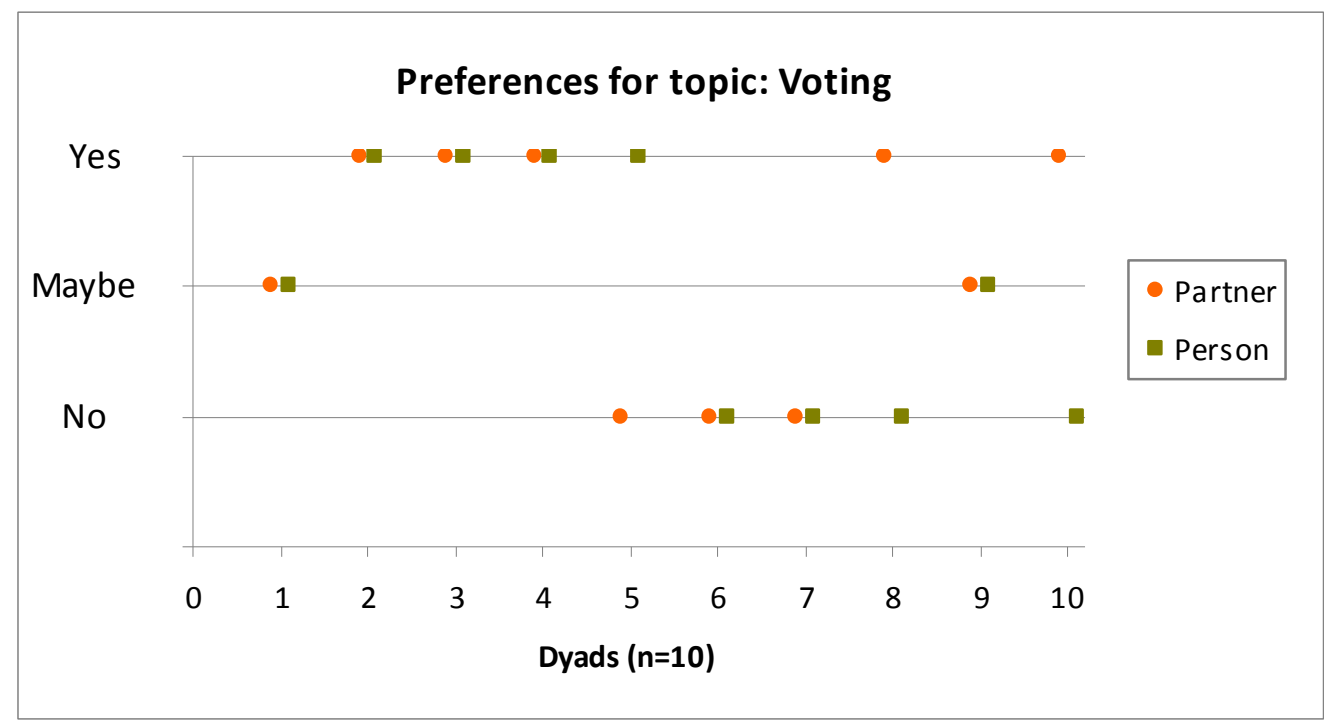

Figure 4.4: Preferences for the topic: Voting

It was noted that the topic my medical decision required more explanation and repetition than the other topics. On the majority of occasions, the participants with aphasia and their familiar communication partners displayed confusion when presented with the topic and requested clarification. It was explained that the topic referred to any medical decision that may need to be made. After additional explanation, the participants appeared confident to place the topic according to their particular preferences.

\subsubsection{Topics that obtained moderate agreement}

Topics that obtained between $40 \%$ and $60 \%$ agreement were regarded as 'moderate agreement'. Topics that obtained $60 \%$ agreement were: my job, my feelings, my transportation, food/diet, occupational therapy, physical progress, sex and my will. Topics that obtained 50\% agreement were: a problem, physiotherapy, underwear, my 
marriage/spouse, and alcohol and drug issues. There were no topics that obtained $40 \%$ agreement.

The moderate percentage agreement obtained by these topics could be due to a number of reasons. It is, however, most likely related to the fact that no matter how intimately acquainted dyads may be; everyone has personal preferences that may not be known by even their closest of companions (Shewan \& Cameron, 1984). Some topics, however, warrant further discussion. These are described below.

My job represents one of these topics and the preferences provided by the 10 dyads are presented in Figure 4.5. As expected, the eight adults with aphasia who had been employed prior to the onset of aphasia wanted to talk about their jobs. Four of their familiar communication partners predicted that the topic would be placed under 'Yes', two were unsure and two partners rejected the topic. The two participants who had been unemployed prior to the onset of aphasia (B08- retired and B10-housewife) rejected the topic and their communication partners predicted that this topic would be rejected.

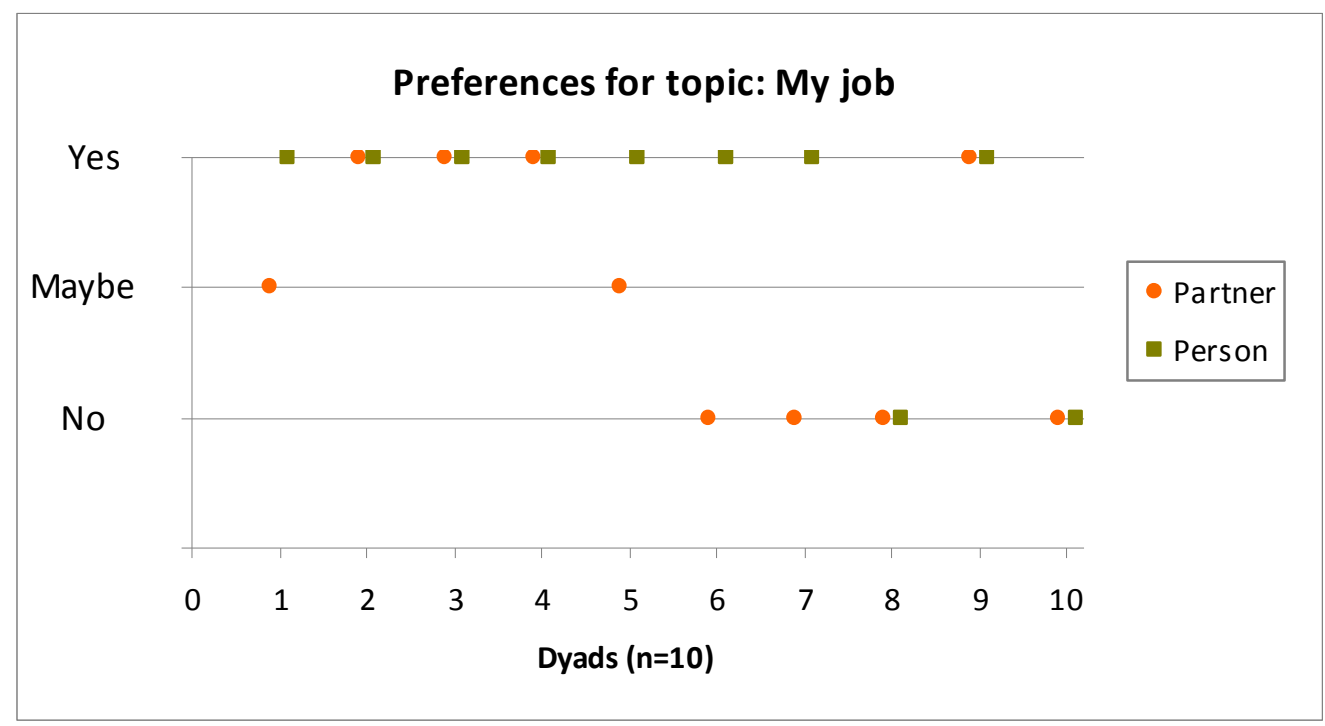

Figure 4.5: Preferences for the topic: My job 
Some of the comments presented by the familiar communication partners when presented with the topic were the following:

Participant A01: "She doesn't have a job" (placed topic under 'Maybe', whereas the partner with aphasia placed the topic under 'Yes').

Participant A03: "If she had a job, of course. But she doesn't have a job. She would want to talk about my job” (placed topic under 'Yes', and partner with aphasia does the same). Participant A10: "It's not applicable, so..." (placed topic card under 'No', partner with aphasia also placed topic under 'No').

Comments made by some of the participants with aphasia were the following:

Participant B01: Sorrowful exclamation (placed the topic card under 'Yes').

Participant B09: “What job?” (placed topic card under 'Yes').

Participant B04: Gestured towards the house said "at home" (placed topic card under 'Yes' with a sorrowful facial expression).

It is evident that some of the familiar communication partners felt that because their partners with aphasia were not currently employed, they would not want to talk about their previous jobs. As was mentioned previously in this chapter, unemployment after the onset of aphasia often results in the loss of a significant role and important part of one's identity (Simmons-Mackie, 2001). Therefore, providing adults with aphasia with the opportunity and freedom to communicate about their previous employment allows them to discuss areas of their lives prior to the onset of aphasia and subsequently assists in the adjustment of their new sense of self.

Figure 4.6 shows that seven participants with aphasia in this study placed the topic sex under 'Yes', whereas four of their communication partners placed the topic under 'Yes'. Six dyads agreed with the preferences of this topic, three presented with partial agreement and one dyad totally disagreed. Comments made by familiar communication partners who were uncertain, or rejected the topic were:

Participant A01: "Sex- we don't discuss" (placed topic under 'Maybe', whereas partner with aphasia placed topic under 'Yes'). 
Participant A06: “I hope he doesn't want to talk about it. Does he need to talk about sex?" (placed topic under 'No', whereas partner with aphasia placed topic under 'Yes). After completion of the Talking Mat, participant A06 noted where her brother had placed the topic and whilst pointing at the topic exclaimed "Oh no!", causing her brother to move the topic from under the 'Yes' option to under the 'No' option. Although this response may be appropriate for a sister-brother dyad, it reveals the efforts of B06 to please his sister. In naturally occurring conversations, the topic sex would presumably be discussed within certain relationships, such as a husband and wife or same-sex friends (Aries \& Johnson, 1983), and not within others, such as siblings or parent-child relationships. The dyads in this study represented a diverse range of relationship types, which may have attributed to the moderate percentage agreement of this topic.

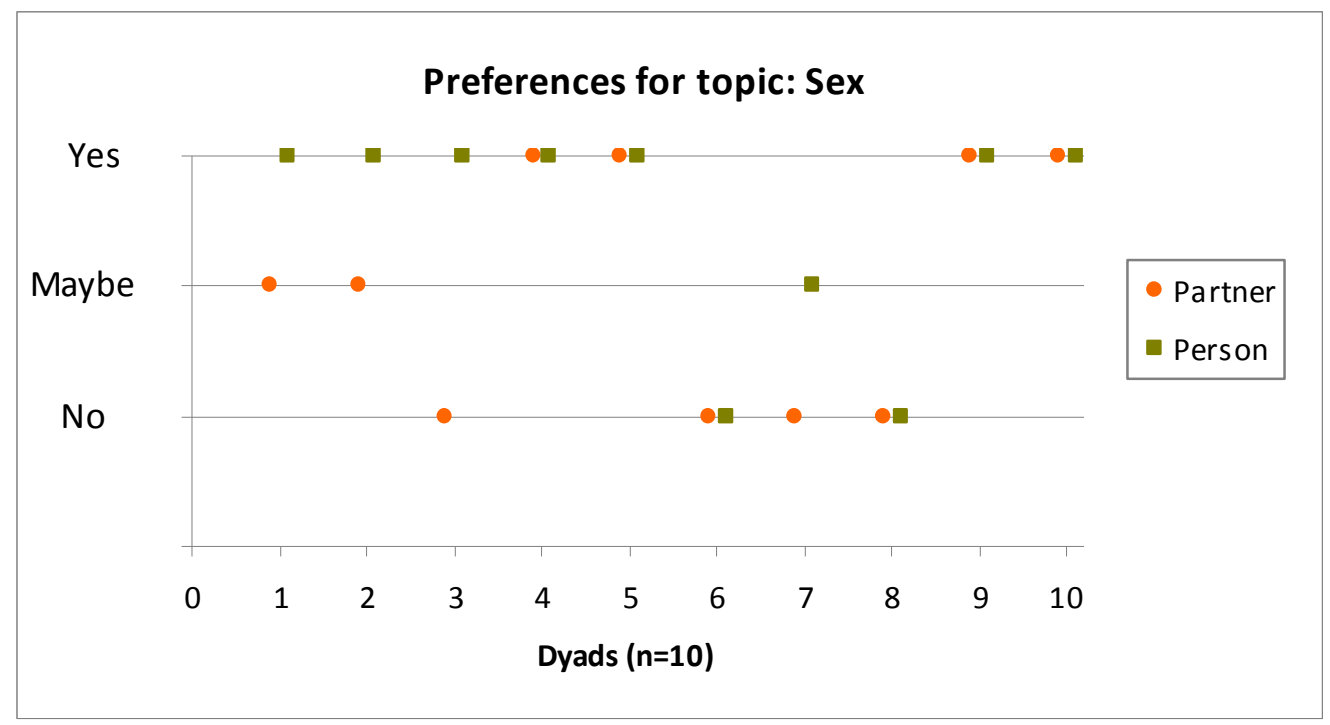

Figure 4.6: Preferences for the topic: Sex

Minimal words supporting topics such as work and sexuality have been found in AAC symbol sets for disabled adults (Bryen, 2008). Picture symbols provide graphic representations of their referents and as a result, symbols supporting topics such as sex may be avoided. Despite this, the findings from the current study suggest that adults with aphasia would benefit from access to the topics of sex and work as well as vocabulary supporting communication about such topics. 
The topic my will is a personal issue and is listed as one of the sensitive topics within the PCR topic list. As a result, the nature of the topic itself may explain the moderate agreement obtained. The preferences provided to the topic by the 10 dyads are presented in Figure 4.7. Comments made by some of the familiar communication partners when presented with the topic are the following:

Participant A03: "Ja well, we are trying to sort this out as we speak" (placed topic under 'Yes', and partner with aphasia did the same).

Participant A06: "We have spoken about this and sorted it out, but it might still come up again" (topic card placed under 'Yes', whereas the partner with aphasia placed the topic under 'No').

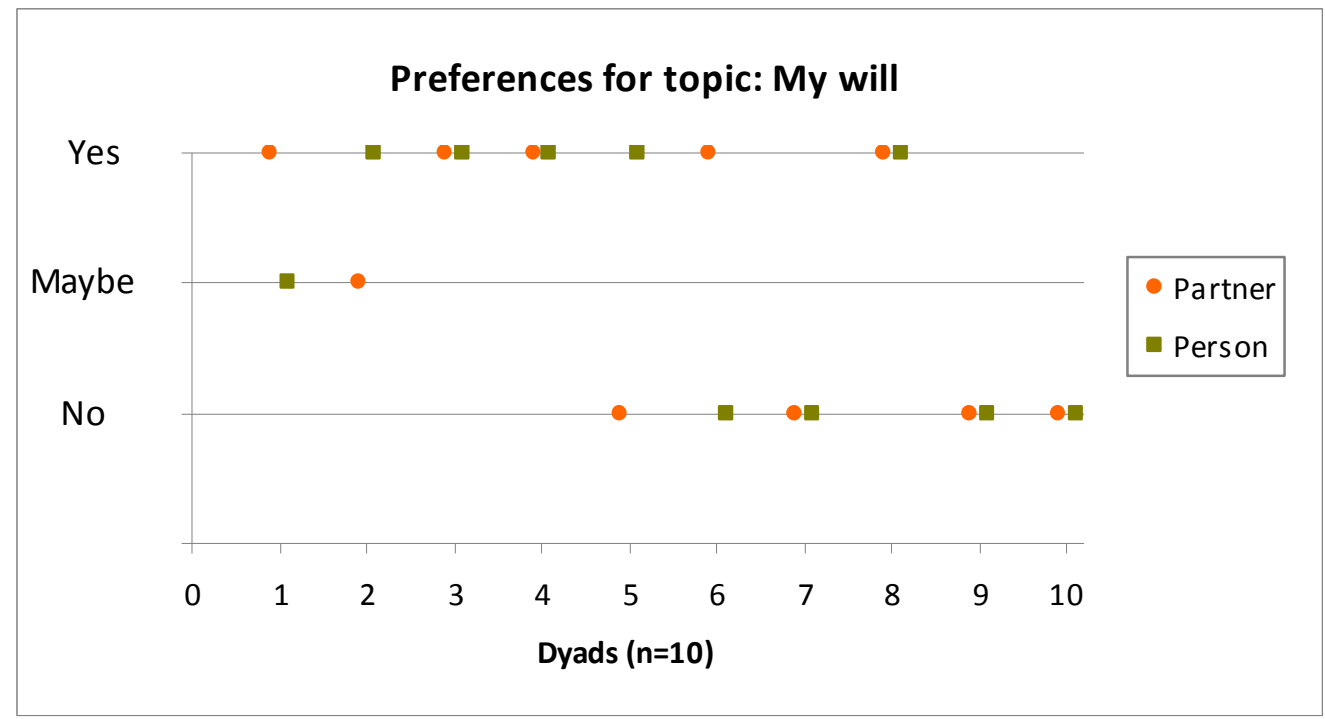

Figure 4.7: Preferences for the topic: My will

The topic food/diet (Figure 4.8) was unclear for some of the participants. Clarification was requested as to whether the topic referred to dieting or the food one eats/one's diet. In addition there was a discrepancy between if the adult with aphasia enjoys food but doesn't want to talk about it, or wants to talk about it as a topic of conversation. Participant A06 verbalized this by saying “He just loves it, but I don't think he wants to talk about it”. 
Certain topics that obtained a percentage agreement of $50 \%$ are described and discussed below. Alcohol and drug issues (Figure 4.9) represent another of the sensitive topics within the PCR topic list. Five dyads agreed with their preference of the topic, and five disagreed; two partially and three totally. The three total disagreements (Dyads 2, 3, and 10) represent an adult with aphasia and her paid companion, and two married couples that knew each other prior to the onset of aphasia, and had known each other for a minimum of 11 years. These findings suggest that the length of time that dyads have known each other as well as familiarity with the adult with aphasia prior to the onset of aphasia, do not necessarily result in agreed topic preferences.



Figure 4.8: Preferences for the topic: Food/diet 


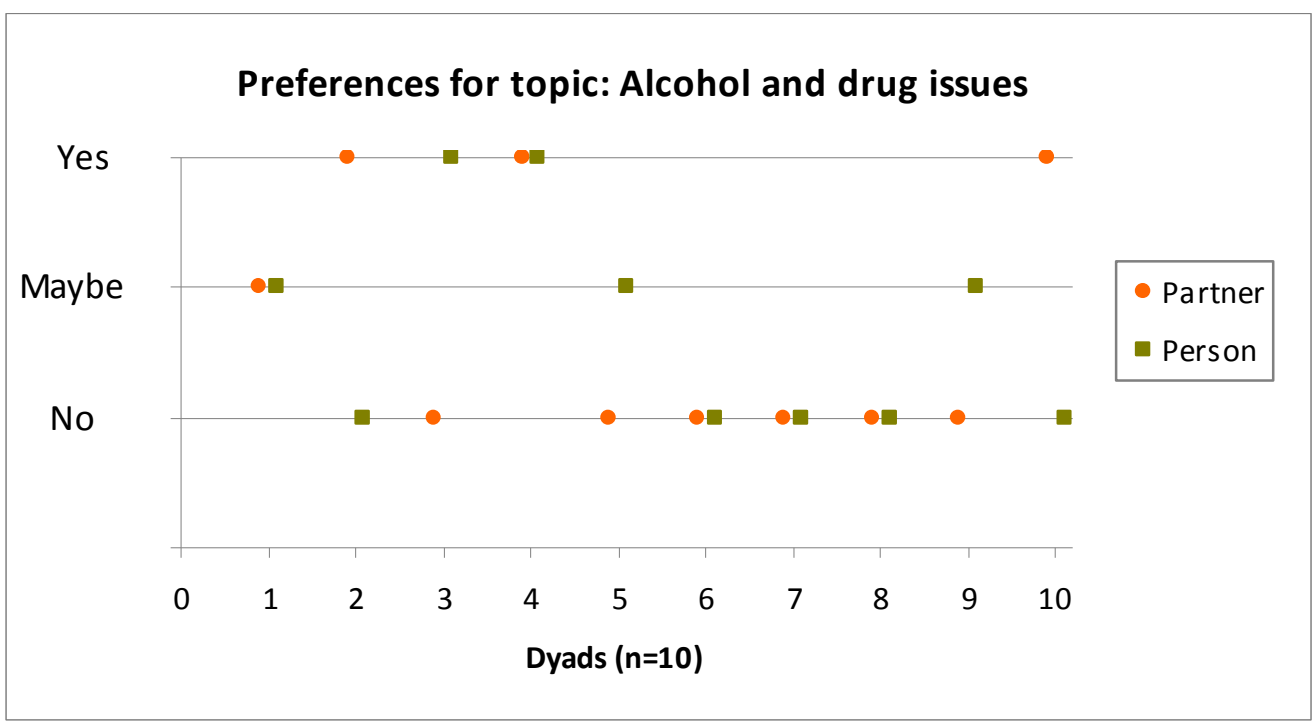

Figure 4.9: Preferences for the topic: Alcohol and drug issues

Five dyads agreed with their preferences of the topic underwear (Figure 4.10). Three dyads partially agreed and two dyads totally disagreed with their preferences. The dyads that obtained total agreement for this topic represented an adult with aphasia and paid companion (Dyad 2), married couples (Dyads 4 and 10), and same sex friends (Dyads 5 and 7). Dyads that obtained total disagreement represented a married couple (Dyad 3) and a parent-child relationship (Dyad 8). These findings suggest that the type of relationship represented by the dyad is not the main attributing factor for preference agreement of this topic. The nature of the topic underwear itself may have attributed to the moderate agreement of preferences due to the fact that some of the dyads may not have discussed this topic before or may not be comfortable with discussing the topic. 




Figure 4.10: Preferences for the topic: Underwear

The demographics of the participants with aphasia need to be examined in order to interpret the topic preferences and percentage agreement obtained by the topic my marriage/spouse (Figure 4.11). The four dyads that selected the topic as preferred are married. Some of their familiar communication partners were their spouses, whereas others were not. Differing topic preferences occurred when the participant with aphasia was divorced, widowed or experiencing marital difficulties. In these instances, the familiar communication partners predicted that their partner with aphasia would want to talk about their marriage/spouse, however, when the adults with aphasia evaluated the topic, they placed it under 'Maybe' or 'No'. These findings indicate that there was an assumption on the part of the familiar communication partners that the adults with aphasia would want to talk about this topic. This topic had possibly never been raised before within some of the dyad relationships. 




Figure 4.11: Preferences for the topic: My marriage/spouse

\subsubsection{Topics that obtained low agreement}

Topics that had agreement of $30 \%$ or less were regarded as 'low agreement'. This included the following topics: power of attorney, counselling, risk of another stroke and abuse. The low percentage agreement obtained by these topics suggests that the majority of familiar communication partners had an inaccurate idea of the preference of their partner with aphasia to talk about these topics.

The topic preferences for power of attorney are presented in Figure 4.12. Three dyads agreed on the preferences of this topic. Five dyads presented with partial agreement and two dyads with total disagreement. The poor agreement and large amount of partial agreement represented by this topic could possibly be due to the abstract nature of the topic and poor understanding of what was being referred to. Three familiar communication partners commented that this topic had already been dealt with and alluded to the fact that there was nothing else to talk about as it had been "done and dusted" (Participant A01). In these cases, however, the partners with aphasia placed the topic card under 'Yes' indicating that it is a topic they would like to talk about. These 
findings indicate that the adults with aphasia wanted to talk about this topic more often than their partners predicted. Although, in many cases, the topic had been dealt with, this was possibly done during the acute stages of the person with aphasia's recovery shortly after the onset of aphasia. It is presumed that lengthy discussions regarding this topic were not held during the acute stages. The adults with aphasia in this study may want to discuss the topic at this later stage, regardless of whether it has been dealt with previously or not.



\section{Figure 4.12: Preferences for the topic: Power of attorney}

Unlike the topics of speech-language therapy and occupational therapy, it is interesting that the topic counselling presented with a poor percentage agreement. One dyad selected the topic as preferred, another as 'Maybe' and one dyad rejected the topic. The remaining seven dyads presented with partial agreement of the topic, indicating an uncertainty and lack of confidence about the topic. These preferences are presented in Figure 4.13. The counselling needs of adults with aphasia and their significant others are considerable, however, counselling has been found to be infrequently organised for adults with aphasia and their family members (Herrmann \& Wallesch, 1989). One familiar communication partner commented: "Counselling, that's not happening" (A01). The preferences obtained by this topic revealed that six adults with aphasia wanted to talk about 
counselling, whilst only one familiar communication partner predicted that the topic would be preferred. Six communication partners placed the topic under 'Maybe'. Counselling may not be a common or familiar topic for the dyads within the study. Counselling is a topic of conversation that some people do not wish to discuss with others or admit that they are in need of. The nature of the topic counselling may therefore have attributed to the ambivalent preferences for this topic. The participants with aphasia in this study presented with moderate to severe expressive aphasia. Counselling in the traditional sense would be difficult for such individuals due to their significant communication impairments (Brumfitt, 1993). This may have influenced the preferences and predicted preferences of the participants.

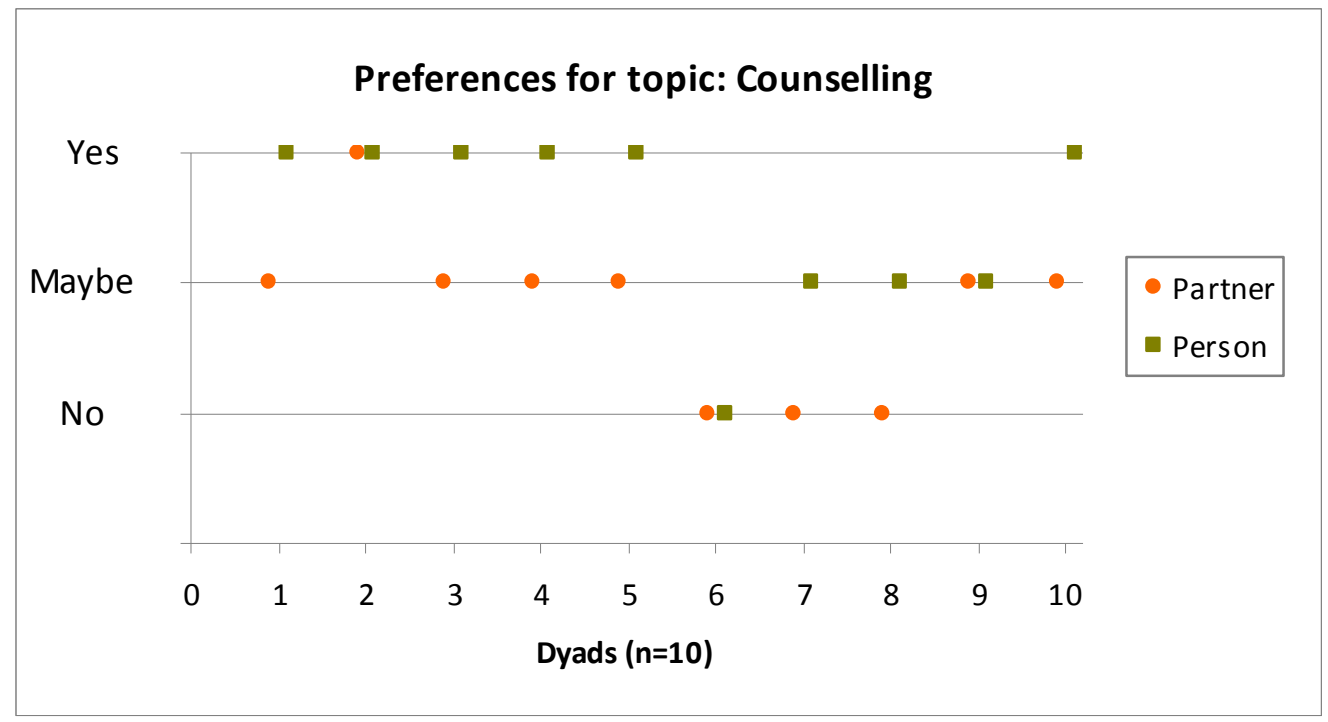

\section{Figure 4.13: Preferences for the topic: Counselling}

When presented with the topic risk of another stroke (Figure 4.14), strong emotional responses were provided by both groups of participants. Two familiar communication partners commented:

Participant A04: “There's no negativity. We're not ignorant, but we're stopping there" (placed the topic under 'Maybe').

Participant A01: "Risk of another stroke- that's not something we talk about. Well, maybe she would want to" (placed topic under 'Maybe'). 
In both of these cases, the corresponding member of the dyad with aphasia selected the topic as preferred. This may indicate that in an attempt to steer clear from negative topics, the familiar communication partners do not initiate such topics, however, their partners with aphasia may actually want to talk about them. Five dyads presented with partial agreement of the topic, in four of these the communication partner placed the topic under 'Maybe'. This indicates a lack of confidence regarding their predictions of their partner with aphasia's opinion on discussing the topic. In another two dyads, the communication partners predicted that their partners with aphasia would want to talk about this topic, whereas, their partners with aphasia actually did not and placed the topic under 'No'. Professionals working with aphasia need to be aware of the necessity for this topic to be made available to adults with aphasia and their families, so that it can be discussed in a sensitive and appropriate manner with relevant persons and in appropriate contexts.

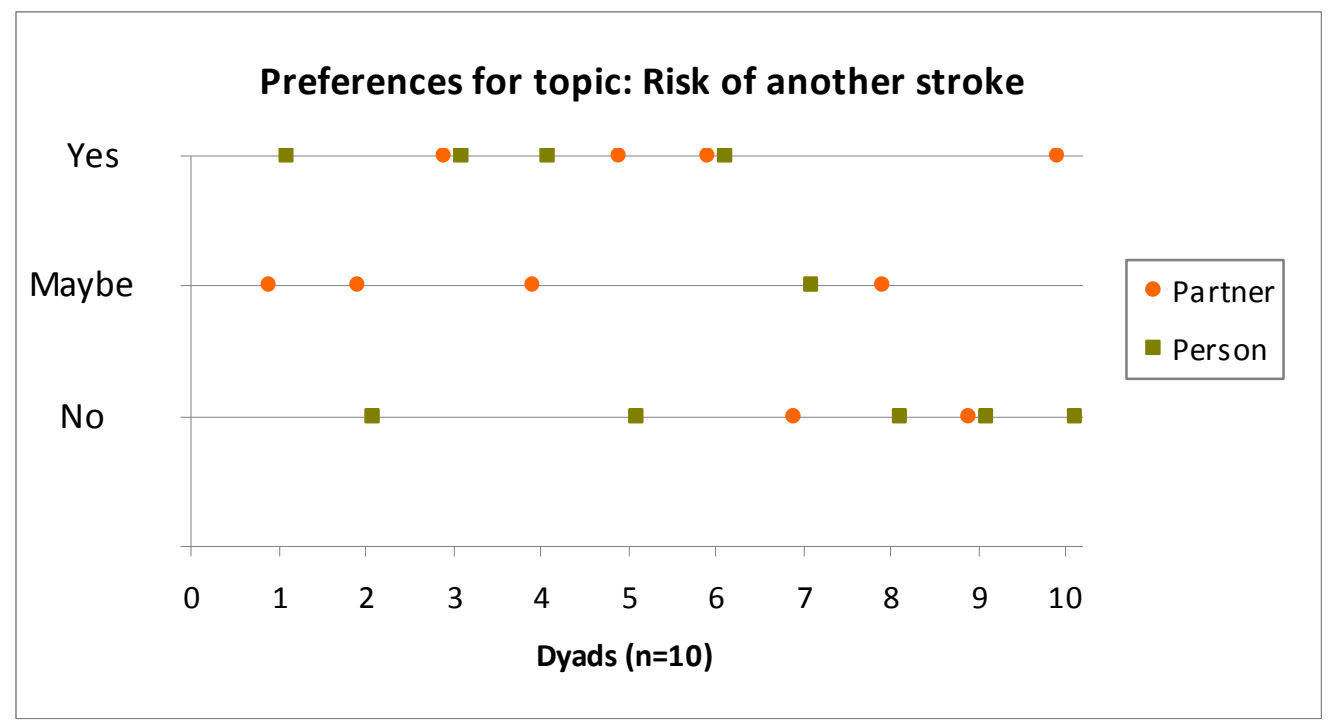

Figure 4.14: Preferences for the topic: Risk of another stroke

\begin{abstract}
Abuse is one of the sensitive topics in the PCR topic list (Figure 4.15). Three dyads obtained total agreement of topic preferences, three obtained partial agreement and four totally disagreed regarding the preferences of the topic.
\end{abstract}




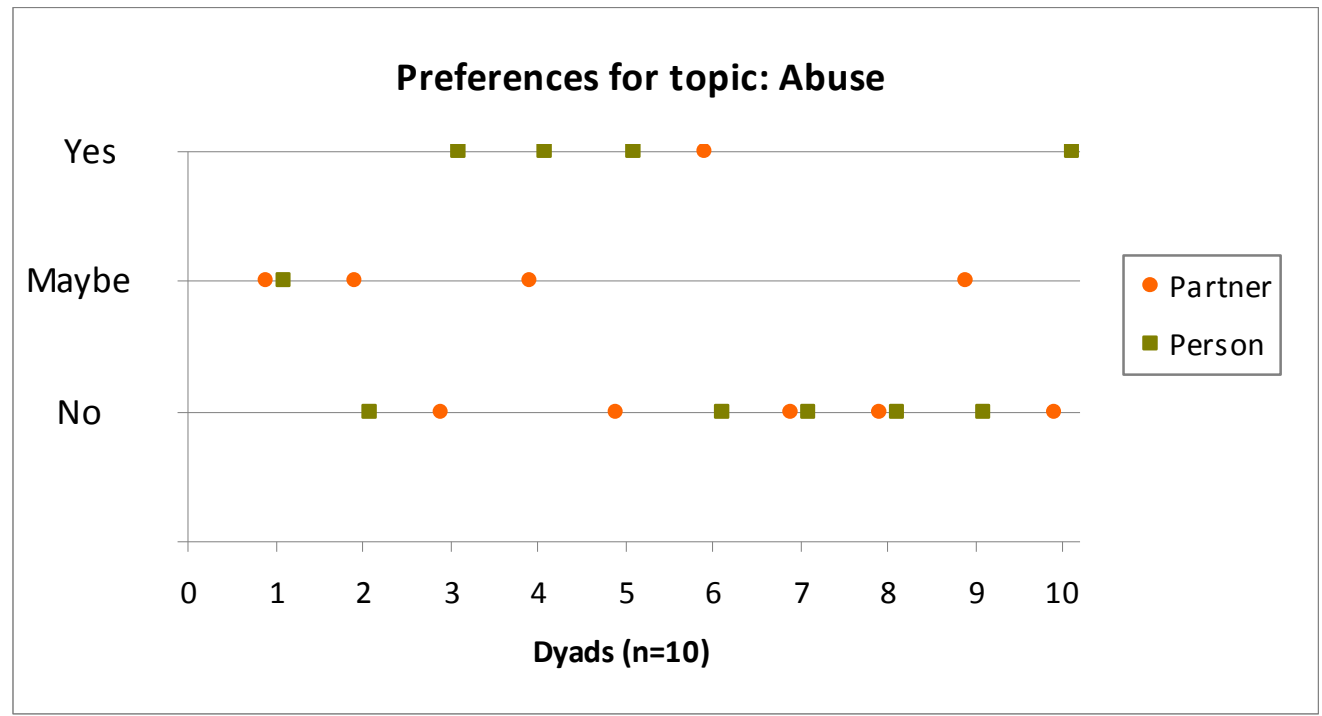

Figure 4.15: Preferences for the topic: Abuse

Participant A01 commented "Abuse, is not an issue" and placed the topic under 'Maybe'. His partner with aphasia (wife) also placed the topic under 'Maybe'.

Dyad 6 represents a brother (adult with aphasia) and his sister (familiar communication partner). The participant with aphasia lives in a home for adults with physical disabilities. When presented with the topic "abuse", his sister commented: "Do you think he gets abused here? Well, I suppose it's a good thing, so that if he ever needs to talk about it, it's here" (placed topic under 'Yes'). Her brother subsequently placed the topic under 'No'.

Familiar communication partner A04 commented "It's quite difficult; these are not topics that form part of our daily conversation!' and placed the topic under 'Maybe'. Her partner with aphasia (husband) placed this topic under 'Yes'.

When the members of Dyad 10 were interviewed, the participant with aphasia placed this topic under 'Yes'. After completion of the interviews, her familiar communication partner (husband) looked at her Talking Mat and in response to her preference of the topic commented "Are you saying that I abuse you?" to which she laughed and 
exclaimed "No man!" In this instance, therefore, there appeared to be a misunderstanding on the part of the familiar communication partner, in that he interpreted his wife's desire to talk about a topic as a personal indication of his behaviour. This indicates that the topic abuse could be interpreted to mean abuse in general (anyone) or abuse to me (adult with aphasia).

In three dyads, the adults with aphasia placed the topic abuse under 'Yes', whereas their communication partners placed the topic under 'No'. These dyads represented a paid companion and adult with aphasia, friends, and married couple respectively. In Dyad 6, the communication partner (sister) placed the topic under 'Yes', whereas her brother (adult with aphasia) placed the topic under 'No'. These differences in topic preferences may emphasize the controversial nature of the topic.

\subsection{COMPARISON OF TOPIC PREFERENCES WITHIN DYADS}

The PCR topic preferences provided by both participant groups were also compared by describing the amount of agreement of topic preferences within each of the 10 dyads.

The topics that obtained the same preferences ('Yes'-'Yes', 'Maybe'-'Maybe' or 'No''No') within each dyad were used to calculate the percentage agreements within each of the 10 dyads for the total 37 topics. These are presented in Table 4.5. None of the dyads obtained $100 \%$ agreement. This reveals the unique nature of every individual's topic preferences and that even those closest to adults with aphasia are not able to accurately predict all topic preferences. Dyads 4, 7 and 1, however, obtained the highest percentage agreement respectively. Dyad 4 obtained a percentage agreement of $89.19 \%$, Dyad 7 obtained a percentage agreement of $78.38 \%$ and Dyad 1 obtained an agreement of 72.97\%. Dyads 3 and 8 obtained the lowest percentage agreement of $48.65 \%$. These findings are interpreted in light of the descriptive information obtained from the biographical questionnaires that relate to the nature of the dyad relationship, as well as comments made during the topic evaluation process by members from the dyads. 
Table 4.5: Percentage agreement within dyads.

\begin{tabular}{|c|c|c|}
\hline $\begin{array}{c}\text { Dyad } \\
\text { number }\end{array}$ & $\begin{array}{c}\text { Number of agreed topic } \\
\text { preferences }\end{array}$ & \begin{tabular}{c} 
Percentage agreement \\
\hline 4
\end{tabular} \\
\hline 33 & $89.19 \%$ \\
\hline 7 & 29 & $78.38 \%$ \\
\hline 1 & 27 & $72.97 \%$ \\
\hline 5 & 24 & $64.86 \%$ \\
\hline 10 & 24 & $64.86 \%$ \\
\hline 2 & 23 & $62.16 \%$ \\
\hline 6 & 23 & $62.16 \%$ \\
\hline 9 & 22 & $59.46 \%$ \\
\hline 3 & 18 & $48.65 \%$ \\
\hline 8 & 18 & $48.65 \%$ \\
\hline
\end{tabular}

\subsubsection{Dyads with high percentage agreement}

Dyad 4 represent a married couple who have known each other for 11 years. They knew each other for 8.5 years prior to the onset of the husband's aphasia. They live together and therefore see each other daily. They reported that both members of the dyad decide on what activities are done together. Activities performed together are: day-to-day living, talking about the day and planning for the next, going to movies, going to the shops, going to church, going to visit friends, watching TV together, talking about each others feelings, cooking together and eating out at restaurants. Comments made by the familiar communication partner during the topic evaluation process emphasized the priority of communication within this couples daily activities.

"I can't say that we don't talk about these topics at all. I would say 'Yes' to everything". When placing the topic power of attorney: "These things we have already discussed" (placed topic under 'Yes').

Abuse: "It's quite difficult; some of these topics are not part of our day-to-day conversations" (placed topic under 'Maybe').

Medication: "He doesn't take any medication at the moment, but if he had to, he would want to talk about it”' (placed topic under 'Yes'). 
My children: "There are no children, but I'm sure if there were, he would want to talk about them" (placed topic under 'Yes').

Risk of another stroke: “There's no negativity. We're not ignorant, but we're stopping there" (placed topic under 'Maybe').

These comments highlight the perceptions of the familiar communication partner that despite his aphasia, her husband is capable of communicating about these topics with her and that should the need arise, various topics would be discussed.

Dyad 7 represent two females who have been friends for 5 years. They both live in a home for adults with physical disabilities. They did not know each other prior to the onset of aphasia. The familiar communication partner reported that they see each daily and that they decide on what activities to do together. It was reported that the activities they perform together are: a daily devotion at $3 \mathrm{pm}$ everyday, sing together, go to church together and attend painting classes together. As the communication partner evaluated each topic, she explained her predictions by mentioning circumstances in which she had spoken to her partner with aphasia about the topic at hand.

When evaluating the topic of transportation: "Yes, we talk about the bus that takes us to church" (placed topic under 'Yes').

Money: "She shows me her money and I remind her to hide her money in her pocket" (placed topic under 'Yes').

My feelings: "Yes, we talk about feelings all the time. She always wants to know how you are too" (placed topic under 'Yes').

Dyad 1 represents a married couple who have known each other for 29 years and knew each other for 23.3 years prior to the onset of the wife's aphasia. They live together and therefore see each other daily. The husband (partner) reported that both members of the dyad decide on what activities should be done together and that the activities they do together are encompassed by living together. The partner demonstrated confidence in his preference predictions of the various topics, providing verbal explanations of his topic placements. 
When placing the topic of sport: "Well, I would like to talk about that, and maybe it's not fair of me to put it under 'No', she would talk about it because I enjoy talking about it. So I think I'll change that" (placed the topic under 'Yes').

Power of attorney: "It's sort of a done deal in a way, but I'll put it under 'Maybe"”.

Privacy: “It's not an issue” (placed under 'Maybe').

Abuse: "It's not an issue" (placed under 'Maybe').

Risk of another stroke: "It's not something we talk about" (placed topic under 'Maybe').

Counselling: "That's not happening” (placed topic under 'Maybe').

Sex: "We don't discuss" (placed topic under 'Maybe').

Voting: "The last time, she wasn't keen on voting, but I said 'No', you must vote" (placed topic under 'Maybe').

Due to the small sample size of the study, findings are not generalised but discussed in terms of trends and observations. The dyads described above, had known each other for varied amounts of time and represent different types of relationships. Dyads 4 and 1 represent married couples who knew each other prior to the onset of aphasia. Dyad 7 , however, represents two friends, who met each other after the onset of aphasia. This suggests that neither the type of relationship nor knowledge of the adult prior to the onset of aphasia seemed to be determining factors in obtaining high topic preference agreement within dyads.

All three dyads commented that they both decide on what activities to do together and provided information regarding the type of activities that they do together. These factors, therefore, appear to be stronger determining factors for obtaining high topic preference agreement. Increased participation in life has been found to provide a rich experiential base for subsequent communication between adults with aphasia and their communication partners, and in this way, the various life experiences that one may be involved in post-onset of aphasia, provide something to talk about (Lyon, Cariski, Keisler, Rosenbek, Levine, Kumpula, Ryff, Coyne, \& Blanc, 1997). The members within 
these dyads may have more to talk about due to the wider range of activities participated in, resulting in better awareness of each others interests and experiences. This may have positively affected the ability of the familiar communication partners to predict the topic preferences of their partners with aphasia.

In addition, factors specific to the dyad such as the functional status of the relationship have been found to facilitate interaction, as well as factors specific to the partner without aphasia, such as their conversational style, communication habits, personality, attitude, and perception of the partner with aphasia (Turner \& Whitworth, 2006). All three dyads represent healthy relationships, where a lot of time is spent together. The familiar communication partners of the dyads commented on the perceptions and interests of their partners with aphasia, demonstrating their belief in their competence and ability to participate in relevant conversations. These factors may have influenced the high percentage agreement within the dyads.

\subsubsection{Dyads with low percentage agreement}

Dyad 3 represent a married couple who have known each other for 40 years. They knew each other for 32 years prior to the onset of the wife's aphasia. They live together and therefore see each other daily. The husband (familiar communication partner) reported that he typically decides on what activities are done together. Activities performed together were listed as; shopping, visiting friends, watching TV, eating meals and going to the movies. Throughout the topic evaluation process it appeared that the familiar communication partner struggled to predict what his wife would like to talk about due to the discrepancy between her communication abilities at present and those prior to the onset of aphasia. This observation suggests that in some cases, knowledge of the adult with aphasia prior to the onset of aphasia may be a hindrance in the process of consolidating the perceptions of the adult prior to the onset of aphasia and post onset of aphasia. Comments made by the familiar communication partner (husband) during the topic evaluation process are listed below. 
Researcher: "Would she like to talk about a communication problem?"

Partner: “No. Well, maybe. You don't know you see. It's interesting now. Are you talking about her before or as she is now?"

Researcher: "Now. And what you think she would like to talk about. Not necessarily what she does talk about, but what she would like to talk about".

Partner: "Well, that's what I was talking about. You have to go back. That kills you".

Later on in the interview:

Partner: "Some of these are... you've got to talk about now. It's my impression because her communication is... because you're talking about the past, and what she used to. But you're saying no, no, no, most of these are now, what I think. Even though I cannot communicate to know whether these are good, bad or different. I'm just going for my own kind of gut-feel".

Dyad 8 represent a mother and son relationship. They have known each other for 56 years, the duration of the son's life. The onset of aphasia was 4.6 years ago. They see each other frequently during the week, although they don't live together. It was reported by the familiar communication partner (son) that circumstances determine what activities are done when they see each other. Activities performed together were reported to be updates on family information and talking. These activities are expected and appropriate for a parent-child relationship in which the parent is elderly. The person with aphasia lives in the frail care section of a retirement village. It was reported that the partner, her son, has lived in a different part of the country for many years and had come to live in the same city as his mother only a few months before the research was conducted. When the adult with aphasia was presented with the topic underwear, she placed it under the 'Yes' option on her Talking Mat. Once the all the topics were evaluated and her son was shown her completed mat, he commented, "But mom, surely you don't want to talk about underwear with me?" This revealed that the communication partner thought that his mother was evaluating topics based on what she would want to talk to him about, although the researcher provided a clear explanation of what both participants were 
required to do. However, this misunderstanding on the part of the familiar communication partner may have impacted the amount of agreed topic preferences obtained by this dyad.

Suggestions and observations can only be made regarding why these dyads obtained low percentage agreements due to the small sample size and limited information obtained on the quality of the relationship. Both dyads did not select activities together. It was reported that the familiar communication partner of Dyad 3 selects the activities that the dyad performs together, whereas in Dyad 8, circumstance determined the dyads joint activities. This factor may have influenced the quality and range of joint activities performed by the dyads.

The difficulty of the familiar communication partner from Dyad 3 to rate the topics based on what his wife's preferences may be, highlight his difficulty to acknowledge his wife's communicative competence despite her significant communication difficulty. The necessity of adults with aphasia and their spouses to combine the memory of the way they were before the onset of aphasia with their new identity has been emphasized in order for the evolution of two new identities after the onset of aphasia (Brumfitt, 1993). Therefore, if the spouse of an adult with aphasia behaves as if the adult with aphasia is handicapped and inadequate, incompetent and degraded, then the adult with aphasia will experience a powerfully negative change, however, if the spouse of an adult with aphasia behaves as if their spouse were still the same, then the adult with aphasia will be able to experience a sense of continuity with the past (Brumfitt, 1993).

Dyad 8 may not be familiar with each other due to the long period where they did not see each other frequently. This dyad presented with the largest age gap between dyad members within this study. Factors related to the dyad such as the communication habits, personality, attitude and perception of both members of the dyad (Turner \& Whitworth, 2006) may have influenced the poor agreement obtained. The nature of the topics themselves may also have attributed to the poor percentage agreement of topic preferences. As mentioned previously, certain topics are discussed with certain 
communication partners (Blackstone et al., 2007). The familiar communication partner's response to his mother's placement of the topic underwear highlights this.

\subsection{SUMMARY}

This chapter presented the results of the study, which were organised, analysed and described according to the sub-aims of the study. The reliability of the responses obtained was discussed, followed by the presentation of the topic preferences provided by the adults with aphasia and the topic predictions made by their familiar communication partners. These topic preferences were then described in terms of similarities and differences across both participant groups and within each dyad. The percentage agreement within each dyad was presented and described. In addition, all of the above results were discussed. 


\section{CHAPTER 5: SUMMARY AND CONCLUSION}

\subsection{INTRODUCTION}

This chapter summarises and integrates the findings of the study. The study is critically evaluated and implications for clinical practices in AAC are discussed, as are recommendations for further research.

\subsection{SUMMARY}

Aphasia has a profound impact on the lives of individuals with the disorder as well as their significant others and family members. AAC systems and techniques that make use of visually represented topics have been found to assist adults with aphasia to communicate more efficiently and effectively, and thereby alleviate some of the effects of the communication impairment (Garrett \& Huth, 2002). Topics implemented in this way provide an effective means of facilitating the co-construction of conversations between adults with aphasia and their communication partners (Stuart et al., 2000), as well as providing a framework around which to derive vocabulary items appropriate to the individual AAC user (Garrett et al., 1989). These topics need to be pre-selected and stored within the AAC systems of adults with aphasia in order for their use within functional communicative contexts.

The active involvement of adults with aphasia in the process of pre-selecting such topics has been advocated for a number of years (Fox \& Fried-Oken, 1996; Blackstone et al., 2007). In order to facilitate the active involvement of these individuals, the provision of resources in the form of communication partners and concrete materials and tools, has been suggested (Fox \& Fried-Oken, 1996).

The main aim of the study was to determine the topic preferences (related to topics from the PCR Manual (Kagan, et al., 1996) of adults with moderate to severe expressive 
aphasia as indicated by both the adults themselves and their familiar communication partners.

Each participant with aphasia was requested to choose someone that knew them well and with whom they communicated regularly. This person was termed a 'familiar communication partner' and was requested to participate in the study by predicting the topic preferences of their partner with aphasia with the use of the Talking Mats ${ }^{\mathrm{TM}}$ framework. These familiar communication partners $(n=10)$ were also requested to think of any additional topics that their partners with aphasia would like to talk about that were not included in the 37 PCR topics presented to them. These additional topics were then added to the 37 PCR topics and presented to the adults with aphasia for evaluation by means of the Talking Mats ${ }^{\mathrm{TM}}$ framework. The topic preference predictions provided by the familiar communication partners and the topic preferences provided by the adults with aphasia were presented and discussed in addition to the similarities and differences between the topic preferences provided by both groups of participants and within each dyad. The findings of the study are described below.

The topic preference predictions provided by the familiar communication partners, revealed that they predicted that their partners with aphasia would want to talk about the majority of the 37 PCR topics (64.05\%). At least seven familiar communication partners predicted that their partners with aphasia would want to talk about topics related to their communication impairment and physical disabilities. Of note, was the overall rejection of the topic related to the adult with aphasia's job as well as ambivalent preference predictions of the topic counselling. These predictions were substantiated by comments provided by the familiar communication partners. The presence of circularity in the preference predictions of the familiar communication partners was noted (Brewster, 2004). At times, the familiar communication partners selected or rejected certain topics based on whether they themselves would want to talk about the topic or not. There was also evidence of topics being predicted based on prior conversations about that topic and not necessarily on what the adult with aphasia would like to talk about, even if talking about such topics would be challenging for them. 
Examination of the topic preferences of the participants with aphasia revealed that they wanted to talk about the majority of the topics presented to them $(70.81 \%)$. This amount was $6.76 \%$ higher than that predicted by the group of familiar communication partners. The high percentage of preferred topics indicated that although the adults with moderate to severe expressive aphasia experience significant difficulty in 'talking' they would still like to 'communicate' about the majority of the topics presented to them.

A significant amount of the topics the participants with aphasia wanted to talk about in this study correlated with those recorded in the naturalistic conversations of adults with intact communication abilities and in the naturally occurring communication activities of adults with aphasia (Davidson et al., 2003; Balandin \& Iacono, 1998b; Tonsing \& Alant, 2004; Stuart et al., 1994). These overlapping topics represent some of the core topics in adult conversation and include my family, my friend, food/diet, my health, current events, sport, my hobbies, my job, money, my transportation, where I live, my feelings, clothing, and the future. In addition, topics related to communication impairment and physical disabilities were selected as preferred by the majority of the adults with aphasia, reinforcing the significant impact of aphasia and associated physical disabilities on the preferred topics of conversation of these individuals. Of note was the finding that the majority of the participants with aphasia wanted to talk about their jobs, despite being unemployed since the onset of aphasia.

These findings indicate that although the PCR topic list is not an extensive list of topics, the 37 topics used within this study are relevant to adults with aphasia and have been found to occur in naturally occurring adult conversations, therefore reinforcing their functional value. Additionally, these findings suggest that the topics within the PCR topic list are not culture-bound for adults from 'Western' cultures due to the fact that the list was determined through large scale research in Canada (Kagan et al., 1996), yet a significant amount of the topics were preferred by South African adults with aphasia.

Almost all of additional topics of conversation provided by the familiar communication partners were placed under the 'Yes' preference option by the respective adults with 
aphasia. This suggests that selection of fringe topics by the familiar communication partners is an efficient way of determining personally relevant and unique topics for adults with aphasia. This finding emphasises the importance and possibility of customising topic lists for use within the AAC systems and techniques by adults with aphasia. Due to the fact that the additional topics were hand drawn in this study, there may have been a possibility of the Hawthorne effect, as the adults with aphasia may have suspected that the topics were provided by their familiar communication partners and provided preference responses based on their desire to please their communication partners or the researcher.

The topic preferences provided by both participant groups were compared by calculating the amount of agreement of topic preferences across topics and dyads. The average agreement over all topics and dyads was $65 \%$. This indicates that in general, the familiar communication partners predicted their partners with aphasia's topic preferences relatively accurately. Variations occurred across topics (30-100\%) and dyads (48.65$89.19 \%)$.

The 37 PCR topics obtained percentage agreements ranging from 30- 100\%. Topics were assigned to three categories:

- 'high agreement' (70-100\%): my children, my family, communication problem, speech and language therapy, current events, politics, my hobbies, my friend, money, communication progress, my medical decision, sports, where I live, my health, my stroke, clothing, my medication, the future, privacy, and voting.

- 'moderate agreement' (40-60\%): my job, my feelings, my transportation, food/diet, occupational therapy, physical progress, sex, my will, a problem, physiotherapy, underwear, my marriage/spouse, and alcohol and drug issues.

- 'low agreement' (0-30\%): power of attorney, counselling, risk of another stroke and abuse. 
Descriptions of the topic preferences obtained per topic across all 10 dyads revealed the following observations:

- The length of time that the dyads had known each other, whether the familiar communication partners knew the adults with aphasia prior to the onset of aphasia or not, as well as the type of dyad relationship did not appear to be attributing factors to the high, moderate or low percentage agreements of the topics.

- The nature of certain topics themselves may have been an attributing factor to certain topics obtaining high, moderate or low percentage agreement.

The percentage agreement of topic preferences within dyads ranged from $48.65-89.19 \%$. Dyads that obtained the highest percentage agreement included Dyads 4 (89.19\%), 7 $(78.38 \%)$ and $1(72.97 \%)$. Dyads that obtained the lowest percentage agreement were Dyads $3(48.65 \%)$ and $8(48.65 \%)$. The following observations were made regarding the percentage agreement obtained by the dyads:

- The dyads that obtained a high percentage agreement of topic preferences appeared to be those that chose activities together and engaged in a wide range of joint activities. In addition, it appeared that the familiar communication partners within these dyads held a positive attitude and belief of the communicative competencies of their partners with aphasia and as a result gave them 'the benefit of the doubt' when predicting their topic preferences, regardless of the severity of the communication difficulty experienced by their partners.

- The dyads that obtained a low percentage agreement of topic preferences did not select activities together. The familiar communication partner from Dyad 3 demonstrated difficulty in predicting what topics his partner with aphasia would like to talk about due to the language impairment experienced by his partner with aphasia and his subsequent difficulty to perceive that, despite the communication difficulty, his partner would still like to communicate about a variety of topics. The familiar communication partner from Dyad 8 demonstrated confusion regarding whether his partner with aphasia would like to talk about specific topics (such as underwear) with him in particular or in general. This dyad also represented the largest age difference out of all the dyads in the study. These 
factors may have influenced the poor percentage agreement of topic preferences obtained by these dyads.

Overall, of interest was the observation that the nature of the dyad relationship (that is, husband-wife, friend-friend, adult with aphasia-paid companion, sibling, parent-child) and whether the dyad knew each other prior to the onset of aphasia or not, did not appear to influence the level of agreement obtained from topic preferences within the dyads. Instead, it was noted that the amount of time spent together, variety of activities performed together and the manner of selecting joint activities appeared to hold the greatest effect on topic preference agreement. In addition, the familiar communication partners within these dyads demonstrated their belief in their partners with aphasia's communicative competencies and ability to participate in relevant conversations. In general, therefore, it appeared that the quality of the dyad relationship influenced topic preference agreement the most.

\subsection{CRITICAL EVALUATION OF THE STUDY}

This study represents a first attempt to describe the topic preferences of adults with aphasia through consultation with the familiar communication partners of the adults with aphasia and the adults with aphasia themselves.

Ten dyads participated in the study. Although this is a small sample, the population of adults with moderate to severe expressive aphasia is relatively small. In addition, the data obtained from requesting 10 dyads to provide their preferences of 37 topics on a threepoint semantic scale is broad. Definitive findings for generalization regarding the topic preferences of adults with aphasia could not be made, however, trends and suggestions could be made.

The sample also represents a heterogenic group of dyads, with four dyads representing married couples, two dyads representing adults with aphasia and their paid companions, two dyads representing same-sex friendships, one dyad representing a brother-sister 
relationship and one dyad representing a mother-son relationship. The variety of these dyad relationships further impacted on the generalisability of the findings. On the other hand, the relationships were representative of broader types of relationships experienced by adults with aphasia and therefore pointed to interesting findings.

Limited information on the quality of each dyad relationship was obtained. The association between the agreement of topic preferences and the quality of the dyad relationship would have provided valuable insights.

The ambiguous nature of some of the PCR topic cards resulted in poor understanding of what the topic was referring to, requiring repetition and reinforcement from the researcher. Requests for clarification were most frequently made by the familiar communication partners. It must be considered that the participants with aphasia may have also experienced confusion regarding the meaning of certain topic cards, however, were not able to communicate their uncertainties and request clarification.

Every attempt was made to provide clear instructions to the participants. Written and verbal explanations of the aim of the study were provided to the participants prior to the study, at the start of both interview sessions as well as throughout the topic evaluation process. However, there appeared to be some confusion regarding whether the topics for evaluation were topics that the adults with aphasia would like to talk about with the specific familiar communication partner participating in the study, or whether the topics were referring to those the adult with aphasia would like to talk about in general, with a variety of communication partners.

Only one familiar communication partner per adult with aphasia was consulted in this study regarding the topic preferences of their partners with aphasia. The use of multiple informants has been recommended in order to obtain a more accurate idea of the topic preferences of communicatively impaired individuals (Beukelman et al., 1991). 


\subsection{CLINICAL IMPLICATIONS}

The main clinical implication of the study is that adults with moderate to severe expressive aphasia are capable of communicating their topic preferences when provided with the necessary consultative support in the form of the Talking Mats ${ }^{\mathrm{TM}}$ framework and input from their familiar communication partners.

The adults with aphasia in this study indicated that they would like to talk about the majority of the 37 PCR topics presented to them for evaluation. The PCR topic list therefore represents an appropriate clinical resource of topics of conversation for adults with aphasia. The topics in this list, however, should not be viewed as the only topics that would be appropriate for adults with aphasia. Fringe topics need to be determined for each individual.

Although many commonalities were noted across the topic preferences provided by the adults with aphasia, the Talking Mat ${ }^{\mathrm{TM}}$ of each participant was unique, representing topics that they would like to talk about, were unsure about and would not like to talk about. Situational vocabulary is provided in Collier's (2000) book for adult AAC users. Words and phrases are organised around a variety of topics specific to adult roles, activities and issues. There is notable overlap between the topics listed in this resource and the 37 PCR topics evaluated in the current study. The topic-specific words and phrases found in Collier's (2000) book represent a valuable resource for determining topic-specific vocabulary for adults with aphasia, once their preferred topics have been identified.

The results of the current study suggest that the length of time that the dyad had known each other, the nature of the dyad relationship, as well as whether the communication partner knew the adult with aphasia prior to the onset of aphasia or not are not as influential as the quality of the dyad relationship in obtaining high agreement of topic preferences. Therefore, factors related to the familiar communication partner (and his/her relationship with their partner with aphasia) consulted regarding the topic preferences of their partner with aphasia should be carefully considered in clinical contexts. 
The method used in this study to determine the topic preferences of adults with aphasia was found to be effective and would provide valuable information if used in a clinical setting. Various aspects of the method used are described below with reference to clinical implications:

- The adults with aphasia were asked to select a familiar communication partner to participate in the study with them. This provided the participants with aphasia with a sense of control and independence. In a clinical setting, it is recommended that the adult with aphasia be asked to choose a few people to help them choose what topics and associated words to use in their communication system. Photographs and matching names of family members and friends could be presented to the person with aphasia, who could then select the individuals they would like to assist in the topic selection process.

- The familiar communication partners were interviewed first without the presence of their partners with aphasia. This provided the opportunity for the familiar communication partners to think about the topic preferences of their partners with aphasia and to think about any additional topics that were not included in the list. The advantages of interviewing the familiar communication partner alone is that the clinician may be able to ascertain the views of the familiar communication partner and establish a relationship with him/her that can be developed and used to facilitate the rehabilitation process with the person with aphasia.

- Using the Talking Mats ${ }^{\mathrm{TM}}$ framework with both members of dyads is recommended in a clinical setting (Gillespie et al., 2010). The use of Talking Mats ${ }^{\mathrm{TM}}$ proved to be a successful method of determining the preferred topics of adults with aphasia and the predicted topic preferences of their familiar communication partners. Verbal and non-verbal explanations of topic preferences were provided spontaneously by both groups of participants and thereby reinforced the topic preferences provided. Clinically, these explanations would 
provide the clinician with additional information regarding the communication activities and capabilities of the person with aphasia as well as the perceptions and opinions of the familiar communication partners towards their partners with aphasia. Observations of circularity on the part of familiar communication partners may be successfully addressed through their involvement in this process and subsequent awareness of the topic preferences of their partners with aphasia. That is, if communication partners were aware that their partners with aphasia would like to communicate about topics which reflect their social roles, interests and knowledge, their perceptions of these individuals may change. This may in turn have important psychosocial implications for adults with aphasia as well as their familiar communication partners (Simmons-Mackie \& Kagan, 1999).

- Ideally, the process of selecting relevant topics for inclusion in an AAC system should involve time, thought and input from various informants (Garrett et al., 1989). In a clinical setting, however, clinicians often do not have sufficient time and resources for this. The use of the Talking Mats ${ }^{\mathrm{TM}}$ framework provided an effective way of determining the preferred topics as well as the fringe topics of the adults with aphasia in a relatively short period of time. In addition, Talking Mats $^{\mathrm{TM}}$ reflects an individual's opinions at a certain time, and is used as a transient means of reflecting opinions, ideas and thoughts (Murphy, 1998). Vocabulary preferences change and vary over time, and periodic re-evaluations are necessary to reflect individual changes (Karlan \& Lloyd, 1983). Talking Mats $^{\mathrm{TM}}$ supports such re-evaluations and provides an efficient way of updating and re-evaluating the topic and vocabulary needs and preferences of individuals.

- The fringe topics selected by the familiar communication partners related to the specific and unique interests and needs of the adults with aphasia. Fringe topics are needed in a communication system in order to provide an adult with aphasia with access to topics that are motivating, interesting and stimulating. Optimal recovery of verbal communication has been found to be obtained through participation in pleasurable communicative experiences (Shewan \& Cameron, 
1994) and determining these unique topics would be a vital aspect in providing motivating communication intervention.

Other clinical implications related to the study include that knowledge of preferred topics provides direction in selecting appropriate and meaningful vocabulary items for use in intervention programs with adults with aphasia (Stuart, et al., 1994). In this way, if adults with aphasia indicate their preference towards certain topics such as work and sex, appropriate vocabulary related to these topics would need to be provided. Adults with aphasia would therefore have better access to words that support relevant and socially appropriate adult roles (Bryen, 2008).

Carers of adults with aphasia have repeatedly stressed that it is a burden for them to have the responsibility for topic initiation and maintenance in conversation (Booth \& Swabey, 1999). Therefore, having access to a list of personally relevant and preferred core and fringe topics may have a positive impact on the ability of adults with aphasia to initiate and maintain topics of conversation, and in this way, reduce the communicative burden experienced by communication partners.

\subsection{RECOMMENDATIONS FOR FUTURE RESEARCH}

Some interesting trends were identified from the results of the study. Further research could investigate these trends further in the following ways:

- This study could be replicated with a larger sample of adults with moderate to severe expressive aphasia, in order to strengthen the ability to generalise the findings to the broad population of adults with expressive aphasia.

- The study could also be replicated to involve groups of adult AAC users with differing aetiologies. 
- Adults with aphasia could be requested to provide topic preferences based on which topics they would like to talk about with various communication partners. Additionally, they could be asked to provide topic preferences based on which topics they would like to talk about within various contexts.

- This study could be expanded by documenting the topics of conversation that adults with aphasia participate in during their daily lives. These findings could then be compared with the topic preferences of the same individuals. Appropriate intervention guidelines may be drawn up following such research.

- A replication of the study with the use of two different familiar communication partners per adult with aphasia may provide interesting insights regarding the topic preference predictions provided by different informants.

- A follow-up replica of the study could be performed with the same participants after a six-month period. It would be of interest to determine whether the topic predictions of the familiar communication partners had altered since their awareness of the topic preferences of their partners with aphasia.

\subsection{SUMMARY}

In this chapter, a summary of the study was provided, with the results presented in a condensed form. The study was critically evaluated and implications for clinical practice were discussed. Recommendations for further research were provided. 


\section{REFERENCES}

Aries, E. J., \& Johnson, F. L. (1983). Close friendship in adulthood: Conversational content between same-sex friends. Sex Roles, 9, 1183-1196.

Arvidson, H. H., \& Lloyd, L. L. (1997). Vocabulary selection. In L. L. Lloyd, D. R. Fuller \& H.H. Arvidson (Eds.), Augmentative and Alternative Communication. A handbook of principles and practices (pp.199-213). Boston: Allyn \& Bacon Inc.

Balandin, S., \& Iacono, T. (1998a). A few well-chosen words. Augmentative and Alternative Communication, 14, 147-161.

Balandin, S., \& Iacono, T. (1998b). Topics of meal-break conversations. Augmentative and Alternative Communication, 14, 131-146.

Balandin, S., \& Iacono, T. (1999). Crews, Wusses, and Whoppas: core and fringe vocabularies of Australian meal-break conversations in the workplace. Augmentative and Alternative Communication, 15, 95-109.

Beukelman, D. R., \& Garrett, K. L. (1988). Augmentative and alternative communication for adults with acquired severe communication disorders. Augmentative and Alternative Communication, 4, 104-121.

Beukelman, D. R., \& Mirenda, P. (2005). Message management: Vocabulary, small talk, and storytelling. In D. R. Beukelman \& P. Mirenda (Eds.), Augmentative and Alternative Commucnation: Supporting children and adults with complex communication needs $\left(3^{\text {rd }}\right.$ ed., pp. 15-35). Baltimore: Paul H. Brookes. 
Beukelman, D. R., Fager, S., Ball, L., \& Dietz, A. (2007). AAC for adults with acquired neurological conditions: A review. Augmentative and Alternative Communication, 23, 230-242.

Beukelman, D. R., McGinnis, J., \& Morrow, D. (1991). Vocabulary selection in Augmentative and Alternative Communication. Augmentative and Alternative Communication, 7, 171-185.

Blackstone, S. W., Williams, M. B., \& Wilkins, D. P. (2007). Key principles underlying research and practice in AAC. Augmentative and Alternative Communication, 23, 191203.

Booth, S., \& Swabey, D. (1999). Group training in communication skills for carers of adults with aphasia. International Journal of Language and Communication Disorders, 34, 291-309.

Bornman, J., \& Murphy, J. (2006). Using the ICF in goal setting: Clinical application using Talking Mats ${ }^{\mathrm{TM}}$. Disability and Rehabilitation: Assistive Technology, 1, 145-154.

Brewster, S. J. (2004). Putting words into their mouths? Interviewing people with learning disabilities and little/no speech. British Journal of Learning Disabilities, 32, 166-169.

Brumfitt, S. (1993). Losing your sense of self: what aphasia can do. Aphasiology, 7, 569591.

Bryen, D. N. (2008). Vocabulary to support socially-valued adult roles. Augmentative and alternative communication, 24, 294-301. 
Cameron, L., \& Murphy, J. (2002). Enabling young people with a learning disability to make choices at a time of transition. British Journal of Learning Disabilities, 30, 105112.

Cherney, L. R., \& Robey, R. R. (2001). Aphasia treatment: Recovery, prognosis, and clinical effectiveness. In R. Chapey (Ed.), Language intervention strategies in aphasia and related neurogenic communication disorders $\left(4^{\text {th }}\right.$ ed., pp.148-169). Baltimore/Philadelpha: Lippincott Williams \& Wilkins.

Collier, B. M. (2000). See what we say: Situational vocabulary for adults who use augmentative and alternative communication. Balitmore, Maryland: Paul H. Brookes Publishing.

Davidson, B., Worrall, L., \& Hickson, L. (2003). Identifying the communication activities of older people with aphasia: Evidence from naturalistic observation. Aphasiology, 17, 243-264.

Fox, L. E., \& Fried-Oken, M. (1996). AAC aphasiology: partnership for future research. Augmentative and alternative communication, 12, 257-271.

Fox, L. E., Sohlberg, M. M., \& Fried-Oken, M. (2001). Effects of conversational topic choice on outcomes of augmentative communication intervention for adults with aphasia. Aphasiology, 15, 171-200.

Garrett, K. L., \& Beukelman, D. R. (1992). Augmentative communication approaches for persons with severe aphasia. In Yorkston K. M. (Ed.), Augmentative Communication in the Medical Setting (pp. 245-323).

Garrett, K. L., \& Beukelman, D. R. (1995). Changes in the interaction patterns of an individual with severe aphasia given three types of partner support. Clinical Aphasiology, 23, 237-251. 
Garrett, K. L., \& Huth, C. (2002). The impact of graphic contextual information and instruction on the conversational behaviours of a person with severe aphasia. Aphasiology, 16, 523-536.

Garrett, K. L., \& Kimelman, M. D. Z. (2000). AAC and aphasia: Cognitive-Linguistic Considerations. In D. R. Beukelman, K. M. Yorkston \& J. Reichle (Eds.), Augmentative and alternative communication for adults with acquired neurologic disorders (pp. 339375). Baltimore: Paul H. Brookes.

Garrett, K. L., \& Lasker, J. P. (2005). Adults with severe aphasia. In D. R. Beukelman \& P. Mirenda (Eds.), Augmentative and alternative communication: Supporting children and adults with complex communication needs ( $3^{\text {rd }}$ ed., pp. 467- 504). Baltimore: Paul H. Brookes.

Garrett, K. L., Beukelman, D. R., \& Low-Morrow, D. (1989). A comprehensive augmentative communication system for an adult with Broca's aphasia. Augmentative and Alternative Communication, 5, 55-61.

Gillespie, A., Murphy, J., \& Place, M. (2010). Divergences of perspective between people with aphasia and their family caregivers. Aphasiology, 24, 1559-1575.

Graves, J. (2000). Vocabulary needs in augmentative and alternative communication: a sample of conversational topics between staff providing services to adults with learning difficulties and their service users. British Journal of Learning Disabilities, 28, 113-119.

Herrmann, M., \& Wallesch, C. (1989). Psychosocial changes and psychosocial adjustment with chronic and severe non-fluent aphasia. Aphasiology, 3, 513-526. 
Ho, K. M., Weiss, S. J., Garrett, K. L., \& Lloyd, L. L. (2005). The effect of remnant and pictographic books on the communicative interaction of individuals with global aphasia. Augmentative and alternative communication, 21, 218-232.

Hough, M., \& Johnson, R. K. (2009). Use of AAC to enhance linguistic communication skills in an adult with chronic severe aphasia. Aphasiology, 23, 965-976.

Hux, K. D., Manasse, N., Weiss, A., \& Beukelman, D. R. (2001). Augmentative and alternative communication for persons with aphasia. In R. Chapey (Ed.), Language intervention strategies in aphasia and related neurogenic communication disorders $\left(4^{\text {th }}\right.$ ed., pp.675-687). Baltimore/Philadelpha: Lippincott Williams \& Wilkins.

Jacobs, B., Drew, R., Ogletree, B. T., \& Pierce, K. (2004). Augmentative and alternative communication for adults with severe aphasia: where we stand and how we can go further. Disability and Rehabilitation, 26, 1231-1240.

Johnson, R. K., Hough, M. S., King, K. A., Vos, P., \& Jeffs, T. (2008). Functional communication in individuals with chronic severe aphasia using augmentative communication. Alternative and Augmentative Communication, 24, 269-280.

Kagan, A. (1998a). Supported conversation for adults with aphasia: methods and resources for training conversation partners. Aphasiology, 12, 811-864.

Kagan, A. (1998b). Reply: Philosophical, practical and evaluative issues associated with 'Supported conversation for adults with aphasia'. Aphasiology, 12, 851-864.

Kagan, A., \& Gailey, G. F. (1993). Functional is not enough: Training conversation partners for aphasic adults. In A. L. Holland \& M. M. Forbes (Eds.), Aphasia treatment: world perspectives (pp.199-223). San Diego: Singular Publishing Group. 
Kagan, A., Black, S. E., Duchan, J. F., Simmons-Mackie, N., \& Square, P. (2001). Training volunteers as conversation partners using "Supported conversation for adults with aphasia" (SCA): A controlled trial. Journal of Speech, Language, and Hearing Research, 44, 624-638.

Kagan, A., Winckel, J., \& Shumway, E. (1996). Pictographic Communication Resources Manual. Toronto, Canada: Aphasia Centre, North York.

Karlan, G. R., \& Lloyd, L. L. (1983). Considerations in the planning of intervention: Selecting a lexicon. Journal of the Association for the Severely Handicapped, 8, 13-25.

Kertesz, A. (1982). Western Aphasia Battery. New York: Grune \& Stratton.

King, J., Spoeneman, T., Stuart, S., \& Beukelman, D. R. (1995). Small talk in adult conversations: Implications for AAC vocabulary selection. Augmentative and Alternative Communication, 11, 260-264.

Koul, R. J., \& Corwin, M. (2003). Efficacy of AAC intervention in individuals with chronic severe aphasia. In R. W. Schlosser (Ed.), The Efficacy of Augmentative and Alternative Communication (pp. 449-470). USA: Elsevier Science.

Koul, R. J., \& Harding, R. (1998). Identification and production of graphic symbols by individuals with aphasia: efficacy of a software application. Augmentative and Alternative Communciation, 14, 11-24.

Kraat, A. W. (1990). Augmentative and alternative communication: does it have a future in aphasia rehabilitation? Aphasiology, 4, 321-338.

Lasker, J., Hux, K., Garrett, K. L., Moncrief, E. M., \& Eischeid, T. J. (1997). Variations on the written choice communication strategy for individuals with severe aphasia. Augmentative and alternative communication, 13, 108-116. 
Lasker, J. P., \& Bedrosian, J. L. (2001). Promoting acceptance of Augmentative and Alternative Communication by adults with acquired communication disorders. Augmentative and Alternative Communication, 17, 141-153.

Le Dorze, G., \& Brassard, C. (1995). A description of the consequences of aphasia on aphasic persons and their relatives and friends, based on the WHO model of chronic diseases. Aphasiology, 9, 239-255.

Light, J. A. (1988). Interaction involving individuals using augmentative and alternative commucniation systems: State of the art and future directions. Augmentative and Alternative Communication, 4, 66-82.

Light, J. A. (1989). Toward a definition of communicative competence for individuals using augmentative and alternative communication. Augmentative and Alternative Communication, 5, 137-144.

Light, J. A., \& Drager, K. (2007). AAC technologies for young children with complex communication needs: State of the science and future research directions. Augmentative and Alternative Communication, 23, 204- 216.

Light, J. C., \& Gulens, M. (2000). Rebuilding communicative competence and selfdetermination. In D. R. Beukelman, K. M. Yorkston \& J. Reichle. (Eds.), Augmentative and alternative communication for adults with acquired neurologic disorders (pp. 137183). Baltimore: Paul H. Brookes.

Light, J. C., Drager, K., McCarthy, J., Mellott, S., Millar, D., Parrish, C., Parsons, A., Rhoads, S., Ward, M., \& Welliver, M. (2004). Performance of typically developing fourand five-year old children with AAC systems using different language organisation techniques. Augmentative and Alternative Communication, 2, 63-88. 
Lloyd, L. L., Fuller, D. R., \& Arvidson, H. H. (1997). Glossary. In L. L. Lloyd, D. R. Fuller, \& H. H. Arvidson (Eds.), Augmentative and alternative communication. A handbook of principles and practices (pp. 522-543). Boston: Allyn \& Bacon Inc.

Lyon, J. G. (1995). Drawing: its value as a communication aid for adults with aphasia. Aphasiology, 9, 33-94.

Lyon, J. G., \& Helm-Estabrooks, N. (1987). Drawing: Its communicative significance for expressively restricted aphasic adults. Topics in Language Disorders, 8, 61-71.

Lyon, J. G., Cariski, D., Keisler, L., Rosenbek, J., Levine, R., Kumpula, J., Ryff, C., Coyne, S., \& Blanc, M. (1997). Communication partners: Enhancing participation in life and communication for adults with aphasia in natural settings. Aphasiology, 11, 693-708.

McKelvey, M. L., Hux, K., Dietz, A., \& Beukelman, D. R. (2010). Impact of personal relevance and contextualization on word-picture matching by people with aphasia. American Journal of Speech-Language Pathology, 19, 22-33.

McMillan, J. H., \& Schumacher, S. (2006). Research in education: Evidence-based inquiry. USA: Pearson.

Morrow, D. R., Mirenda, P., Beukelman, D. R., \& Yorkston, K. M. (1993). Vocabulary selection for augmentative communication systems: A comparison of three techniques. American Journal of Speech, Language Pathology, 2, 19-30.

Murphy, J. (1998). Talking Mats ${ }^{\mathrm{TM}}$ : Speech and Language research in practice. Speech and Language Therapy in practice, pp.11-14. www.speechmag.com.

Murphy, J. (2000). Enabling people with aphasia to discuss quality of life. British Journal of Therapy and Rehabilitation, 7, 454-458. 
Murphy, J., \& Cameron, L. (2008). The effectiveness of Talking Mats® with people with intellectual disability. British Journal of Learning Disabilities, 36, 232-241.

Murphy, J., Gray, C. M., \& Cox, S. (2007). Communication and Dementia: How Talking Mats $^{\mathrm{TM}}$ can help people with dementia to express themselves. www.jrf.org.uk.

Murphy, J., Tester, S., Hubbard, G., Downs, M., \& MacDonald, C. (2005). Enabling frail older people with a communication difficulty to express their views: the use of Talking Mats $^{\mathrm{TM}}$ as an interview tool. Health and Social Care in the Community, 13, 95-107.

Parr, S. (2007). Living with severe aphasia: Tracking social exclusion. Aphasiology, 21, 98-123.

Parr, S., \& Byng, S. (1998). Breaking new ground in familiar territory: a comment on 'Supported conversation for adults with aphasia', by Aura Kagan. Aphasiology, 12, 847850.

Penn, C., Frankel, T., Watermeyer, J., \& Muller, M. (2008). Informed consent and aphasia: Evidence of pitfalls in the process. Aphasiology, 23, 3-32.

Rao, P. R. (2001). Use of Amer-Ind code by persons with severe aphasia. In R. Chapey (Ed.), Language intervention strategies in aphasia and related neurogenic communication disorders (4 ${ }^{\text {th }}$ ed., pp.688-701). Baltimore/Philadelpha: Lippincott Williams \& Wilkins.

Rautakoski, P., Korpijaakko-Huuhka, A., \& Klippi, A. (2008). People with severe and moderate aphasia and their partners as estimators of communicative skills: A clientcentered evaluation. Aphasiology, 22, 1269-1293.

Rogers, M. A., King, J. M., \& Alarcon, N. B. (2000). Proactive management of primary progressive aphasia. In D. R. Beukelman, K. M. Yorkston \& Reichle, J. (Eds.), 
Augmentative and alternative communication for adults with acquired neurologic disorders (pp. 305-337). Baltimore: Paul H. Brookes.

Scherer, K. R. (2005). What are emotions? And how can they be measured? Social Science Information, 44, 695-729.

Shelton, J. R., Weinrich, M., McCall, D., \& Cox, D. M. (1996). Differentiating globally aphasic patients: data from in-depth language assessments and production training using C-VIC. Aphasiology, 10, 319-342.

Shewan, C. M., \& Cameron, H. (1984). Communication and related problems as perceived by aphasic individuals and their spouses. Journal of Communication Disorders, $17,175-187$.

Simmons-Mackie, N. (1998). In support of supported conversation for adults with aphasia. Aphasiology, 12, 831-838.

Simmons-Mackie, N. (2001). Social approaches to aphasia intervention. In R. Chapey (Ed.), Language intervention strategies in aphasia and related neurogenic communication disorders (4 ${ }^{\text {th }}$ ed., pp.246-267). Baltimore/Philadelpha: Lippincott Williams \& Wilkins.

Simmons-Mackie, N. N., \& Damico, J. S. (1995). Communicative competence in aphasia: Evidence from compensatory strategies. Clinical Aphasiology, 23, 95-105.

Simmons-Mackie, N. N., \& Kagan, A. (1999). Communication strategies used by 'good' versus 'poor' speaking partners of adults with aphasia. Aphasiology, 13, 807-820.

Steele, R. D., Weinrich, M., Wertz, R. T., Klezewska, M. K., \& Carlson, G. S. (1989). Computer-based visual communication in aphasia. Neuropsychologica, 27, 409-426. 
Stuart, S., Beukelman, D. R., \& King, J. (1997). Vocabulary use during extended conversations by two cohorts of older adults. Augmentative and Alternative Communication, 13, 40-46.

Stuart, S., Lasker, J. P., \& Beukelman, D. R. (2000). AAC message management. In D. R. Beukelman, K. M. Yorkston \& J. Reichle (Eds.), Augmentative and alternative communication for adults with acquired neurologic disorders (pp. 25-54). Baltimore: Paul H. Brookes.

Stuart, S., Vanderhoof, D., \& Beukelman, D. R. (1993). Topic and vocabulary use patterns of elderly women. Augmentative and Alternative Communication, 9, 95-110.

Stuart, S., Vanderhoof-Bilyeu, M. A., \& Beukelman, D. R. (1994). Differences in topic reference of elderly men and women. Journal of Medical Speech-Language Pathology, 2, 89-104.

Tonsing, K., \& Alant, E. (2004). Topics of social conversation in the work place: A South African perspective. Augmentative and Alternative Communication, 20, 89-102.

Turner, S., \& Whitworth, A. (2006). Conversational partner training programmes in aphasia: A review of key themes and participant's roles. Aphasiology, 20, 483-510.

van de Sandt-Koenderman, M. W. M. E. (2004). High-tech AAC and aphasia: Widening horizons? Aphasiology, 18, 245-263.

Waller, A., Dennis, F., Brodie, J., \& Cairns, A. Y. (1998). Evaluating the use of TalksBac, a predictive communication device for nonfluent adults with aphasia. International Journal of Language and Communication Disorders, 33, 45-70. 
Weinrich, M., Steele, R. D., Carlson, G. S., Kleczewska, M., Wertz, R. T., \& Baker, E. (1989). Processing of visual syntax in a globally aphasic patient. Brain and Language, $36,391-405$.

Zemva, N. (1999). Aphasic patients and their families: wishes and limits. Aphasiology, $13,219-224$. 


\section{APPENDIX A: RECRUITMENT ASSISTANCE LETTER}

Centre for Augmentative and Alternative Communication Sentrum vir Aanvullende en Alternatiewe Kommunikasie

\section{INTERFACE}

Award, Education Innovation for the Fofa Project

T-Systems Age of Innovation \& Sustainability Awards: Excellence in Innovation and Sustainability: Social

2003 National Science \& Technology Awards: Corporate Organization over the last ten years.

2002 Shirley McNaughton Award for Exemplary Communication received from the International Society for Augmentative and Alternative Communication

1998 Rolex Award for Enterprise: Associate Laureate

1995 Education Africa Presidential Award for Special Needs

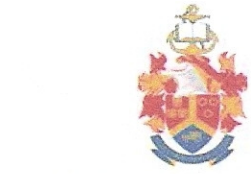

UNIVERSITEIT VAN PRETORIA UNIVERSITY OF PRETORIA YUNIBESITHI YA PRETORIA $100 \underline{1908-2008}$

\section{Faculty of Human Sciences} Fakulteit Geesteswetenskappe

Dear Colleague

\section{Request for assistance in recruitment of participants for Masters Research.}

Thank you for taking the time to read this letter. I am a Speech-Language Therapist currently registered for a master's degree in Augmentative and Alternative Communication (AAC) through the University of Pretoria. I am currently in the process of conducting a research study with the focus on adults with expressive aphasia.

Study title: Topic preferences of adults with expressive aphasia and their familiar communication partners.

The study aims to recruit 10 adults with moderate to severe expressive aphasia along with a familiar communication partner (someone who knows them well and spends time with them frequently) for their participation. Within each dyad, the adult with aphasia will be requested to provide their personal preference ratings of topic items, whereas their familiar communication partner will be requested to provide perceived preference ratings on behalf on the adult with aphasia. Each topic will be presented in picture format with an accompanying written label. The rating process will be conducted with the use of the Talking Mats* procedure in order to lessen the linguistic demands of the task and provide each participant with aphasia an opportunity to rate conversational topics that are typically chosen for them by their family members, caregivers, or Speech-Language Therapists. A three-point rating scale (Yes; Maybe; No) will be used to aid the participants in the rating process. Any similarities and differences between the topic ratings within each dyad will be described and discussed as well as possible implications for clinical practice.

*Talking Mats are a simple low-technology strategy that was specifically developed to help people with a range of communication difficulties express their opinions. It consists of a textured mat on which picture symbols are placed to convey the user's opinions regarding a certain topic.

If you are currently treating, or have previously treated any individuals who fit the following criteria, I would greatly appreciate it if you could assist me by providing them and/or their familiar member with detailed information sheets explaining the nature of the study. Please find these sheets attached.

Screening criteria: - $\quad$ presents with moderate-severe expressive aphasia

fluent speaker of English prior to the neurological injury.

Neurological injury occurred more than 6 months ago

normal or corrected vision

normal or corrected hearing

between the age of $40-85$ years.

has functional use of one arm and hand

does not present with dramatic fluctuations in levels of alertness

does not present with a psychiatric disorder

does not present with a learning disorder

Centre for Augmentative and Alternative Communication (CAAC), Communication Pathology Building University of Pretoria, Lynnwood Road PRETORIA, 0002

Republic of South Africa
Fax/Faks: $+2712420-4389$ Tel: $\quad+2712420-2001$ uan.bornman@up.ac.za www.caac.up.ac.za
Sentrum vir Aanvullende en Alternatiewe Kommunikasie (SAAK), Kommunikasie Patologie gebou Universiteit van Pretoria, Lynnwoodweg PRETORIA, 0002 Republiek van Suid Afrika 
If your client expresses interest in participating in the study, I would be much obliged if you could forward their contact details on to me for arrangements to be made for their participation in the study.

Once the study has been completed, you will be provided with the topic items which were rated favorably by the participants in the study.

If you have any questions regarding the study, please do not hesitate to contact me via email or telephonically on 0724758945 .

Kind regards,

\section{Ange Beringer}

Speech-Language Therapist

Fax/Faks: + $2712420-4389$
Sentrum vir Aanvullende en Alternatiewe Kommunikasie (SAAK), Kommunikasie Patologie gebou Universiteit van Pretoria, Lynnwoodweg PRETORIA, O002 Republiek van Suid Afrika 
APPENDIX B: SELECTION OF FAMILIAR COMMUNCIATION PARTNER

Please choose someone to participate with you in the project.

This person must be someone that knows you well and that communicates with you regularly.

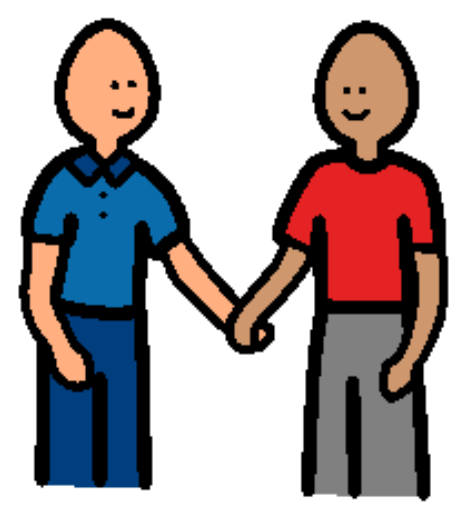

Name of participant with aphasia:

Name of selected familiar communication partner:

Date: 


\section{APPENDIX C: BACKGROUND INFORMATION: FAMILIAR COMMUNICATION PARTNER}




8. When you see the person with aphasia, what do you typically do? Eg. Go to the shops.

Please be as specific as possible:

9. Who typically decides on where you go and what you do?

- Person

- Partner

- Both

- Circumstance

- Other:

10. What is your occupation?

11. What is your highest level of education?

- Standard nine or lower

- Matric

- Diploma

- Degree

- Postgraduate qualification

- Other: 


\section{APPENDIX D: BACKGROUND INFORMATION: PERSON WITH APHASIA}

This form is to be completed by the participant with aphasia with the assistance of a family member. Please provide the name of the family member who assisted with the completion of this form as well as the nature of his/her relationship to the person with aphasia:

Please complete the following questionnaire in order to provide the researcher with some background information about you.

Official use

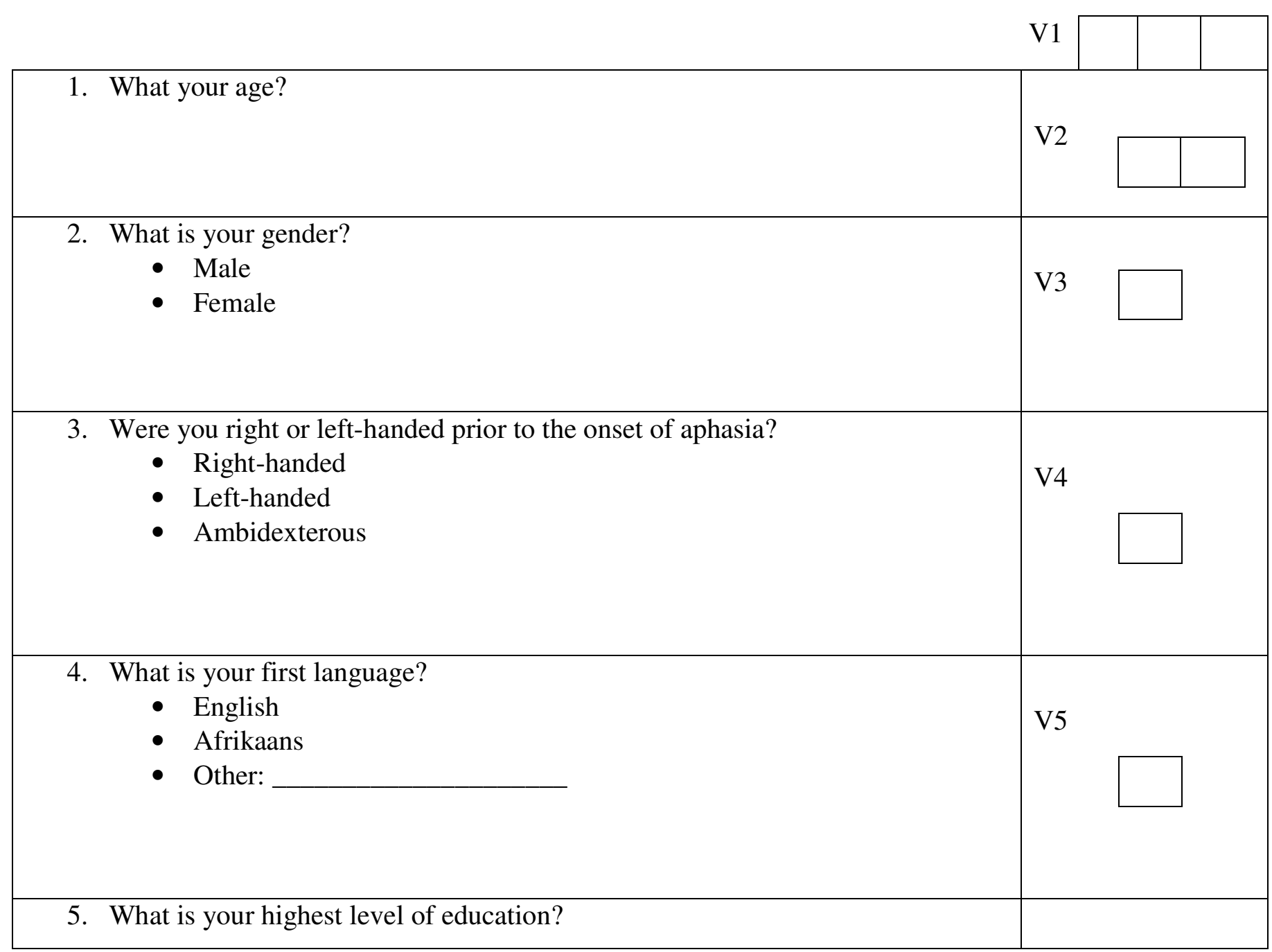




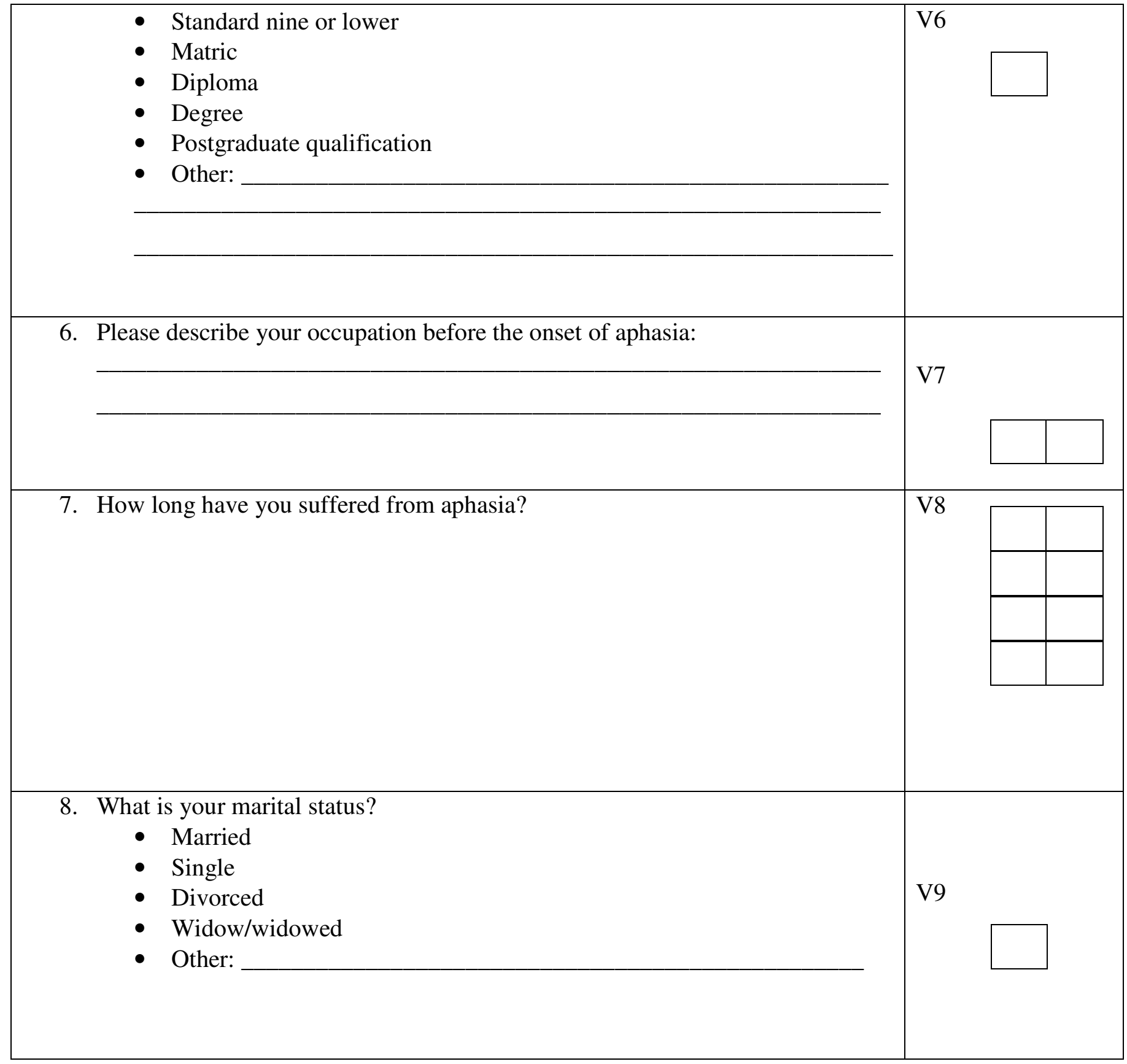


APPENDIX E: PCR TOPIC CARDS

\section{I want to talk about...}
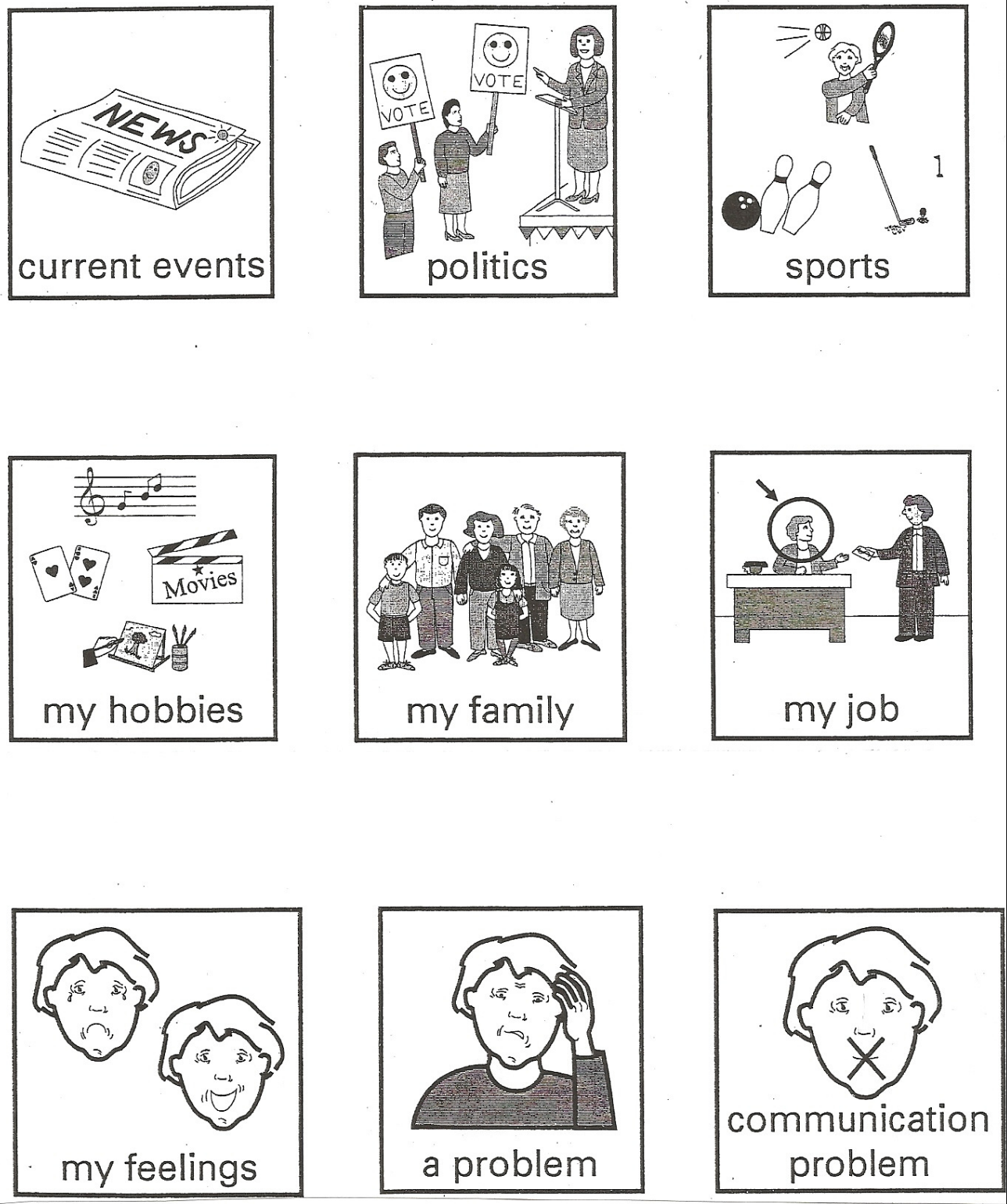
I want to talk about...
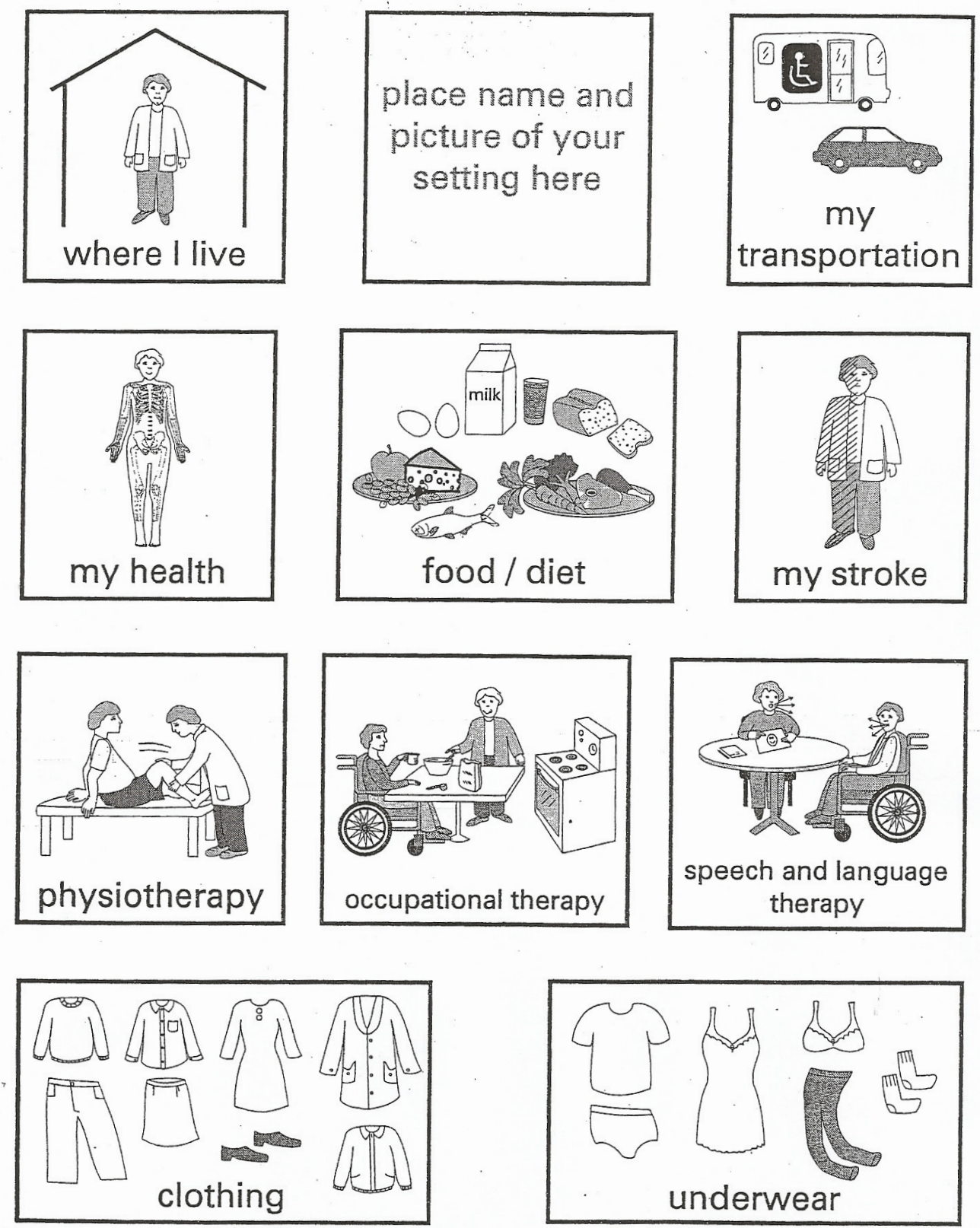

(C) copyright 1996 Aphasia Centre - North York 


\section{I want to talk about...}



\section{I want to talk about...}
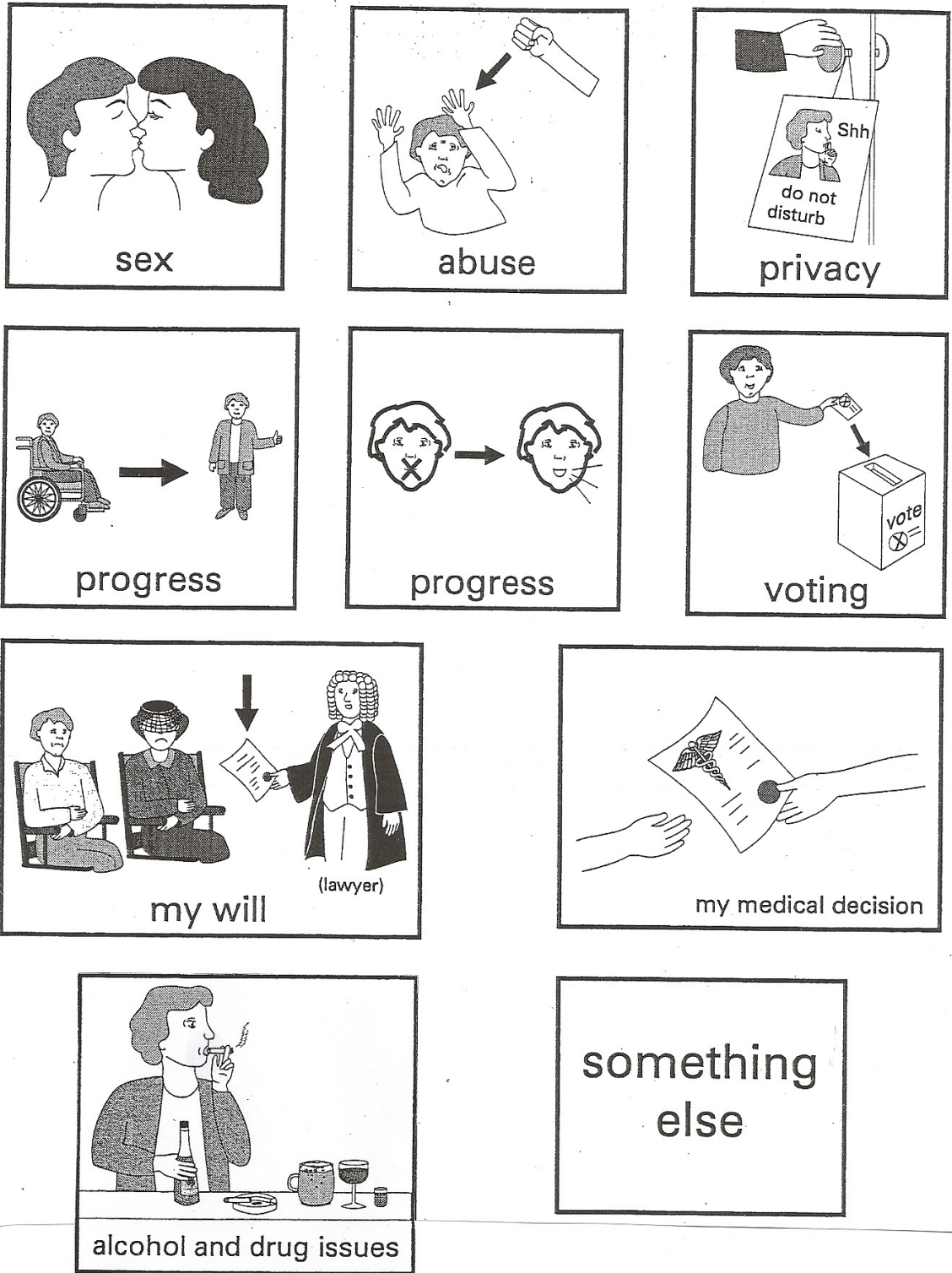
APPENDIX F: PRACTICE ITEMS
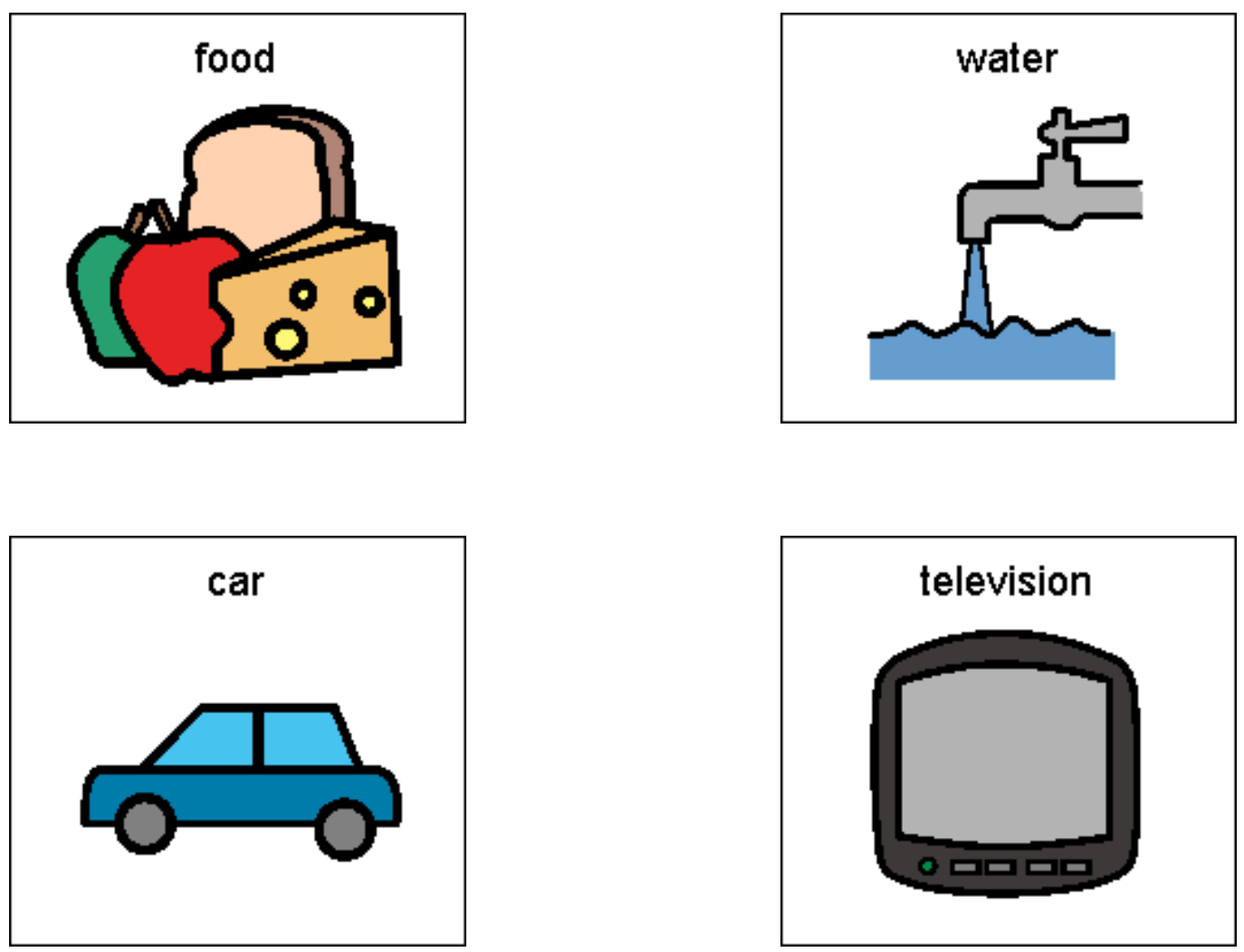


\section{APPENDIX G: UNIVERSITY ETHICS APPROVAL ${ }^{1}$}



Research Proposal and Ethics Committee

2 April 2009

Dear Prof Bornman,

Project:

Researcher:

Supervisor:

Department:

Reference number:

Social validation of vocabulary words by adults with aphasia

A Halland

Prof J Bornman

Centre for Augmentative and Alternative communication

28601582

Thank you for the well written application you submitted to the Research Proposal and Ethics Committee, Faculty of Humanities.

I have pleasure in informing you that the Research Proposal and Ethics Committee formally approved the above study on 26 March 2009. The approval is subject to the candidate abiding by the principles and parameters set out in her application and research proposal in the actual execution of the research.

The Committee requests you to convey this approval to Ms Halland.

We wish you success with the project.

Sincerely

I) 1

Prof. Brenda Louw

Chair: Research Proposal and Ethics Committee

Faculty of Humanities

UNIVERSITY OF PRETORIA

e-mail: brenda.louw@up.ac.za

Research Proposal and Ethics Committee Members: Prof P Chiroro; Dr M-H Coetzee; Dr JEH Grobler; Prof KL Harris; Ms H Kiopper; Prof E Kruge Prof B Louw (Chair); Prof A Mlambo; Prof G Prinsloo; Mr C Puttergill; Prof H Stander; Prof E Taljard; Dr J van Dyk; Prof C Walton; Mr FG Wolmarans

\footnotetext{
${ }^{1}$ Please note that the above letter refers to Ange Halland, which is the author's maiden name.
} 


\section{APPENDIX H: FAMILY INFORMATION SHEET}

\section{Centre for Augmentative and Alternative Communication Sentrum vir Aanvullende en Alternatiewe Kommunikasie \& \\ INTERFACE}

2006
Laureate Award, Education Innovation for the Fofa Project T-Systems Age of Innovation \& Sustainability Awards: Excellence in Innovation and Sustainability: Social

National Science \& Technology Awards: Corporate Organization over the last ten years.

Shirley McNaughton Award for Exemplary Communication received from the International Society for Augmentative and Alternative Communication

Rolex Award for Enterprise: Associate L aureate

Education Africa Presidential Award for Special Needs

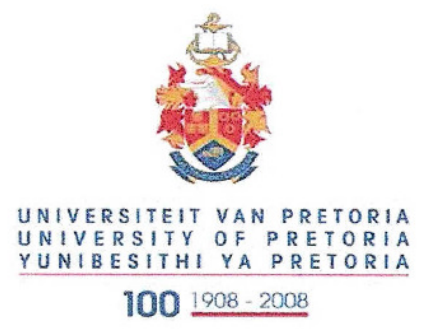

Faculty of Human Sciences Fakulteit Geesteswetenskappe

\section{Family Information Sheet}

I am a Speech-Language Therapist working in Rivonia, Johannesburg. I am currently registered towards a Masters Degree in Augmentative and Alternative Communication (AAC) at the University of Pretoria. As partial fulfillment of the degree requirements, the submission of a research-based thesis is required.

May I supply a brief outline of the research project:

The title for the study is "Topic preferences of adults with expressive aphasia and their familiar communication partners". The purpose of the study is to determine which topics of conversation adults with aphasia would like to talk about during communication with others as well as to determine which topics of conversation familiar communication partners select on behalf of the person with aphasia. The topics selected by the adult with aphasia will be compared to those selected for them by their familiar communication partner in order to detect any similarities and differences.

Aphasia is the name used for the communication problem presented by individuals who have suffered from a stroke or other neurological injury. This communication problem affects all relationships and previous interactive activities enjoyed by individuals with aphasia. Adults with aphasia frequently depend on significant others to initiate conversations about certain topics and to provide the necessary communicative support for them to be able to participate in such conversations.

Providing adults with aphasia and their familiar communication partner the opportunity to rate various topics of conversation according to their personal preferences may provide valuable insights and guidelines for professionals working with people with aphasia. This in turn may provide more functional opportunities for adults with aphasia to participate in conversations of personal interest and value.

I am aiming to recruit 10 people with moderate-severe expressive aphasia, as well as their selected familiar communication partner to take part in the research study explained above. Conversational topics will be presented in picture format with an accompanying written label. Participants will be required to rate each conversational topic using a technique known as Talking Mats. Talking Mats are a simple strategy that was specifically developed to help people with a range of communication difficulties express their opinions. It consists of a textured mat on which picture symbols are placed to convey the user's opinions regarding a certain topic.

I will meet with each participant and their spouse/family member/carer on two occasions at a place where they feel comfortable. During the first visit, I will explain the project to them, introduce them to the Talking Mats procedure, and ask them if they would be happy to take part. If they consent to partake in the study, a language assessment test will be performed in order to obtain information regarding the type and severity of aphasia presented by that person. The person with aphasia will be asked to select someone who knows them well and with whom they spend time frequently (familiar communication partner). This person will then be requested to participate in the second visit.

Centre for Augmentative and Alternative Communication (CAAC), Communication Pathology Building

University of Pretoria, Lynnwood Road

PRETORIA, 0002

Republic of South Africa

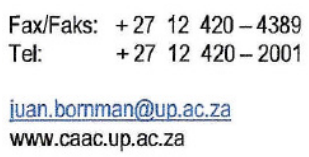

Sentrum vir Aanvullende en Alternatiewe Kommunikasie (SAAK), Kommunikasie Patologie gebou Universiteit van Pretoria, Lynnwoodweg PRETORIA, 0002 Republiek van Suid Afrika 
During the second visit, the familiar communication partner will be requested to rate 40 conversational topics according to three categories "Yes", "Maybe" and "No" based on what they perceive the personal preferences of the person with aphasia to be. Thereafter, they will be requested to think of 2-3 additional topics that they think the person with aphasia would like to talk about.

After this, the person with aphasia will be required to rate each topic (the original 40 as well as any additional topics provided by the communication partner) according to the three categories mentioned above. Both of these sessions will be videotaped in order to ensure accurate collection and analysis of the results of the study.

Your family member's name and the name of the selected familiar communication partner will not be disclosed in the research report and confidentiality will be maintained at all times throughout the research process. Your family member and his/her familiar communication partner will be able to withdraw from the study at any stage.

After the research study has been completed, each participant will receive a communication booklet containing all of the conversational topics that were rated favorably by themselves.

I very much hope that your relative will be able to help in the proposed study. Previous work suggests that most people with aphasia enjoy the experience of Talking Mats.

Yours faithfully

\section{OBeringer \\ Ange Beringer}

Candidate: M(AAC)

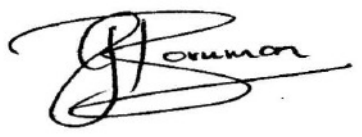

Prof. Juan Bornman

Supervisor

I would love to answer any questions or queries that you might have about the project.

Please feel free to contact me:

Researcher: Ange Beringer

Email: angeh@absamail.co.za

Contact number: 0724758945

Promoter: Prof. Juan Bornman

E-mail: juan.bornman@up.ac.za

Contact number: 012-420 2001

Centre for Augmentative and Alternative Communication (CAAC), Communication Pathology Building

University of Pretoria, Lynnwood Road

PRETORIA, 0002

Republic of South Africa
Fax/Faks: $+2712420-4389$

Tel:

$+2712420-2001$

juan,bormman@up.ac.za

www.caac.up.ac.za
Sentrum vir Aanvullende en Alternatiewe Kommunikasie (SAAK), Kommunikasie Patologie gebou Universiteit van Pretoria, Lynnwoodweg PRETORIA, 0002 Republiek van Suid Afrika 


\section{APPENDIX I: PARTICIPANT INFORMATION SHEET}

Centre for Augmentative and Alternative Communication Sentrum vir Aanvullende en Alternatiewe Kommunikasie

\section{INTERFACE}

\footnotetext{
2006 Laureate Award, Education Innovation for the Fofa Project

2004 T-Systems Age of Innovation \& Sustainability Awards: Excellence in Innovation and Sustainability: Social

2003 National Science \& Technology Awards: Corporate Organization over the last ten years.

2002 Shirley McNaughton Award for Exemplary Communication received from the International Society for Augmentative and Alternative Communication

1998 Rolex Award for Enterprise: Associate Laureate

1995 Education Africa Presidential Award for Special Needs
}

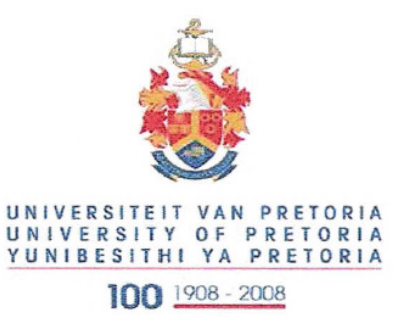

Faculty of Human Sciences

Fakulteit Geesteswetenskappe

\section{Participant (adult with aphasia) Information Sheet}

My name is Ange Beringer. I am a Speech Therapist. I am carrying out a study to find out which topics of conversation people with aphasia would like to talk about when communicating with other people.

The title of the study is "Topic preferences of adults with expressive aphasia and their familiar communication partners".

I would like you to help me.

If you agree to help me, I will use Talking Mats to help you tell me which topics you would like to talk about during communication.

I will not reveal your identity and views to anyone unless you want me to.

You will get a copy of the conversational topics that you thought were useful when we are finished.

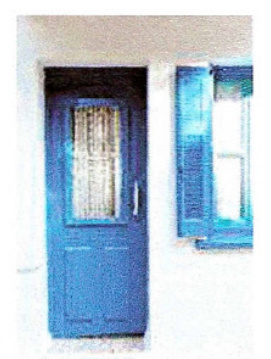

If you agree to help, I will meet you today and on one other occasion.

I will always see you at a place that is comfortable and familiar to you.

When I come back to see you, I will ask you to rate different topics of conversation. I will also ask your familiar communication partner to do the same.

Centre for Augmentative and Alternative Communication (CAAC), Communication Pathology Building

University of Pretoria, Lynnwood Road

PRETORIA, 0002

Republic of South Africa
Fax/Faks: + $2712420-4389$

Tel: $\quad+2712420-2001$

juan.bornman@up.ac.za www.caac.up.ac.za
Sentrum vir Aanvullende en Alternatiewe Kommunikasie (SAAK), Kommunikasie Patologie gebou Universiteit van Pretoria, Lynnwoodweg PRETORIA, 0002 Republiek van Suid Afrika 
I will video these chats.

Yours faithfully

OBeringer

Ange Beringer

Candidate: $\mathrm{M}(\mathrm{AAC})$

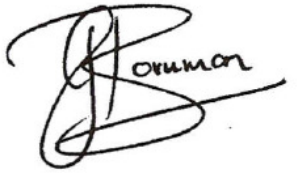

Prof. Juan Bornman

Supervisor

I would love to answer any questions or queries that you might have about the project.

Please feel free to contact me:

Researcher: Ange Beringer

Email: angeh@absamail.co.za

Contact number: 0724758945

Promoter: Prof. Juan Bornman

E-mail: juan.bornman@up.ac.za

Contact number: 012-420 2001

Centre for Augmentative and Alternative Communication

(CAAC), Communication Pathology Building

University of Pretoria, Lynnwood Road

PRETORIA, 0002

Republic of South Africa
Fax/Faks: $+2712420-4389$

Tel: +27 $12420-2001$

juan,bornman@up.ac.za

www.caac.up.ac.za
Sentrum vir Aanvullende en Alternatiewe Kommunikasie

(SAAK), Kommunikasie Patologie gebou

Universiteit van Pretoria, Lynnwoodweg PRETORIA, 0002

Republiek van Suid Afrika 


\section{APPENDIX J: ADULT WITH APHASIA CONSENT FORM}

Centre for Augmentative and Alternative Communication Sentrum vir Aanvullende en Alternatiewe Kommunikasie INTERFACE



UNIVERSITEIT VAN PRETORIA

UNIVERSITY OF PRETORIA

YUNIBESITHI YA PRETORIA

Faculty of Education

Fakulteit Opvoedkunde

2002 Shirley McNaughton Award for Exemplary Communicatio received from the International Society for Augmentative and Alternative Communication

1998 Rolex Award for Enterprise: Associate Laureate

1995 Education Africa Presidential Award for Special Needs
T-Systems Age of Innovation \& Sustainability Awards: Excellence in

Innovation and Sustainability: Social

the last ten years.
Have you read the information sheet, or had it explained to you?

YES

NO

Have you had time to ask questions and talk about the study?

YES

NO

Are you happy with the answers you have been given?

YES NO
Centre for Augmentative and Alternative Communication (CAAC), Communication Pathology Building University of Pretoria, Lynnwood Road

PRETORIA, 0002

Republic of South Africa
Fax/Faks: $+2712420-4389$ Tel: $\quad+2712420-2001$

juan.bornman@up.ac.za umw.caac.up.ac.7a
Sentrum vir Aanvullende en Alternatiewe Kommunikasie (SAAK), Kommunikasie Patologie gebou Universiteit van Pretoria, Lynnwoodweg PRETORIA, 0002 


do not have to say why you want to stop).

YES

NO

Are you happy to take part in the study?

YES NO the study?

YES

NO the study?

YES NO

Name

Signature.

Do you understand that it is your choice to take part in

Do you understand that I will use a videocamera during

Place.

\section{Aberinger}

Ange Beringer

Candidate: $\mathrm{M}(\mathrm{AAC})$



Prof Juan Bornman Supervisor

I would love to answer any questions or queries that you might have about the project.

Please feel free to contact me:

Researcher: Ange Beringer

Email: angeh@absamail.co.za

Contact number: 0724758945

Promoter: Prof Juan Bornman

E-mail: juan.bornman@up.ac.za

Contact number: 012-420 2001 
APPENDIX L: FAMILIAR COMMUNICATION PARTNER CONSENT FORM

Centre for Augmentative and Alternative Communication Sentrum vir Aanvullende en Alternatiewe Kommunikasie \&

INTERFACE

\begin{tabular}{|c|c|}
\hline 006 & aureate Award, Education Innovation for the Fofa Project \\
\hline 200 & $\begin{array}{l}\text { T-Systems Age of Innovation \& Sustainability Awards: Excellence in } \\
\text { Innovation and Sustainability: Social }\end{array}$ \\
\hline 2003 & $\begin{array}{l}\text { National Science \& Technology Awards: Corporate Organization over } \\
\text { the last ten years. }\end{array}$ \\
\hline 2002 & $\begin{array}{l}\text { Shirley McNaughton Award for Exemplary Communication received } \\
\text { from the International Society for Augmentative and Alternative } \\
\text { Communication }\end{array}$ \\
\hline & Rolex Award for Enterprise: Associate Laureate \\
\hline & Education Africa Presidential Award for Special Needs \\
\hline
\end{tabular}

UNIVERSITEIT VAN PRETORIA UNIVERSITY OF PRETORIA YUNIBESITHI YA PRETORIA $100 \underline{1908-2008}$

Faculty of Human Sciences Fakulteit Geesteswetenskappe

\section{Consent Form: Communication partner}

NAME

Relationship to participant

I have read the information sheet and consent to taking part in the research project.

Signature. Date

Place.
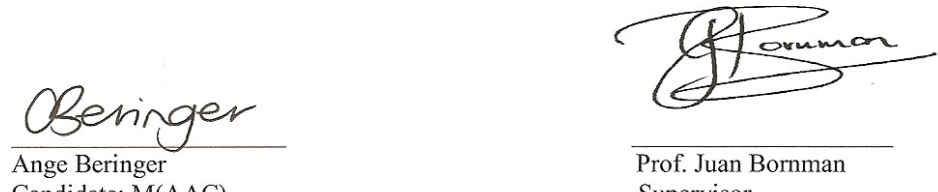

Candidate: M(AAC)

Prof. Juan Bornman

Supervisor

I would love to answer any questions or queries that you might have about the project.

Please feel free to contact me:

Researcher: Ange Beringer

Email: angeh@absamail.co.za

Contact number: 0724758945

Promoter: Prof. Juan Bornman

E-mail: iuan.bornman@up.ac.za

Contact number: 012-420 2001

Centre for Augmentative and Alternative Communication (CAAC), Communication Pathology Building University of Pretoria, Lynnwood Road
Fax/Faks: $+2712420-4389$ Tel: $\quad+2712420-2001$ juan.bornman@up.ac.za www.caac.up.ac.za
Sentrum vir Aanvullende en Alternatiewe Kommunikasie (SAAK), Kommunikasie Patologie gebou Universiteit van Pretoria, Lynnwoodweg PRETORIA, 0002 Republiek van Suid Afrika 
APPENDIX M: VIDEO CONSENT FORM FOR PARTICIPANT WITH

\section{APHASIA}

Centre for Augmentative and Alternative Communication Sentrum vir Aanvullende en Alternatiewe Kommunikasie \&

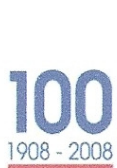
INTERFACE
Laureate Award, Education Innovation for the Fofa Project T-Systems Age of Innovation \& Sustainability Awards: Excellence in Innovation and Sustainability: Social

National Science \& Technology Awards: Corporate Organization over the last ten years.
UNIVERSITEIT VAN PRETORIA

UNIVERSITY OF PRETORIA YUNIBESITHI YA PRETORIA

\section{Faculty of Education}

Fakulteit Opvoedkunde

2002 Shirley McNaughton Award for Exemplary Communication received from the International Society for Augmentative and Alternative Communication

1998 Rolex Award for Enterprise: Associate L aureate

1995 Education Africa Presidential Award for Special Needs

\section{Video Consent Form}

I agree to video and photographs being recorded on the understanding that the material will be retained securely and only be used for the current study.

I understand that my full identity will not be revealed.

SIGNATURE OF PARTICIPANT

Date

SIGNATURE OF CARER

Date.

RELATIONSHIP TO PARTICIPANT

PLACE.
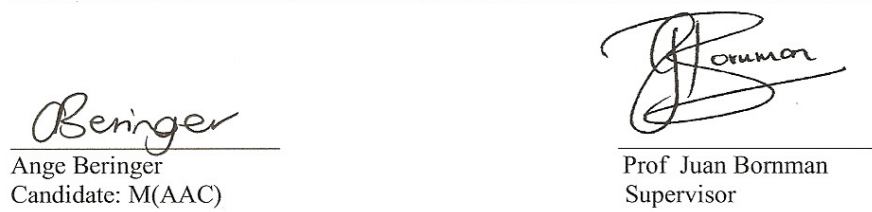

Prof Juan Bornman

Supervisor

I would love to answer any questions or queries that you might have about the project

Please feel free to contact me:

Researcher: Ange Beringer

Email: angeh@absamail.co.za

Contact number: 0724758945

Promoter: Prof Juan Bornman

E-mail: juan.bornman@up.ac.za

Contact number: 012-420 2001

Centre for Augmentative and Alternative Communication (CAAC), Communication Pathology Building University of Pretoria, Lynnwood Road

PRETORIA, 0002

Republic of South Africa
Fax/Faks: $+2712420-4389$

Tel: $\quad+2712420-2001$

juan,bornman@up.ac.za

www.caac.up.ac.za
Sentrum vir Aanvullende en Alternatiewe Kommunikasie (SAAK), Kommunikasie Patologie gebou Universiteit van Pretoria, Lynnwoodweg PRETORIA, 0002 Republiek van Suid Afrika 


\section{APPENDIX N: VIDEO CONSENT FORM FOR FAMILIAR COMMUNICATION \\ PARTNER}

Centre for Augmentative and Alternative Communication Sentrum vir Aanvullende en Alternatiewe Kommunikasie

$$
\begin{aligned}
& \& \\
& \text { INTERFACE }
\end{aligned}
$$


Faculty of Human Sciences Fakulteit Geesteswetenskappe

\section{Video Consent Form}

I agree to video and photographs being recorded on the understanding that the material will be retained securely and only be used for the current study.

I understand that my full identity will not be revealed.

SIGNATURE OF PARTICIPANT. ..Date.

Communication partner)

PLACE.

$$
\begin{aligned}
& \text { Beringer } \\
& \text { Ange Beringer } \\
& \text { Candidate: M(AAC) }
\end{aligned}
$$

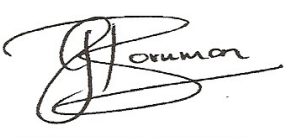

Prof. Juan Bornman Supervisor

I would love to answer any questions or queries that you might have about the project.

Please feel free to contact me:

Researcher: Ange Beringer

Email: angeh@absamail.co.za

Contact number: 0724758945

Promoter: Prof. Juan Bornman

E-mail: juan.bornman@up.ac.za

Contact number: 012-420 2001

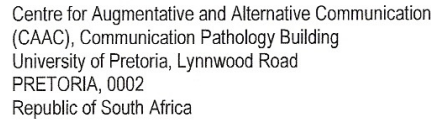


APPENDIX O: INTERVIEW AND TALKING MATSTM PROCEDURAL GUIDELINES

\section{INTERVIEW SESSION ONE}

\begin{tabular}{|c|c|c|c|}
\hline \multirow[t]{2}{*}{ GUIDELINE } & \multicolumn{2}{|c|}{$\begin{array}{l}\text { OBSERVED DURING } \\
\text { INTERVIEW: }\end{array}$} & \multirow[t]{2}{*}{ COMMENTS } \\
\hline & YES & NO & \\
\hline Greeting & & & \\
\hline Verbally explain what will be covered during the interview. & & & \\
\hline Read through Family Information Sheet. & & & \\
\hline Read through Participant Information Sheet. & & & \\
\hline $\begin{array}{l}\text { Mention that they will be provided with a booklet containing } \\
\text { their preferred conversational topics after the study has been } \\
\text { completed. }\end{array}$ & & & \\
\hline Allow any questions to be asked. & & & \\
\hline Verbally explain consent forms. & & & \\
\hline $\begin{array}{l}\text { Stress freedom for the participants to pull-out of the study at } \\
\text { any stage. }\end{array}$ & & & \\
\hline Obtain consent from participant with aphasia. & & & \\
\hline $\begin{array}{l}\text { Obtain Observer Consent Support Form from individual with } \\
\text { participant with aphasia. }\end{array}$ & & & \\
\hline Set-up video-camera and necessary materials. & & & \\
\hline $\begin{array}{l}\text { Person with aphasia to complete biographical questionnaire } \\
\text { with assistance from family member as necessary. }\end{array}$ & & & \\
\hline $\begin{array}{l}\text { Administration of test items from the WAB according to the } \\
\text { test procedures specified in the manual. }\end{array}$ & & & \\
\hline $\begin{array}{l}\text { Request participant with aphasia to select a familiar } \\
\text { communication partner to join them during the second }\end{array}$ & & & \\
\hline
\end{tabular}


interview session.

Arrange a second meeting

\section{INTERVIEW SESSION TWO}

\begin{tabular}{|c|c|c|c|}
\hline \multirow[t]{2}{*}{ GUIDELINE } & \multicolumn{2}{|c|}{$\begin{array}{l}\text { OBSERVED } \quad \text { DURING } \\
\text { INTERVIEW: }\end{array}$} & \multirow[t]{2}{*}{ COMMENTS } \\
\hline & YES & NO & \\
\hline Set-up video camera and necessary materials & & & \\
\hline Greeting & & & \\
\hline Verbally explain what will be covered during the interview. & & & \\
\hline $\begin{array}{l}\text { Re-iterate to both members of the dyad the freedom to pull } \\
\text { out of the study at any point during the interview session. }\end{array}$ & & & \\
\hline Familiar communication partner to complete consent form. & & & \\
\hline $\begin{array}{l}\text { Familiar communication partner to complete biographical } \\
\text { questionnaire in presence of researcher within a semi- } \\
\text { structured interview (adult with aphasia not present). }\end{array}$ & & & \\
\hline $\begin{array}{l}\text { Familiar communication partner to evaluate PCR topics } \\
\text { using the Talking Mats }{ }^{\mathrm{TM}} \text { framework. (See specific } \\
\text { procedural guidelines for the Talking Mats }{ }^{\mathrm{TM}} \text { framework). }\end{array}$ & & & \\
\hline $\begin{array}{l}\text { Request familiar communication partner to think of } \\
\text { additional topics of conversation (maximum 5) that would be } \\
\text { of interest to the person with aphasia. }\end{array}$ & & & \\
\hline $\begin{array}{l}\text { Practice mat used with person with aphasia to ensure that the } \\
\text { framework is understood. }\end{array}$ & & & \\
\hline $\begin{array}{l}\text { Person with aphasia to evaluate PCR and additional topics } \\
\text { using the Talking Mats }{ }^{\mathrm{TM}} \text { framework. (See specific } \\
\text { procedural guidelines for the Talking Mats }{ }^{\mathrm{TM}} \text { framework). }\end{array}$ & & & \\
\hline
\end{tabular}


Thank dyad for their participation in the study.

Explain that they will receive a booklet containing the person with aphasia's preferred conversational topics once the study has been completed.

TALKING MATSTM PROCEDURAL GUIDELINES:

\begin{tabular}{|c|c|c|c|}
\hline \multirow[t]{2}{*}{ GUIDELINE } & \multicolumn{2}{|c|}{$\begin{array}{l}\text { OBSERVED } \\
\text { DURING } \\
\text { INTERVIEW }\end{array}$} & COMMENTS \\
\hline & YES & NO & \\
\hline $\begin{array}{l}\text { Researcher must explain the topic of the Talking } \\
\text { Mat; that is "Topics that you would like to talk } \\
\text { about", or in the case of the familiar communication } \\
\text { partner "Topics that the person with aphasia would } \\
\text { like to talk about" }\end{array}$ & & & \\
\hline $\begin{array}{l}\text { Researcher must ask if the participant understands } \\
\text { the topic of conversation that will be discussed } \\
\text { during the Talking Mat and if they have any } \\
\text { questions. }\end{array}$ & & & \\
\hline $\begin{array}{l}\text { PCR topic cards must be presented one at a time, } \\
\text { with each topic expressed verbally as it is presented } \\
\text { to the participant. }\end{array}$ & & & \\
\hline $\begin{array}{l}\text { Language used by the researcher must be consistent } \\
\text { and clear: "Would you like to talk about....." or } \\
\text { "Would ....... like to talk about ..." }\end{array}$ & & & \\
\hline $\begin{array}{l}\text { A practice Talking Mat must be used with the } \\
\text { participants with aphasia before evaluating the PCR }\end{array}$ & & & \\
\hline
\end{tabular}




\begin{tabular}{|l|l|l|l|}
\hline $\begin{array}{l}\text { topics in order to ensure that they understand the } \\
\text { process. }\end{array}$ & \multirow{2}{*}{$\begin{array}{l}\text { The participants must be allowed } 20 \text { seconds to } \\
\text { respond to each topic card presented to them. }\end{array}$} & & \\
\hline $\begin{array}{l}\text { Any verbal or non-verbal responses during the } \\
\text { Talking Mat conversation must be recorded. }\end{array}$ & & \\
\hline $\begin{array}{l}\text { Once the mat is complete, researcher must confirm } \\
\text { that the participant is happy with where they have } \\
\text { placed topic cards on the mat. Researcher must } \\
\text { allow participant to move any topic cards that they } \\
\text { have had second thoughts about. }\end{array}$ & & \\
\hline A photograph is taken of the completed mat. & & \\
\hline
\end{tabular}

